sität Göttingen, zu den Voraussetzungen für wissenschaftlichen Fortschritt wurde von einer Podiumsdiskussion (J. Klein, BWG; W. Krull, VolkswagenStiftung; G. Litfin, Dt. Physikal. Gesell. und LINOS AG) unter der Leitung von A. Brünjes (Göttinger Tageblatt) begleitet. Den Schlussvortrag mit dem Titel „Wissenschaft als Erwartung des Unerwarteten“ hielt J. Wanka, Ministerin für Wissenschaft und Kultur des Landes Niedersachsen.

\title{
II. Vorhaben aus dem Akademienprogramm
}

Für die regelmäßige Begutachtung der Vorhaben ist seit 2000 die Union der deutschen Akademien der Wissenschaften zuständig.

\section{Byzantinische Rechtsquellen}

Leitungskommission:

Vorsitzender: Behrends

Duve (Frankfurt/Main), G. A. Lehmann, Mühlenberg, Papagianni (Athen/ Griechenland), Schindel, Schreiner

Kontaktadresse: Max-Planck-Institut für Europäische Rechtsgeschichte, Hausener Weg 120, 60489 Frankfurt a. M., Tel.: 069-78978-142, Fax 06978978-169, Burgmann@rg.mpg.de (Dr. Burgmann),

Arbeitsbericht: Gelehrte des 16. Jahrhunderts prägten den Ausdruck Ius Graecoromanum und meinten damit römisches Recht in griechischer Sprache. Auch Karl Eduard Zachariä von Lingenthal (1812-1894), ein Meister seines Fachs, sprach noch vom "griechisch-römischen“ Recht. Die Rede vom „byzantinischen“ Recht kam erst am Ende des 19. Jahrhunderts auf, als in München und St. Petersburg nahezu gleichzeitig byzantinistische Lehrstühle errichtet und Zeitschriften gegründet wurden.

Den Löwenanteil der erhaltenen byzantinischen Rechtstexte bilden griechische Übersetzungen aus dem Lateinischen, die im Rechtsunterricht der justinianischen Zeit (6.Jhdt.) entstanden sind. Auf dieser Grundlage wurden mehrere systematisch oder alphabetisch geordnete Auswahlsammlungen hergestellt und zum Teil auch offiziell veröffentlicht. Die Produktion neuer Gesetze nahm gegenüber der justinianischen Gesetzesflut deutlich ab, jedoch sind aus der Zeit zwischen dem Tod Justinians (565) und der Eroberung Konstantinopels durch die Kreuzfahrer (1204) immerhin noch etwa 200 Novellen erhalten. Die normative Textbasis des kanonischen Rechts 
war wesentlich schmaler, was seiner kontinuierlich wachsenden Bedeutung keineswegs entsprach. Seine Fortentwicklung erfolgte durch Patriarchalbzw. Synodalentscheidungen, die in großer Zahl überliefert sind.

Zu den druckfertigen, bereits ins Netz gestellten Beschreibungen kanonistischer Handschriften wurden Register (Kopisten, Vorbesitzer, datierte Handschriften, Incipit sowie Autoren und Werke) angefertigt, die ebenfalls elektronisch zugänglich gemacht werden sollen.

Die Sondierungen bezüglich der in fast keiner kanonistischen Handschrift fehlenden Synodengeschichten wurden abgeschlossen. Mit der Arbeit an Edition und Kommentierung eines historiographisch besonders ergiebigen Exemplars wurde begonnen. Eine monographische Publikation lässt sich absehen.

Ebenfalls abgeschlossen wurden die Arbeiten an der Ausgabe des Nomos Stratiotikos. Inhaltlich von zweifelhaftem Interesse, hat dieses kleine Militärstrafgesetzbuch eine lange und geradezu abenteuerliche Editionsgeschichte, die sich nur auf der Grundlage einer neuen Edition beschreiben lässt.

Nach der inzwischen verwirklichten Aufarbeitung der Nebenüberlieferung der „Peira“, einer der wichtigsten Quellen zur mittelbyzantinischen Rechtspraxis, wurde die Arbeit an Text, Übersetzung und Kommentar forciert.

Im Druck befindet sich ein Beitrag über die nachjustinianischen Novellen. Er stellt gewissermaßen die materielle Ergänzung zu einem 1995 erschienenen Aufsatz dar, in dem derselbe Autor die Editionsgeschichte dieser Gesetze behandelt hat.

\title{
E. Papagianni
}

\author{
Deutsche Inschriften des Mittelalters und der frühen Neuzeit \\ (Arbeitsstellen Göttingen und Greifswald) \\ Leitungskommission: \\ Vorsitzender: Henkel \\ Stellv. Vors.: Stackmann \\ Arndt, Arnold (Wolfenbüttel), Auge (Kiel), Grubmüller, Haye (Göttingen), \\ Michael (Lüneburg), Petke (Göttingen), Reitemeier (Göttingen), Rexroth, \\ Schindel, Schröder (Hamburg), Spieß, Winghart (Hannover)
}


Kontaktadresse: Arbeitsstelle Göttingen: Theaterstraße 7, 37073 Göttingen, Tel.: 0551-39-5336, Fax: 0551-39-5407, cwulf@gwdg.de (Dr. Wulf), http://www.inschriften.uni-goettingen.de, http://www.inschriften. net/

Arbeitsstelle Greifswald: Historisches Institut der Ernst Moritz Arndt-Universität Greifswald, Soldmannstraße 15, 17487 Greifswald, Tel.: 03834863342, Fax: 03834-863345, cmagin@uni-greifswald.de (Dr. Magin), http://www.inschriften.uni-greifswald.de, http://www.inschriften.net/

Arbeitsbericht: Das Forschungsprojekt hat die Sammlung und kommentierte Edition der mittelalterlichen und der frühneuzeitlichen Inschriften zur Aufgabe. Erfaßt werden die Inschriften in lateinischer und in deutscher Sprache vom frühen Mittelalter bis zum Jahr 1650, und zwar nicht nur die im Original erhaltenen, sondern auch die nur mehr in Abschriften (kopial) überlieferten. Die Leitungskommission hat die Aufsicht über zwei Arbeitsstellen: eine für Niedersachsen zuständige Arbeitsstelle in Göttingen und eine weitere, die an der Universität Greifswald angesiedelt ist und die Inschriften in Mecklenburg-Vorpommern erfaßt. Beide Arbeitsstellen sind Teil eines Gemeinschaftsprojekts der wissenschaftlichen Akademien in Deutschland und Österreich. Die gedruckten Publikationen erscheinen in der Reihe „Die Deutschen Inschriften“ im Dr. Ludwig Reichert-Verlag, Wiesbaden. Für Niedersachsen liegen bisher 13 Bände vor: die städtischen Bestände Göttingen, Osnabrück, Hameln, Hannover, Braunschweig I u. II, Einbeck, Goslar, Hildesheim und Helmstedt sowie der Landkreis Göttingen (incl. Hann. Münden und Duderstadt), Lüneburg St. Michaelis und Kloster Lüne bis 1550 und die Inschriften der Lüneburger Klöster: Ebstorf, Isenhagen, Lüne, Medingen, Walsrode, Wienhausen (bis 1700). In Bearbeitung sind die Inschriften der Landkreise Hildesheim, Holzminden und Schaumburg sowie die Inschriften der Stadt Lüneburg. Neun Göttinger Bände sind mittlerweile auch online verfügbar auf der Plattform DIO (Deutsche Inschriften Online) unter der URL www.inschriften.net: Stadt und Landkreis Göttingen, die Städte Hameln, Hannover, Einbeck, Goslar, Braunschweig 1529-1671, Hildesheim und Helmstedt. Die OnlinePublikationen bieten gegenüber den gedruckten Bänden erheblich mehr und überwiegend farbige Abbildungen. Bis Ende 2011 werden voraussichtlich die noch fehlenden Bände der Göttinger Reihe folgen.

Die Arbeitsstelle Greifswald widmet sich schwerpunktmäßig kulturellen Zentren des Ostsee-Hanseraums. Sie hat die Inschriften der Stadt Greifswald publiziert. In Bearbeitung sind die Inschriften der Hansestädte Stralsund und Wismar sowie des Klosters Dobbertin. 
Die publizierten Bände stellen reichhaltiges Quellenmaterial für unterschiedliche historische und philologische Disziplinen bereit, wie z. B. Landesgeschichte, Kirchengeschichte, lateinische und deutsche Sprachgeschichte, Schriftgeschichte und Kunstgeschichte. $\mathrm{Zu}$ den neuerschlossenen Informationen gehören zunächst die personengeschichtlichen Daten, die sich vor allem aus den Grabinschriften gewinnen lassen. Daneben spiegeln die Texte vielfältige frömmigkeits- und kulturgeschichtliche Entwicklungen, wie z. B. die im Laufe der Jahrhunderte sich wandelnden Vorstellungen von Tod, Jenseits und Auferstehung oder die verschiedenen Ausdrucksformen bürgerlichen Bildungsbewußtseins und ständischer Repräsentation. Viele Inschriften geben authentische Hinweise aufZeit und Umfeld der Stücke, auf denen sie angebracht sind. In Zeiten fortschreitender Umweltzerstörung, der die oft im Freien befindlichen Denkmäler in starkem Maße ausgesetzt sind, ist die Sammlung der Inschriften besonders dringend geworden.

\section{Arbeitsstelle Göttingen}

Laufende Einzelprojekte: Kanonissenstift Gandersheim (Wulf), Landkreis Hildesheim (Wulf), Landkreis Holzminden (Lampe), Schaumburg (Finck), Stadt Lüneburg (Wehking).

Im September 2010 wurden die Arbeiten am Landkreis Holzminden wieder aufgenommen. Die Beschreibung der Objekte und die Edition des 302 Inschriftentexte umfassenden Bestands sind weitgehend abgeschlossen, für etwa ein Drittel davon sind auch die Kommentare bereits erarbeitet. Der Abschluß ist Ende 2011 vorgesehen. Für die 442 Inschriften des Landkreises Hildesheim sind Beschreibung und Edition ebenfalls weitgehend abgeschlossen, für etwa 300 Inschriftenartikel ist auch der Kommentar fertiggestellt. Der Band soll Anfang 2012 gedruckt werden Die Arbeit an den Inschriften des Kanonissenstifts Gandersheim und seiner Eigenkirchen Brunshausen und Clus ist abgeschlossen, der Bestand wird in zweifacher Form publiziert: zum einen in dem von Hedwig Röckelein herausgegebenen Tagungsband „Der Gandersheimer Schatz im Vergleich“, zum anderen in digitaler Form auf der Plattform Deutsche Inschriften Online (Februar/März 2011). Die Vorbereitung beider Publikationen ist nahezu abgeschlossen. Für den Landkreis Schaumburg konnten bis jetzt 660 Inschriften (einschließlich Jahreszahlen) ermittelt werden. Für mehr als zwei Drittel des Bestands sind die Aufnahmearbeiten erledigt, deren Ergebnisse fortlaufend eingearbeitet werden. Mit der Kommentierung der Inschriften wurde begonnen - der Abschluß des Projekts ist für 2013 vorgesehen. Für die Stadt Lüneburg konnten bis jetzt 784 Inschriften gesammelt 
werden. Diese erfreulich hohe Zahl verdankt sich vor allem der umfangreichen kopialen Überlieferung (Rikemann, Büttner, Bertram). Mit einem weiteren Anwachsen des Bestands ist zu rechnen. Zur Zeit werden die Handschriftenkataloge der Ratsbücherei Lüneburg, der Leibniz-Bibliothek Hannover und der Herzog August-Bibliothek in Wolfenbüttel im Hinblick auf weitere kopiale Überlieferung der Lüneburger Inschriften durchgesehen.

Weitere Projekte der Arbeitsstelle: Zur Erleichterung einer mittel- und langfristigen Projektplanung wird das aus der heimathistorischen Literatur und den Kunstdenkmälerbänden bis 1981 handschriftlich erstellte Niedersächsische Inschriftenarchiv sukzessiv computergerecht nach Landkreisen erfaßt und durch Standort- und Namenregister erschlossen. Eingegeben sind bisher folgende Landkreise: Northeim, Osterode, Goslar, Hameln-Pyrmont, Wolfenbüttel, Gifhorn, Celle, Soltau-Fallingbostel, Uelzen, Lüneburg, Helmstedt, Peine, Nienburg mit Kloster Loccum, Verden, Osnabrück und die Region Hannover.

Digitalisierung: In Zusammenarbeit mit der Digitalen Akademie Mainz hat die Göttinger Arbeitsstelle im Jahr 2010 zehn der insgesamt 14 bisher erschienenen Bände der Göttinger Reihe (s. oben) online verfügbar gemacht (www.inschriften.net). Weitere drei Bände (Lüneburg St. Michaelis und Kloster Lüne sowie Osnabrück und Braunschweig bis 1528) und der Inschriftenbestand Gandersheim werden Anfang des Jahres 2011 folgen. Die in der Arbeitsstelle Göttingen zu leistende Vorbereitung der Textund der Bilddaten sind für die Bände Osnabrück und Braunschweig abgeschlossen, die Textdaten des Inschriftenbandes Lüneburg St. Michaelis und Kloster Lüne werden zur Zeit in China erfaßt, die Bilddaten in der Arbeitsstelle vorbereitet. Die Koordination der Arbeiten erfolgt gemeinschaftlich in den Arbeitsstellen Göttingen (Wulf, Wehking, Brosenne, Hofmeister, Moos, Zech) und Greifswald (Herold). Die technischen Arbeiten leistet die von der Göttinger Akademie mitfinanzierte Arbeitsgruppe in Mainz.

Vom 16. bis zum 18. Februar 2010 wurde die St. Michaelis-Kirche in Hildesheim in einem 3-D Laser-Scanning-Verfahren durch ein Team des i3-Instituts Mainz aufgenommen. Ziel des Projekts ist es, die wissenschaftlichen Ergebnisse eines Inschriftenprojekts und damit exemplarisch die Forschungsarbeit der Akademie in einer attraktiven Form der interessierten Öffentlichkeit zu vermitteln (wissenschaftliche Begleitung Wulf).

Interakademische Kontakte: Die Göttinger Arbeitsstelle hat die diesjährige Tagung der Mitarbeiter und Mitarbeiterinnen des Gesamtunternehmens 
Deutsche Inschriften am 3. und am 4. März in Göttingen veranstaltet, Gegenstand war die Gestaltung der Plattform „Deutsche Inschriften Online". Herr Henkel und Frau Wulf haben am 5. Mai 2010 in Mainz an einer Sitzung der Interakademischen Kommission teilgenommen. Auf dieser Sitzung wurde Herr Henkel bis 2013 zum Vorsitzenden der Interakademischen Kommission gewählt. Frau Finck, Frau Wehking und Frau Wulf haben an der Internationalen Epigraphiktagung in Mainz vom 5. bis zum 8. Mai teilgenommen.

Lehr- und Vortragstätigkeit: Im WS 2009/2010 und im SS 2010 hat Frau Wulf im Rahmen eines Lehrauftrags am Seminar für Mittlere und Neuere Geschichte der Universität Göttingen im Studiengang Historische Hilfswissenschaften jeweils ein Seminar zur mittelalterlichen und zur frühneuzeitlichen Inschriftenpaläographie gehalten. Die jährliche Seminarsitzung mit Studierenden der Deutschen Rechtsgeschichte im Göttinger Rathausgefängnis fand am 14. Dezember 2010 statt.

Frau Wulf hat mit einem Vortrag zum Thema „Die Gandersheimer Inschriften zwischen Hildesheim und Halberstadt" an der Tagung „Der Gandersheimer Schatz im Vergleich" in Gandersheim teilgenommen (30. September-2. Oktober).

Sonstiges: Die Inschriftenkommission ist Patronatsmitglied der Historischen Kommission für Niedersachsen und Bremen. Die Mitarbeiterinnen und Mitarbeiter der Arbeitsstelle nehmen regelmäßig am Arbeitskreis Mittelalter der Historischen Kommission im Staatsarchiv Hannover teil.

Im Februar 2010 hat die Arbeitsstelle den DAAD-Stipendiaten Prof. Dr. Jarosław Wenta von der Nikolaus-Kopernikus-Universität Thorn betreut.

Die Göttinger Arbeitsstelle ist Kooperationspartner des am Göttinger Institut für Historische Landesforschung bearbeiteten Niedersächsischen Klosterbuchs.

Im Jahr 2010 fanden zwei Sitzungen der Göttinger Leitungskommission statt: am 5. März 2010 und aus Anlaß des Jubiläums „40 Jahre Inschriften in Göttingen“ am 22. Oktober 2010. Dieses Jubiläum wurde mit einem Kolloquium „Inschriften als Zeugnisse kulturellen Gedächtnisses“ gefeiert (s. unter „Sonstige Veranstaltungen“, Seite 464).

Veröffentlichungen:

Klöster und Inschriften - Glaubenszeugnisse, gestickt, gemalt, gehauen, graviert, herausgegeben von Christine Wulf, Sabine Wehking und Nikolaus Henkel. Beiträge zur Tagung am 30. Oktober 2009 im Kloster Lüne. Wiesbaden 2010. Darin: 
Katharina Ulrike Mersch und Christine Wulf, Klöster und Inschriften. Einführung in das Tagungsthema. S. 13-22.

Inga Finck, Gemalte Gelehrsamkeit, gesammelte Glaubensgrundsätze und beständiges Gedächtnis. Inschriften des Klosters Möllenbeck. S. 71-93.

Sabine Wehking, Begrabenwerden im Kloster. Das Begräbnis der Dorothea von Meding im Jahr 1634 nach der Beschreibung im Anschreibebuch des Klosters Lüne. S. 209221.

\section{Arbeitsstelle Greifswald}

Laufende Einzelprojekte: Hansestadt Stralsund (Magin), Hansestadt Wismar (Herold), Kloster Dobbertin (Magin, Herold)

Die im Jahr 2003 begonnene Bearbeitung der Stralsunder Inschriften (Magin) wurde Anfang 2005 zurückgestellt, damit gemeinsam an den Greifswalder Inschriften und der Weiterentwicklung der Datenbank gearbeitet werden konnte. Nach der Publikation und der öffentlichen Vorstellung des Greifswald-Bandes am 18. Januar 2010 wurde im Frühjahr damit begonnen, die seit 2005 neu erschienene, umfangreiche Literatur zu Stralsund einzuarbeiten. Im Landesamt für Kultur und Denkmalpflege (Schwerin) fand eine erste mehrtägige Sichtung der Akten- und der Fotobestände statt. Kopiale Inschriftenüberlieferung im Stadtarchiv Stralsund ist bereits ermittelt, jedoch noch nicht ausgewertet. Als Abschluss des Projekts ist Ende 2014 ins Auge gefasst.

Mit der Bearbeitung der Inschriften der mecklenburgischen Hansestadt Wismar wurde begonnen (Herold). Gegenwärtig werden die bis jetzt vorliegenden Fotos der Grabplatten aus St. Georgen, St. Marien und St. Nikolai in die Datenbank eingearbeitet sowie Beschreibungen und Transkriptionen der Inschriften angefertigt. Noch nicht erfasst sind die Grabplatten im Museum und im Heilig-Geist-Hospital. Als Abschluss des Projekts ist das Jahr 2015 vorgesehen.

Kloster Dobbertin (Magin, Herold): Für einen Sammelband zur Geschichte und Sanierung dieses mecklenburgischen Benediktinerinnenklosters, hg. vom Landesamt für Kultur und Denkmalpflege in Schwerin, sind von der Arbeitsstelle bereits 2008 zwei Beiträge eingereicht worden, die sich mit den Inschriften auf 23 Grabplatten des 14. bis 19. Jh. und auf zwei Gewölbekonsolen des 14. Jh. im Dobbertiner Kreuzgang befassen. Die Publikation ist vom Landesamt für 2011 angekündigt.

Deutsche Inschriften Online: Die Arbeitsstelle war an der Aufbereitung der Katalogdaten des Goslar-Bandes (Herold, Magin) sowie der Registerdaten von fünf Inschriftenbänden (Volontär Alexander v. Weber) für den DIOnline-Auftritt (www.inschriften.net) beteiligt. Darüber hinaus hat Jür- 
gen Herold fortlaufend Unterstützung für die Datenaufbereitung weiterer Inschriftenbände geleistet und wird dies auch in Zukunft in Kooperation mit der Digitalen Akademie Mainz tun. Der Band DI 77 „Die Inschriften der Stadt Greifswald“" wurde mittels der in der Arbeitsstelle entwickelten Inschriftendatenbank erstellt, die es ermöglicht, Daten in verschiedenen Formaten auszugeben (pdf-Dateien als Vorstufe zum gedruckten Buch, Word-Dateien zur weiteren Bearbeitung z. B. für Vorträge, Präsentationen im Internet). Daher wird nach Ablauf des mit dem Reichert-Verlag vereinbarten Zeitraums von zwei Jahren nach der Buchveröffentlichung auch der Greifswald-Band ohne großen Nachbearbeitungsbedarf online verfügbar gemacht werden können.

Weiteres: Die Kurzerfassung von Inschriften aus den mecklenburgischen und den pommerschen Kunstdenkmälerinventaren konnte im Frühjahr 2010 abgeschlossen werden. Mit den Angaben „Inschriftenträger“, „Datierung “, „Wortlaut der Inschrift(en)“ und „Literaturnachweis“ wurden die für das Land Mecklenburg-Vorpommern (M-V) ermittelten Inschriften in die Datenbank aufgenommen. Somit ist eine erste Basis für die zukünftige Projektplanung gegeben, die jedoch noch erweitert werden muss. Daher wurde im Anschluss an die Durchsicht der Kunstdenkmälerinventare mit der Durchsicht der wichtigsten regional- und landeshistorischen sowie archäologischen Zeitschriften begonnen.

Im Schweriner Landesamt für Kultur und Denkmalpflege wurden ca. 75 Abreibungen vorpommerscher Glocken, angefertigt vor dem Zweiten Weltkrieg, an Ort und Stelle verzeichnet, fotografiert und danach in die Datenbank eingeordnet. Diesen Arbeitsschritt vorläufig abschließend, wurde für ganz M-V ein Register der namentlich bekannten Glockengießer erstellt (Volontär Alexander v. Weber).

Der umfangreiche deutsch-lateinische Bericht des Lüneburger Patriziersohnes Heinrich Witzendorff über eine Reise durch Mecklenburg und Vorpommern im Jahr 1623 wurde vollständig transkribiert (Schattschneider). Es handelt sich um eine außerordentlich bedeutsame Quelle für die Inschriftenüberlieferung der Region vor dem Dreißigjährigen Krieg und darüber hinaus um den ältesten überhaupt bekannten Reisebericht zu dem heutigen Bundesland. Der erste Korrekturdurchgang ist abgeschlossen, die Inschriften wurden in die Datenbank aufgenommen.

Die Homepage der Arbeitsstelle wurde auf neuer technischer Basis modernisiert, um künftig deren Pflege zu erleichtern.

Im September 2010 musste das Gebäude des Historischen Instituts (Domstr. 9a) einschließlich der Fachbibliothek Geschichte wegen Einsturz- 
gefahr gesperrt werden. Danach wurden die Büros vollständig geräumt. Die Arbeitsstelle konnte als Ausweichquartier für einen Monat im Krupp-Kolleg ein Büro mit zwei Arbeitsplätzen anmieten. Der Auszug der Arbeitsstelle aus der Domstraße erfolgte am 21./22. Oktober, Anfang November konnte das Personal des Instituts einschließlich der fünf Mitarbeiter/innen der Arbeitsstelle Inschriften dann in Ausweichräume der ehem. Kinderklinik der Universität (Soldmannstr. 15) einziehen und die Arbeit wieder aufnehmen. In den Zeiten, in denen keine Arbeitsplätze zur Verfügung standen bzw. in denen der Umzug vorbereitet und durchgeführt werden musste, konnte an den laufenden Projekten nur eingeschränkt gearbeitet werden. In welchem Umfang das Haus Domstraße saniert werden muss, wie lange die Unterbringung in der Soldmannstraße dauern wird und ab wann und an welchem Ort die Fachbibliothek Geschichte wieder zugänglich sein wird, steht zum gegenwärtigen Zeitpunkt noch nicht fest.

Interakademische Kooperation, wissenschaftliche Kontakte, Tagungen: Am jährlichen Mitarbeitertreffen der Inschriftenarbeitsstellen in Göttingen am 3./4. März 2010 sowie an der vom 5. bis zum 8. Mai in Mainz stattfindenden Interakademischen Tagung „Inschriften zwischen Realität und Fiktion“ nahmen C. Magin und J. Herold teil. Vor der Eröffnung der Tagung fand am 5. Mai eine Sitzung der Interakademischen Kommission statt (C. Magin). J. Herold traf sich zu derselben Zeit mit den Mitarbeitern der Digitalen Akademie Mainz, um Aktuelles zu DI Online zu besprechen.

Am 24. Juni 2010 fand auf Einladung des Präsidenten der Göttinger Akademie ein Gespräch zu den Themen „Digitalisierung von Forschungsergebnissen und Weiterbildung von Mitarbeiter/-innen" statt. Daran sowie auf der Tagung „Häuslich, persönlich, innerlich. Bereiche der privaten Frömmigkeitsausübung im späten Mittelalter und in der frühen Neuzeit“, Universtät Leipzig, 8. bis 10. Juli, und an einem eintägigen Kommunikationstraining an der Akademie der Wissenschaften Mainz am 19. Oktober nahm C. Magin teil.

Auf der Kommissionssitzung am 22. Oktober 2010 in Göttingen sowie bei dem anschließenden Festkolloquium „40 Jahre Deutsche Inschriften in Göttingen“ vertrat J. Herold die Greifswalder Arbeitsstelle. C. Magin war wegen des Umzugs der Arbeitsstelle verhindert. Auf der interdisziplinären Tagung „Medialität - Unmittelbarkeit - Präsenz: Die Nähe des Heils im Verständnis der Reformation“ an der Universität Erlangen-Nürnberg, 29.-31. Oktober, sprach C. Magin über „Soli Deo gloria? Inschriftliche Medien der Reformationszeit". 
Zuarbeiten zum entstehenden Mecklenburgischen Klosterbuch erfolgen von Fall zu Fall nach Anfragen der Bearbeiter der einzelnen Standorte. Im Jahr 2010 wurden 30 Anfragen beantwortet, davon etwa ein Drittel aus dem Landesamt für Kultur und Denkmalpflege.

N. Henkel

Veröffentlichungen:

Die Inschriften der Stadt Greifswald, ges. und bearb. von Jürgen Herold, Christine Magin, Wiesbaden 2009 (Die deutschen Inschriften 77).

Christine Magin, Akademische Epigrafik? Die Universitäten Rostock und Greifswald im Spiegel historischer Inschriften. In: Tochter oder Schwester - Die Universität Greifswald aus Rostocker Sicht, hg. von Hans-Uwe Lammel, Gisela Boeck, Rostock 2010 (Rostocker Studien zur Universitätsgeschichte 8), S. 85-112.

Christine Magin, Neue Freidank-Inschriften des 14. Jahrhunderts in einem mecklenburgischen Kloster. In: Zeitschrift für deutsches Altertum und deutsche Literatur 139 (H. 2), 2010, S. 191-196.

Christine Magin, Klösterliche Begräbnisformen im Mittelalter und in der frühen Neuzeit: eine Problemskizze. In: Klöster und Inschriften. Glaubenszeugnisse gestickt, gemalt, gehauen, graviert. Beiträge zur Tagung am 30. Oktober 2009 im Kloster Lüne, hg. von Christine Wulf, Sabine Wehking, Nikolaus Henkel, Wiesbaden 2010, S. 129-139.

\section{Deutsches Wörterbuch von Jacob Grimm und Wilhelm Grimm \\ Interakademische Leitungskommission: \\ Stackmann, Gardt, Klein (NL), H. Schmidt (Berlin) \\ Leitungskommission für auf Göttingen beschränkte Belange: \\ Vorsitzender: Stackmann \\ Stellv. Vors.: Henne \\ Barner, Blosen (Egå/DK), Casemir (Münster), Detering, Gardt}

Kontaktadresse: Papendiek 14, 37073 Göttingen, Tel.: 0551-39-9544, Fax: 0551-39-9881, vharm@gwdg.de (Dr. Harm), http://www.grimm. adw-goettingen.gwdg.de

Arbeitsbericht: Das 1960 in erster Auflage mit 32 Bänden abgeschlossene Deutsche Wörterbuch wurde als historisches Wörterbuch der neuhochdeutschen Schriftsprache angelegt. Es enthält in alphabetischer Ordnung den gebräuchlichen deutschen Wortschatz von der Mitte des 15. Jahrhunderts bis zur Gegenwart. Geplant und begonnen wurde es von den Brüdern Jacob und Wilhelm Grimm. Nach ihrer Vorstellung und ihrem Vorbild stellt das Wörterbuch die Geschichte der deutschen Wörter dar, gibt ihre Her- 
kunft, ihre Verwandtschaft und ihre Formen an und beschreibt ihre landschaftliche Verbreitung innerhalb des deutschen Sprachgebiets. Die Hauptaufgabe des Wörterbuchs besteht in der Herausarbeitung und Beschreibung der Bedeutung der Wörter und ihrer verschiedenen Gebrauchsweisen in der schriftsprachlichen Überlieferung anhand von ausgewählten Belegen. Auf diese Weise sollen Entwicklung, Veränderung und Variation der Bedeutungen vom ersten Auftreten bis heute aufgezeigt werden. Der besondere Wert des Deutschen Wörterbuchs liegt in der umfassenden Wortschatzsammlung und in der breiten Dokumentation der historischen Belege. Es bildet ein Grundlagenwerk der deutschen Wortforschung. Mit der vollständigen Neubearbeitung der ältesten Teile A-F soll in Konzeption und Darstellungsweise an die letzten Bände der Erstausgabe angeknüpft, zugleich aber auch der Anschluß des Werks an zeitgemäße Standards der historischen Lexikographie gewährleistet werden. Die Arbeiten an der Neubearbeitung wurden 1960 begonnen. Seit 1965 erscheinen Lieferungen der Unternehmensteile in Berlin und Göttingen. Das Unternehmen wird von der Berlin-Brandenburgischen und der Göttinger Akademie der Wissenschaften getragen und verfügt über zwei Forschungsstellen an den Sitzorten der Akademien. Der in Göttingen bearbeitete Teil D-F des ${ }^{2}$ DWB ist im Frühsommer 2006 planmäßig abgeschlossen worden und liegt gedruckt vor.

Im Rahmen einer Kooperationsvereinbarung der beiden Unternehmensteile über den beschleunigten Abschluß der Neubearbeitung des Deutschen Wörterbuchs wurde im Juli 2006 das Belegmaterial des fünften Bandes im Alphabet von BETRIEB bis Ende C von der Berliner Arbeitsstelle nach Göttingen überstellt. Es handelt sich um ca. 500.000 Zettel, die, auf fünf Lieferungen verteilt, bis 2012 in Göttingen abschließend bearbeitet werden sollen.

Im Jahr 2010 wurde die lexikographische Bearbeitung der dritten Lieferung des fünften Bandes in großen Teilen abgeschlossen. Damit besteht nach wie vor ein Rückstand von rund einer Lieferung gegenüber der ursprünglichen Planung. Die Personalfluktuation, die die Arbeitsstelle seit $2007 \mathrm{zu}$ verkraften hat, dauert an. So wechselte der Arbeitsstellenleiter, Prof. Dr. Michael Schlaefer, zum 31.12.2010 in die Freistellungsphase seiner Altersteilzeit. Er hat sich in den 25 Jahren seiner Tätigkeit große und bleibende Verdienste um die Neubearbeitung des Deutschen Wörterbuchs erworben. Frau Sabine Elsner-Petri verlässt das Vorhaben ebenfalls zum Jahresende und tritt eine Stelle in einem anderen Projekt der Akademie an. Vor dem Hintergrund des anhaltenden personellen Umbruchs wurde bereits im Vorjahr deutlich, daß ein planmäßiger Abschluß der Neubearbei- 
tung nicht mehr zu erreichen sein wird. In Zusammenarbeit mit der BerlinBrandenburgischen Akademie der Wissenschaften, die gemeinsam mit der Göttinger Akademie die Verantwortung für das Vorhaben trägt, wurde daher für den Göttinger Projektteil ein Antrag auf Verlängerung der Förderung vorbereitet. Grundzüge der Antragstellung wurden in drei Sitzungen (30.11.2009, 24.3.2010 in Göttingen, 21.5.2010 in Berlin) festgelegt. Um den Abschluß des Unternehmens sicherzustellen, wurde eine gemeinsame Leitung des Projekts beschlossen. Der Leitungskommission gehören Herr Stackmann und Herr Gardt als Vertreter der Göttinger Akademie sowie Herr Klein und Herr Schmidt als Vertreter der Berlin-Brandenburgischen Akademie an.

Die im Vorjahr begonnenen Arbeiten an der digitalen Fassung des Quellenverzeichnisses konnten fortgesetzt werden. Im Rahmen der Reihe „Kolloquien für junge Wissenschaftler“ hat die Arbeitsstelle am 1. und am 2.3.2010 ein deutsch-dänisches Wörterbuchkolloquium zum Thema „Phraseologie im historischen Wörterbuch" veranstaltet (s. dazu unter „Sonstige Veranstaltungen“, Seite 442). Neben Sprachwissenschaftlern aus Dänemark haben an der Veranstaltung auch Vertreter des Mittelhochdeutschen Wörterbuchs sowie des Deutschen Rechtswörterbuchs (Heidelberg) teilgenommen. Am 25.8.2010 fand in Berlin ein Treffen der beiden Arbeitsstellen statt, das Gelegenheit zum fachlichen Austausch zwischen den Unternehmensteilen bot. Mitarbeiter der Arbeitsstelle haben im laufenden Jahr externe wissenschaftliche Veranstaltungen besucht und universitäre Lehrveranstaltungen durchgeführt. Eine Sitzung der Kommission für das Deutsche Wörterbuch fand am 27.9.2010 statt.

K. Stackmann

\section{Die Inschriften des ptolemäerzeitlichen Tempels von Edfu \\ Leitungskommission: \\ Vorsitzender: Junge \\ Behlmer (Göttingen), Beinlich (Würzburg), Kurth (Hamburg), G. A. Leh- mann, Loprieno (Basel)}

Kontaktadresse: Universität Hamburg, Fakultät für Geisteswissenschaften, Departement Kulturgeschichte und Kulturkunde, Abt. Archäologisches Institut, Arbeitsstelle „Edfu-Projekt“, Edmund-Siemers-Allee 1, Flügel West, 20146 Hamburg, Tel.: 040-42838-3209, -3254, contact@edfuprojekt.gwdg.de (Dr. Waitkus), http://www.edfu-projekt.gwdg.de 
Arbeitsbericht: Der ptolemäische Tempel von Edfu gilt als einer der besterhaltenen Sakralbauten der Antike. Schon bald nach der bis 1865 erfolgten Freilegung des jahrhundertelang in weiten Teilen verschütteten Tempels wurden einige größere Texteinheiten von verschiedenen Ägyptologen wie Ernst von Bergmann, Heinrich Brugsch, Johannes Dümichen, Edouard Naville, Karl Piehl und Jacques de Rougé in Abschriften publiziert. Erst 1876 begann jedoch die systematische Aufnahme der Hieroglyphen und der Dekoration durch Maxence de Rochemonteix, der seine Arbeit jedoch nicht zu Ende führen konnte. Sein Nachfolger wurde Émile Gaston Chassinat, der die Abschriften der Texte des Haupttempels und des Mammisis schließlich veröffentlichte. Die Gesamtpublikation umfaßt von seiten Rochemonteixs/Chassinats 14 Bände, acht Textbände, welche die hieroglyphischen Texte in Drucktypen wiedergeben, zwei Bände mit Strichzeichnungen sowie vier Bände mit Photographien (1897-1960). Ein 15. Band mit Texten und Darstellungen, deren Aufnahme von Maxence de Rochemonteix übersehen worden war, wurde mit weiteren Photographien 1985 von Sylvie Cauville und Didier Devauchelle publiziert. Die beiden ersten Textbände wurden in einer revidierten Auflage ebenfalls von Cauville und Devauchelle zwischen 1984-1990 herausgegeben. Die Inschriften des Mammisi von Edfu wurden von Chassinat 1939 veröffentlicht. 2008 erschien mit Faszikel 10.3 ein weiterer Band mit Strichzeichnungen von Yousreya Hamed im Verlag des IFAO. Die Strichzeichnungen der Umfassungsmauer und des Pylonen, angefertigt von Uwe Bartels, wurden 2009 durch das Edfu-Projekt als ITE II/1 publiziert.

Erst nach den Basisarbeiten, insbesondere den hieroglyphischen $\mathrm{Ab}-$ schriften durch Chassinat, wurde eine umfassende und detaillierte wissenschaftliche Bearbeitung der Tempeltexte möglich. Die Edfu-Inschriften zählen nach Umfang und Inhalt zu den wichtigsten religiösen Quellen aus der Zeit der Ptolemäerherrschaft in Ägypten.

1986 gründete Dieter Kurth ein Langzeitprojekt, das sich der philologischen Gesamtbearbeitung der Inschriften des Tempels von Edfu widmet. Bis 2001 wurde das Edfu-Projekt von der Deutschen Forschungsgemeinschaft finanziert und betreut. Seit 2002 gehört das Projekt zum Programm der Akademie der Wissenschaften zu Göttingen. Die Arbeitsstelle selbst ist in Räumlichkeiten der Universität Hamburg beheimatet. Während Dieter Kurth die Projektleitung innehat, wurde Wolfgang Waitkus 2008 als Arbeitsstellenleiter eingeführt.

Der erste aus der Arbeit des Projektes hervorgegangene Übersetzungsband mit Umschrift und Kommentar wurde 1998 publiziert. Er enthält die Inschriften des Pylonen (Edfou VIII). Die Inschriften der Außenseite der 
Umfassungsmauer (Edfou VII) erschien 2004 (ISBN 978-3-447-03862-1 und 978-3-447-05016-6).

Zwecks Überprüfung der Originaltexte wurden während bislang sieben Kampagnen am Edfu-Tempel (1995-2005) ausgewählte Inschriftenpassagen der Bände Edfou IV-VII sowie der gesamte Band VIII vor Ort kollationiert. Insbesondere an den höher gelegenen Bereichen - der Pylon misst heute noch über $32 \mathrm{~m}$ - sowie an den beschädigten Stellen sind zahlreiche Zeichen und Textpassagen der Publikation von Chassinat zu korrigieren und zu ergänzen. So konnten dem ersten Übersetzungsband (ITE I/1, Edfou VIII) 40 Seiten hieroglyphische Korrekturen und dem zweiten Band (ITE I/2, Edfou VII) 48 Seiten Korrekturen zu Chassinat beigegeben werden. Der zweite Band enthält des Weiteren auf einer beigefügten CD-ROM ein Datenbankprogramm mit den bislang publizierten Texten in Umschrift und Übersetzung.

Die Inschriften der inneren Umfassungsmauer sowie diejenigen des Hofes und der Säulen des Hofes sind in einer Vorübersetzung abgeschlossen.

2009 erschien im Harrassowitz-Verlag der Band „Die Darstellungen auf den Außenseiten der Umfassungsmauer und auf dem Pylonen. Strichzeichnungen und Photographien. Die Inschriften des Tempels von Edfu, Abteilung II, Dokumentationen, Band 1" (ITE II/1) von Uwe Bartels (ISBN 978-3-447-05834-6), der die von Chassinat nicht publizierten Strichzeichnungen der Ritualszenen zu Edfou VII (Außenseite der Umfassungsmauer) und zu Edfou VIII (Pylon) enthält. Der Monographie wurde eine DVDROM beigelegt, die es ermöglicht, der jeweiligen als Strichzeichnung ausgeführten Szene eine zugehörige Photographie des Edfu-Archivs zuzuordnen.

2010 erschien der zweite Band in der Dokumentationen-Reihe: „Neue Graffiti und Ritualszenen des Tempels von Edfu. Die Inschriften des Tempels von Edfu, Abteilung II, Dokumentationen, Band 2" (ITE II/2); auch diesem Band liegt eine CD-ROM mit 38 Strichzeichnungen und 277 Farbphotographien bei (ISBN 978-3-935012-06-5). Dieser Dokumentationsband enthält sechs Artikel, in denen bisher unpublizierte Graffiti und hieroglyphische Texte veröffentlicht und bearbeitet wurden. Den Anfang bilden drei Ritualszenen, die im Eingangskorridor des östlichen Pylonturmes entdeckt wurden und einen Beitrag zur Baugeschichte des Tempels liefern. Es folgen Ritualszenen eines Soubassements, das zur Dekoration des zweiten Hofes des Mammisi gehört. Der anschließende Artikel behandelt demotische Versatzmarken des Tempels von Edfu, die sich vor allem auf der Brücke zwischen den Pylontürmen erhalten haben. Sie eröffnen Einblicke in die bautechnische Planung und Ausführung des Tempelgebäudes. Der nächste Artikel befasst sich mit den bisher nicht beachteten Resten eines 
kleinen Kultbaues, von dem sich noch sieben dekorierte Blöcke nahe der Nordwestecke des großen Tempels in situ befinden. Es folgen Publikation und Bearbeitung einiger hieratischer, demotischer und koptischer Graffiti. Abschließend werden Graffiti vorgestellt, die aus der Zeit der Ägyptenexpedition Napoleons stammen. Der Inhalt des vorliegenden Bandes zeigt, dass die Erforschung des großen Tempels von Edfu nicht nur im Bereich der Bearbeitung seiner Inschriften, sondern auch im Bereich der Dokumentation längst noch nicht abgeschlossen ist.

Seit 1990 wurden sechs Bände der Reihe „Edfu-Begleithefte“ herausgegeben. Zuletzt erschienen ist im Dezember 2009 eine von Stefan Rüter angefertigte monographische Untersuchung einer spezifischen Hymnenform in Edfu und weiteren Tempeln der Ptolemäerzeit: („Habt Ehrfurcht vor der Gottheit NN. Die snd-n-Hymnen in den ägyptischen Tempeln der griechisch-römischen Zeit“; ISBN 978-3-935012-05-8).

Im Jahr 2010 konnte EDFU: Materialien und Studien. Die Inschriften des Tempels von Edfu; Begleitheft 6 publiziert werden (ISBN 978-3935012-07-2). Das Buch enthält insgesamt zwölf Beiträge von D. Budde, A. Effland, M. von Falck, J.-P. Graeff, S. Martinssen-von Falck und W. Waitkus. Im Vordergrund der unterschiedlichen Beiträge stehen die Themen, die sich aus der Beschäftigung mit dem Edfu-Tempel bzw. der Arbeit des Edfu-Projektes ergeben. So widmen sich einige Studien der Textgestaltung und der Dekoration des Edfu-Tempels sowie dessen Baugeschichte. In den Bereich der Hilfsmittel zur methodischen Erforschung der EdfuTexte gehört ein Beitrag zu den Datenbanken des Edfu-Projektes. Etwas herausgehoben aus dem üblichen Rahmen der Begleithefte sind zwei Beiträge, die der Rezeptionsgeschichte des Edfu-Tempels in Architektur und Dekoration des 19. Jahrhunderts sowie in den Neuen Medien nachgehen. An die im Begleitheft 5 publizierten Berichte über die Surveys im Hinterland von Edfu schließt ein Beitrag an, in dem neue Beobachtungen und Überlegungen zur Lage der Götternekropole Behedet vorgestellt werden. Über den Tempel von Edfu hinausgehend, werden übergreifend einige Themen zur Theologie, zu Dekorationprinzipien und Ritualen der Tempel der griechisch-römischen Zeit behandelt.

Nachdem 2007 ( ${ }^{3}$ 2009) der erste Band der ptolemäischen Grammatik (ISBN 978-3-9810869-1-1) erschienen ist und im Dezember 2008 der zweite Band (ISBN 978-3-9810869-3-5), der auch die ausführlichen vereinigten Indizes beider Bände enthält, werden seither für Folgeauflagen fortwährend Verbesserungen und Korrekturen eingearbeitet. 2010 erschien mit „A Ptolemaic Sign-List. Hieroglyphs Used in the Temples of the GraecoRoman Period of Egypt and their Meanings" (ISBN 978-3-9810869-9-7) 
ein englischsprachiger Exzerpt des ersten Grammatikbandes, das eine ausführliche hieroglyphische Zeichenliste enthält.

Im Berichtszeitraum 2010 wurden folgende Arbeiten durchgeführt: Die Übersetzung der Texte der Innenseite der Umfassungsmauer (Edfou VI) wurde fortgesetzt. Dieser Band enthält u. a. den überwiegenden Teil der innerhalb der gesamten Edfu-Inschriften verstreut überlieferten Schöpfungsmythen. Darüber hinaus sind in Edfou VI auch die Texte des Großen Horusmythos zu finden, bei dem es sich um den größten erzählenden Text des Tempels handelt. Die Fertigstellung der Übersetzung ist nahezu abgeschlossen. Vor der geplanten Publikation des Bandes ITE I/3 (Edfou VI) in 2011 sind noch die ausführlichen Indizes anzufertigen und die computererstellten hierglyphischen Korrekturen am originalen Chassinat-Text sowie die üblichen redaktionellen Arbeiten abzuschließen.

Die 2009/10 publizierte relevante Sekundärliteratur wurde gesichtet, aufgenommen und verarbeitet. Ebenso wurde die Arbeit an den Datenbanken des Projektes fortgeführt (dazu s. u.).

Die digitalisierte Erfassung der Wortliste mit Transliteration, Übersetzung und hieroglyphischer Umsetzung wurde fortgesetzt.

Im Rahmen der von der Akademienunion befürworteten und unterstützten Aufgabe der Digitalisierung, Langzeitarchivierung und Schaffung verläßlicher Repositorien zum Erhalt der erarbeiteten Ressourcen und Materialien wurde u. a. damit begonnen, die bereits in Printform erschienenen Publikationen zu digitalisieren und zu transformieren. An dem Workshop „Repositorien“ der Arbeitsgruppe „Elektronisches Publizieren“ der Union der deutschen Akademien der Wissenschaften (Digitale Bibliotheken der Zukunft: Workshop der Akademienunion zu Repositorien, Düsseldorf, 04.-06.10.2010) nahm J. P. Graeff als Vertreter des Edfu-Projektes mit einem Vortrag teil. Eine Textdatenbank („Edfu Explorer Online“) wurde im Oktober online gestellt (s. u.).

Im Kontext der Planungen und Vorarbeiten zur 8. Kollationierungskampagne in Edfu (März/April 2011) konnte mit Mitteln der Akademie ein mobiles Hochstativsystem erworben werden, das es ermöglicht, an hochgelegenen und nahezu unzugänglichen Stellen des Tempels von Edfu digitale Photographien anzufertigen.

Die Arbeiten an der Lemmatisierung, die der Zuarbeit für den Thesaurus Linguae Aegyptiae des Altägyptischen Wörterbuchprojekts der BerlinBrandenburgischen Akademie der Wissenschaften dienen, wurden von R. Brech fortgeführt.

Während der letzten drei Kalendermonate wurden die verbliebenen halben Stellen der Mitarbeiter des Edfu-Projekts zeitlich befristet aufgestockt. 
Im Berichtszeitraum wurden mehrere Vorträge zu Edfu-Themen gehalten: D. Kurth, Die Rolle des Königs im altägyptischen Tempelkult (Berlin); A. Effland, Old and New. Graffiti in the Edfu-Temple (London); J.-P. Graeff, Vom Zettelarchiv zur Datenbank: Die Inschriften des Tempels von Edfu in Oberägypten (Düsseldorf).

Die Internetpräsenz des Projektes wurde fortlaufend überarbeitet und gepflegt. Seit November befinden sich die Web-Seiten auf einem Server der Universität Göttingen (http://www.edfu-projekt.gwdg.de/); sie sind weiterhin auch in einer englischsprachigen Version aufrufbar (http://www.edfuprojekt.gwdg.de/Home_engl.html). Zudem wurde eine Textdatenbank (Edfu Explorer Online) ins Netz gestellt. Der Edfu Explorer Online ist eine Datenbankplattform, die das Formular der Texte des Tempels von Edfu enthält, soweit es durch die Publikationen „Die Inschriften des Tempels von Edfu“ bereits freigegeben wurde. Zur Zeit betrifft dies die Übersetzungen der Chassinat-Bände Edfou VII und VIII (ca. 4.000 Datensätze). Des Weiteren hat der Nutzer Zugriff auf die mit den jeweiligen Datensätzen verbundenen Photos des Edfu-Archives in einem Umfang von etwa 15.000 Photographien sowie die betreffende Seite der Chassinat-Publikation (etwa 1.300 Seiten). Für Formularstudien steht darüber hinaus ein zweidimensionaler Plan des Tempels zur Verfügung, der den Zugriff auf die ChassinatSeite über die Szenenposition ermöglicht.

Erneut engagierten sich Projektleiter und Mitarbeiter des Vorhabens in der akademischen Lehre an der Universität Hamburg. Zur Zeit sind als Wissenschaftliche Mitarbeiter beim Projekt beschäftigt: Ruth Brech, Andreas Effland, Jan-Peter Graeff, Martin von Falck. Als studentische Hilfskraft ist Leon Ziemer tätig, der die durch die Akademie finanzierten Titel in die Bibliothek des Projektes einpflegt. Projektleiter ist Dieter Kurth, Arbeitsstellenleiter ist Wolfgang Waitkus.

D. Kurth

Veröffentlichungen:

D. Kurth \& W. Waitkus (Hgg.), Neue Graffiti und Ritualszenen des Tempels von Edfu. Die Inschriften des Tempels von Edfu - Abteilung II Dokumentationen, Band 2, Gladbeck 2010 (ISBN 978-3-935012-06-5) 
Edition der naturwissenschaftlichen Schriften Lichtenbergs

Leitungskommission:

Vorsitzender: Christensen

Stellv. Vors.: Barner

Beuermann (Göttingen), Joost, Lieb, Patzig, Samwer, Schöne

Kontaktadresse: Am Papendiek 14, 37073 Göttingen, Tel.: 0551-398409, Fax: 0551-39-9661, akrayer@gwdg.de (Dr. Krayer)

Arbeitsbericht: Auf mehr als 1300 Blättern und in 41 kleinen Heftchen des in der Göttinger Bibliothek aufbewahrten Nachlasses von Georg Christoph Lichtenberg steht ein Fülle von Beobachtungen, Gedanken und Bemerkungen zu Erxlebens Lehrbuch „Anfangsgründe der Naturlehre“, das der Physikprofessor Lichtenberg über Jahrzehnte hinweg als Leitfaden seiner Vorlesungen zur Experimentalphysik, zur physischen Geographie und zur Astronomie verwandte. Dieses Werk liefert das Ordnungsprinzip für die Edition der bisher unveröffentlichten Aufzeichnungen; ihre Transkription und Kommentierung sind die Hauptaufgaben der Arbeitsstelle.

Im Berichtsjahr 2010 konnte planmäßig der vierte Band der Edition erscheinen, mit dem die „Notizen und Materialien zur Experimentalphysik“ in zwei Bänden (3 und 4) nun vollständig vorliegen. Jedes ihrer Kapitel korrespondiert einem der ersten elf Abschnitte des Erxlebenschen Lehrbuchs, das nach einem von Lichtenberg annotierten Exemplar als Band 1 der Edition vorliegt. Jedes enthält nach einer kurzen Einleitung durch die Bearbeiter zunächst die entsprechenden Passagen aus Lichtenbergs Aufzeichnungen für die Vorlesung des Sommersemesters 1785 und sodann die übrigen thematisch einschlägigen Texte, jeweils mit textkritischem Kommentar. Die Sachkommentare sind gesammelt am Ende der Bände abgedruckt. Etwa 750 Seiten Lichtenbergschen Textes stehen Sachkommentare im Umfang von gut 700 Seiten gegenüber.

Im Anschluß daran wurde mit der Arbeit an Band 5 begonnen, der die Texte zu den Abschnitten 12 („Vom Weltgebäude und der Erde überhaupt“) und 13 („Von der Erde insbesondere“) enthalten wird. Den darin behandelten Fächern Astronomie und physische Geographie (mit Meteorologie und den Lehren vom Erdmagnetismus und der Erdentstehung) widmete Lichtenberg eine besondere Vorlesung. In ihrer vierstündigen Endform hielt er sie erstmals im Wintersemester 1785/86. Die bei der Vorbereitung darauf entstandenen umfangreichen Aufzeichnungen bilden den Kernbestand der zur Edition in diesem Band vorgesehenen Lichtenbergschen Manuskripte. 
Ebenfalls angelaufen sind die Planungen für Band 6, der neben einem Gesamtregister der Ausgabe als Glanzpunkt in einer reich illustrierten Form Lichtenbergs Verzeichnis seiner Instrumentensammlung enthalten soll, die den Grundstock und Ausgangspunkt einer universitären Sammlung physikalischer Apparate in Göttingen bildete (heute in der Sammlung historischer Apparate des I. Physikalischen Instituts).

U. Christensen

Veröffentlichung:

Georg Christoph Lichtenberg: Vorlesungen zur Naturlehre. [Bd. 4.], Notizen und Materialien zur Experimentalphysik, Teil II. Hrsg. von der Akademie der Wissenschaften zu Göttingen. (Bearb.: Albert Krayer, Thomas Nickol, Horst Zehe) Wallstein-Verlag, Göttingen 2010. XXVI, 920 S., zahlr. Abb. ISBN 978-3-8353-0658-5

\section{Enzyklopädie des Märchens}

Leitungskommission:

Vorsitzender: Roth (München)

Alzheimer (Bamberg), Brednich (Göttingen), Brückner (Würzburg), Drascek (Regensburg), Gerndt (München), Köhler-Zülch (Göttingen), Mölk, Nagel, Terwiel, Uther (Göttingen)

Kontaktadresse: Friedländer Weg 2, 37085 Göttingen, Tel.: 0551-395358, Fax: 0551-39-2526, uther@gwdg.de (Prof. Dr. Uther), http://gwdg. de/ enzmaer

Arbeitsbericht: Die Enzyklopädie des Märchens (EM) ist ein Handwörterbuch zur historischen und vergleichenden Erzählforschung. Es stellt die Ergebnisse von zwei Jahrhunderten internationaler Forschungsarbeit im Bereich volkstümlicher Erzähltraditionen in Vergangenheit und Gegenwart umfassend dar. Das Werk erfaßt dabei schwerpunktmäßig die oralen und die literalen Erzählformen Europas und der europäisch beeinflußten Kulturen, bemüht sich aber auch um eine angemessene Berücksichtigung außereuropäischer Kulturkreise. Darüber hinaus werden anhand der verschiedenen Quellenbereiche die ständigen Wechselbeziehungen zwischen Literatur und Volksüberlieferung deutlich gemacht. Die in der EM präsentierten Informationen sind für Fachleute verschiedenster Forschungsbereiche von Interesse, u. a. für Volkskundler, Philologen, Ethnologen, Religionswissenschaftler, Soziologen, Psychologen, Pädagogen, Kunsthistoriker, Medienforscher. Die Göttinger Forschungsstelle verfügt über ein weltweit einzigartiges Archiv 
von mehreren 100.000 Erzähltexten sowie eine Spezialbibliothek mit etwa 15.000 Einheiten. Die bisher über 800 Autoren und Autorinnen der EM stammen aus über 70 Ländern in allen Kontinenten.

2010 liegen dreizehn komplette Bände (A - Verführung) vor. Im Berichtsjahr wurden außerdem die Artikel für die erste Lieferung des 14. Bandes (Vergeltung - Weg) zum Druck vorbereitet.

Im Oktober 2010 erschien die dritte Lieferung des dreizehnten Bandes der „Enzyklopädie des Märchens“; sie umfaßt die Artikel „Troja-Roman“ bis „Verführung“. Ein Großteil der Manuskripte für die erste Lieferung des 14. Bandes („Vergeltung“ bis ca. „Weg“) liegt bereits vor. Die redaktionelle Bearbeitung der ausstehenden Manuskripte soll im Februar 2011 abgeschlossen werden, so daß die erste Lieferung des 14. Bandes ca. August 2011 erscheinen kann.

Außer auf die Redaktionstätigkeit zu den Artikeln der Buchstaben V bis $Z$ verwandten die Mitarbeiter erhebliche Zeit darauf, die außerordentlich umfangreichen Archive und Kataloge der Arbeitsstelle zu ergänzen und auf den neuesten Stand zu bringen. Dies betraf insbesondere die Betreuung des Textarchivs sowie die Auswertung von Typenkatalogen und Spezialbibliographien. Die Anschaffung und Einarbeitung wichtiger in- und ausländischer Primär- und Sekundärliteratur in die Bibliothek und die diversen Archive wurde gleichfalls in angemessenem Maßstab betrieben.

Fortgeführt wurde die EDV-Erfassung zur Aufbereitung des Archivmaterials, der verschiedenen Katalog- und Karteisysteme sowie der Namen-, Sach-, AaTh/ATU- und Motivregister, die für die redaktionelle Arbeit einen schnellen und umfassenden Zugriff auf die Materialien ermöglicht und sich in der Praxis vielfach bewährt hat. Die Register der EM sind nach umfangreichen Umstellungen seit Sommer 2000 bei der GWDG gespeichert. Abfragen und Bearbeitungen werden per Internetschnittstelle vorgenommen.

J. Uther

Veröffentlichungen:

Enzyklopädie des Märchens, Handwörterbuch zur historischen und vergleichenden Erzählforschung

Band 13, Lieferung 3 (Troja-Roman - Verführung). Begründet von Kurt Ranke. Mit Unterstützung der Akademie der Wissenschaften zu Göttingen herausgegeben von Rolf Wilhelm Brednich, Göttingen, zusammen mit Heidrun Alzheimer, Bamberg, Hermann Bausinger, Tübingen, Wolfgang Brückner, Würzburg, Daniel Drascek, Regensburg, Helge Gerndt, München, Ines Köhler-Zülch, Göttingen, Klaus Roth, München, Hans-Jörg Uther, Göttingen. Verlag Walter de Gruyter \& Co., Berlin/New York 2010. Sp. 961-1440. 
Erschließung der Akten des kaiserlichen Reichshofrats

Leitungskommission:

Vorsitzende: Schumann

Cordes (Frankfurt/Main), Just (Wien), Oestmann (Münster), Olechowski (Wien), Sellert

Kontaktadresse: Institut für Rechtsgeschichte, Rechtsphilosophie und Rechtsvergleichung, Abt. für Deutsche Rechtsgeschichte, Weender Landstraße 2, 37073 Göttingen, Tel.: 0551-39-7444, Fax: 0551-39-13776, e.schumann@jura.uni-goettingen.de (Prof. Dr. Schumann)

Arbeitsbericht: Das seit 2007 bestehende (in Zusammenarbeit mit der Österreichischen Akademie der Wissenschaften und dem Österreichischen Staatsarchiv betreute) Forschungsprojekt zur Erschließung der Judicialia des Kaiserlichen Reichshofrats (ausführlich zu Umfang und Zielsetzungen des Projekts: Wolfgang Sellert, Jahrbuch der Akademie der Wissenschaften zu Göttingen 2009, S. 506-509) ist im vergangenen Jahr - trotz Mitarbeiterwechsel in den Jahren 2009 und 2010 - gut vorangekommen. Zwei Bände sind 2010 und Anfang 2011 beim Erich Schmidt Verlag (Berlin) erschienen: der von Eva Ortlieb bearbeitete zweite Band aus der Serie I (Alte Prager Akten, Band 2: E-J) und der von Ursula Machoczek bearbeitete erste Band aus der Serie II (Antiqua, Band 1: Karton 1-43). Die Arbeiten an zwei weiteren Bänden aus der Serie I (Alte Prager Akten, Band 3 und 4, bearbeitet von Eva Ortlieb und Tobias Schenk) stehen vor dem Abschluss und werden 2011/2012 erscheinen; die Arbeiten am zweiten Band aus der Serie II (Antiqua, Bearbeiter: Ulrich Rasche) kommen ebenfalls gut voran. $\mathrm{Zu}$ den Bänden stellt der Verlag eine kostenpflichtige digitale Version unter der Adresse http://www.RHRdigital.de zur Verfügung.

Die bisher erschienenen Rezensionen waren durchgängig sehr positiv: Anja Amend-Traut, sehepunkte 10 (2010), Nr. 11 [15.11.2010], http:// www.sehepunkte.de/2010/11/17657.html; Filippo Ranieri, Archiv für hessische Geschichte und Altertumskunde, Neue Folge, Bd. 68 (2010), S. 489491; Dieter Pöschke: Jahrbuch für Geschichte Mittel- und Ostdeutschlands, Zeitschrift für vergleichende und preußische Landesgeschichte, Bd. 55, 2009, S. 293-297; Robert Riemer, sehepunkte 10 (2010), Nr. 7/8 [15.07.2010], http://www.sehepunkte.de/2010/07/17651.html; Bernd Schildt, http://www.koeblergerhard.de/ZRG128Internetrezensionen2011/ DieAktendesKaiserlichenReichshofrats.htm; Raimund J. Weber, Zeitschrift für die Geschichte des Oberrheins (ZGO), Bd. 157 (2009), S. 505-507. 
Von Tobias Schenk wurden in Zusammenarbeit mit dem Projektleiter „Ordnungs- und Verzeichnungsrichtlinien“ als arbeitsgruppeninterne Ergänzung der in den Inventarbänden publizierten Benutzerhinweise erstellt. Sie sollen zukünftig die formale Einheitlichkeit aller Verzeichnungen als wichtiges Qualitätskriterium gewährleisten. Es wurde außerdem eine von Ulrich Rasche betreute Homepage für das Projekt eingerichtet: www. reichshofratsakten.de und http://www.reichshofratsakten.uni-goettingen. del

In Kooperation mit der Wetzlarer Gesellschaft für Reichskammergerichtsforschung fand in Göttingen vom 2. bis zum 4. September 2010 das Symposion „Geld und Gerechtigkeit im Spiegel höchstrichterlicher Rechtsprechung des Alten Reichs“ statt . Die Ergebnisse der Tagung werden der Akademie im Wintersemester 2011/2012 vorgelegt; der Tagungsband soll unter dem Titel „Geld, Handel, Wirtschaft - Höchste Gerichte im Alten Reich als Spruchkörper und Institution" im Jahr 2012 in den Abhandlungen erscheinen.

Am 28. April 2010 und am 2. Dezember 2010 fanden Arbeitssitzungen der Projektgruppe „Die Akten des Kaiserlichen Reichshofrats“ im Haus-, Hof-, und Staatsarchiv Wien unter der Leitung von Wolfgang Sellert statt; die Leitungskommission tagte ebenfalls unter der Leitung von Wolfgang Sellert am 3. September 2010 in Göttingen.

Ende Oktober 2010 ist Werner Ogris auf eigenen Wunsch als Mitglied aus der Leitungskommission ausgeschieden; als sein Nachfolger wurde Thomas Olechowski (Wien) in die Leitungskommission gewählt. Außerdem hat auf Vorschlag der Leitungskommission Eva Schumann im Oktober 2010 den Vorsitz der Leitungskommission übernommen. Die Projektleitung liegt weiterhin in den bewährten Händen von Wolfgang Sellert; wissenschaftliche Mitarbeiter sind Dr. Ulrich Rasche und Dr. Tobias Schenk.

E. Schumann

Veröffentlichungen:

Wolfgang Sellert (Hrsg.), Die Akten des Kaiserlichen Reichshofrats, Serie II: Antiqua, Band 1: Karton 1-43, bearbeitet von Ursula Machoczek, Berlin 2010.

Ulrich Rasche, Tagungsbericht: Geld und Gerechtigkeit im Spiegel höchstrichterlicher Rechtsprechung des Alten Reichs (Akademie der Wissenschaften zu Göttingen, Gesellschaft für Reichskammergerichtsforschung, Göttingen 2. 9. - 4. 9. 2010), in: H-SozKult, 15. November 2010.

Tobias Schenk, Ein Erschließungsprojekt für den kaiserlichen Reichshofrat, in: Archivar 63, 2010, S. 285-290. 


\section{Germania Sacra}

Leitungskommission:

Vorsitzende: Röckelein

Black-Veldtrup (Münster), Flachenecker (Würzburg), Gatz (Città del Vaticano/Italien), Heimann (Potsdam), Henkel, Monnet (Paris), Muschiol (Bonn), Rexroth

Kontaktadresse: Theaterstraße 7, 37073 Göttingen, Tel.: 0551-39-4283 (Frau Dr. Kruppa), Fax: 0551-39-13784, germania-sacra@gwdg.de, www. germania-sacra.de

Arbeitsbericht: Das Forschungsprojekt Germania Sacra hat zur Aufgabe, die Quellen der Kirche des Alten Reiches zu erschließen, das überlieferte Material aufzubereiten und in Handbuchformat zu publizieren. So werden kirchengeschichtliche Basisinformationen zu ganz unterschiedlichen Bereichen der historisch ausgerichteten Wissenschaften wie Verfassungsund Kirchengeschichte, Reichs- und Landesgeschichte, Wirtschafts- und Sozialgeschichte, Bildungsgeschichte, Historische Geographie, Siedlungsgeschichte, Prosopographie, Mentalitäten-, Frömmigkeits- und Patroziniengeschichte des Mittelalters und der Neuzeit erarbeitet. Der Untersuchungszeitraum erstreckt sich über die ganze Vormoderne, von den Anfängen der Bistümer des Reiches im 3./4. Jahrhundert bis zu deren Auflösung in der Reformation bzw. im Zeitalter der Säkularisation zu Beginn des 19. Jahrhunderts.

Das Vorhaben konzentriert sich auf die Bearbeitung der Bistümer (in ihren Grenzen um 1500) und der Domstifte auf dem Gebiet der Bundesrepublik Deutschland. Die unter der Federführung des Max-Planck-Instituts für Geschichte begonnenen Bände zu einzelnen Stiften und Klöstern werden bis 2018 abgeschlossen.

Die Germania Sacra richtet jährlich ein Colloquium für ihre ehrenamtlichen Mitarbeiterinnen und Mitarbeiter aus. Das diesjährige Colloquium fand am 23./24. April 2010 im Historischen Gebäude der Staats- und Universitätsbibliothek Göttingen statt und widmete sich den Reformbewegungen der Klöster und Stifte des Alten Reiches. Im öffentlichen Abendvortrag referierte Prof. Dr. Gert Melville (TU Dresden) über „Bischöfe und religiöse Bewegungen im Hochmittelalter". Aus dem Kreis der ehrenamtlichen Mitarbeiterinnen und Mitarbeiter sprachen Prof. Dr. Immo Eberl (Die Hirsauer Reform und die Gründung des Klosters Blaubeuren), Dr. Peter Rückert (Spätmittelalterliche Klosterreform und Schriftkultur im Umfeld südwestdeutscher Benediktinerklöster), Dr. Bruno Krings (Refor- 
men im Prämonstratenserstift Rommersdorf), Sr. Dr. Maria Magdalena Zunker OSB (Reformen in St. Walburg/Eichstätt [1453-1457]) und Prof. Dr. Hans-Georg Aschoff (Reformation und Gegenreformation im Bistum Hildesheim im 16. Jh.).

Zu den Forschungsvorhaben der Germania Sacra, die bis 2018 abgeschlossen und publiziert werden sollen, gehören elf Bände zu Klöstern des Benediktinerordens. Um die Arbeit an den Bänden zielgerichtet voranzutreiben, richtete die Arbeitsstelle am 26. November 2010 in Göttingen einen Workshop aus, an dem fünf Bearbeiterinnen und Bearbeiter von Benediktinerklöstern teilnahmen: Prof. Dr. Immo Eberl (Blaubeuren und Ellwangen), Dr. Jutta Krimm-Beumann (St. Peter im Schwarzwald), Dr. Bertram Resmini (St. Maximin/Trier), Dr. Peter Rückert (Gottesaue), Sr. Dr. Maria Magdalena Zunker OSB (St. Walburg/Eichstätt). P. Dr. Marcel Albert OSB (Abtei Gerleve) gab eine Einführung in den Stand der Ordensforschung. Gemeinsam mit der Projektleitung und der Redaktion diskutierten die Bearbeiterinnen und Bearbeiter inhaltliche und formale Probleme bei der Abfassung ihrer Bände.

Die Projektleitung und die Mitglieder der Redaktion vertraten die Germania Sacra auf zahlreichen wissenschaftlichen Konferenzen im In- und im Ausland. Intensive wissenschaftliche Kontakte wurden mit der Central European University Budapest und dem Deutschen Historischen Institut in Rom geknüpft.

Das Redaktionsteam der Germania Sacra war aktiv in das DAAD-Austauschprogramm „Medieval Monastic Regions in Central Europe - The Spiritual and Physical Landscape Setting of Monastic Orders and Religious Houses“ eingebunden, welches von der Universität Göttingen (Prof. Dr. Hedwig Röckelein) und der Central European University Budapest (Prof. Dr. József Laszlovszky) betreut wird. Das Programm bestand aus vier Workshops. Der dritte Workshop fand am 9./10. April 2010 zum Thema „Monastic Topography and Ecclesiastical Topography“ in Göttingen statt und wurde von der Germania Sacra ausgerichtet.

Am 12./13. Oktober 2010 fand in Rom ein gemeinsamer Workshop des Deutschen Historischen Instituts und der Germania Sacra zu den Themen Digitalisierung, Datenbanken und Kartographie statt. Dort wurde eine künftige Kooperation zwischen der Germania Sacra und dem Deutschen Historischen Institut in Rom vereinbart.

Im Rahmen der „Kolloquien für junge Wissenschaftler“ der Akademie der Wissenschaften zu Göttingen richtete die Germania Sacra am 29./30. Oktober 2010 einen Workshop für Nachwuchswissenschaftler aus, auf dem sowohl Doktorandinnen und Doktoranden als auch Habilitandin- 
nen und Habilitanden ihre kirchenhistorischen Projekte vorstellen konnten (s. unter „Sonstige Veranstaltungen“, Seite 466).

Das Forschungsvorhaben Germania Sacra wurde im Berichtsjahr zum ersten Mal seit dem Übergang des Projektes an die Akademie der Wissenschaften 2008 evaluiert. Die Begehung durch auswärtige Fachgutachter fand am 9. Juli 2010 in der Arbeitsstelle statt.

Im Berichtszeitraum konnte die Redaktion die Bearbeitung folgender neuer Bände zu Diözesen und Domstiften der Reichskirche vertraglich vereinbaren: Bischofsreihe Mainz (Anfänge bis 1088; 1089-1200; 1396-1514; 1647-1802), Bischofsreihe Konstanz (1206-1410; 1410-1600), Bischofsreihe Regensburg (bis 1649; 1649-1817), Domstift Regensburg (bis 1250; 1250 bis zur Säkularisation).

Mitarbeiter der Redaktion der Germania Sacra unterrichteten am Seminar für Mittlere und Neuere Geschichte der Georg-August-Universität Göttingen. Im Sommersemester 2010 bot Dr. Nathalie Kruppa ein Aufbauseminar über „Adel im mittelalterlichen (Nieder)Sachsen“ an. Im Wintersemester 2010/11 leitete Dr. Christian Popp ein Seminar zu mittelalterlichen Kalendarien.

Im Mai 2010 erschien mit der Monographie von Wilhelm Kohl „Die Zisterzienserabtei Marienfeld“ der zweite Band der Dritten Folge der Germania Sacra. In Druckvorbereitung sind die Bände von Walburga Scherbaum (Das Augustinerchorherrenstift Bernried) und von Winfried Romberg (Die Würzburger Bischöfe von 1617 bis 1684). Außerdem wird im Frühjahr 2011 der erste Band der „Studien zur Germania Sacra. Neue Folge" von Miriam Montag-Erlwein (Heilsbronn von der Gründung 1132 bis 1321. Das Beziehungsgeflecht eines Zisterzienserklosters im Spiegel seiner Quellenüberlieferung) publiziert werden.

H. Röckelein

Veröffentlichungen:

Wilhelm Kohl: Die Zisterzienserabtei Marienfeld (Germania Sacra Dritte Folge 2; Das Bistum Münster 11), Berlin/New York 2010.

Jasmin Hoven/Bärbel Kröger/Nathalie Kruppa/Christian Popp: Germania Sacra. Bericht der Arbeitsstelle,Germania Sacra' bei der Akademie der Wissenschaften zu Göttingen für das Jahr 2009/2010, in: Deutsches Archiv für Erforschung des Mittelalters 66 (2010), S. 137-143. 
Goethe-Wörterbuch (Arbeitsstelle Hamburg)

Interakademische Leitungskommission:

Vorsitzender: J. Schmidt (Freiburg i. Br.)

Barner, Bierwisch (Berlin), Gardt, Frick, Knapp (Heidelberg), H. Schmidt (Mannheim)

Kontaktadresse: Von-Melle-Park 6, 20146 Hamburg, Tel./Fax: 04042838-2756, christiane.schlaps@uni-hamburg.de (Dr. Schlaps), http:// www.rrz.uni-hamburg.de/goethe-woerterbuch/

Arbeitsbericht: Das seit 1966 erscheinende Goethe-Wörterbuch dokumentiert als größtes semasiologisches Autorenwörterbuch der Germanistik den Wortschatz Johann Wolfgang Goethes in über 90.000 Stichwörtern und gestützt auf circa 3,3 Mio. Belegexzerpte. In alphabetisch angeordneten Wortartikeln wird der spezifische Individualstil Goethes, wie er sich in der Überlieferung eines extrem weitgefächerten Textsorten- und Bereichsspektrum zeigt, in Wortbedeutung und -gebrauch mittels genauer hierarchischer Gliederungsstruktur sowie reichhaltiger Zitat- und Stellenbelegdarbietung herausgearbeitet.

Im Berichtszeitraum sind die zehnte und die elfte Lieferung des 5. Bandes (Libanon - Lokalbildung sowie Lokale - manchmal) erschienen. Die Redaktion der 12. (und letzten) Lieferung des 5. Bandes erfolgte in der Hamburger Arbeitsstelle. Zugleich wurde die Internetversion der unter www.goethe-woerterbuch.de zugänglichen Bände des GWb in ihrer Benutzerfreundlichkeit verbessert.

Zum 1. März verließ Herr Dr. Niels Bohnert die Arbeitsstelle; die Vollstelle ist seither vakant und konnte erst zum 1. Januar 2011 wiederbesetzt werden. Eine halbe Mitarbeiterstelle zur Förderung des wissenschaftlichen Nachwuchses wurde zum 15. November neu eingerichtet und konnte mit Frau Jana Ilgner, M.A., besetzt werden.

Die Mitarbeiterinnen und Mitarbeiter vertraten das Projekt in bewährter Form in verschiedenen wissenschaftlichen Institutionen und auf einer Reihe wissenschaftlicher Konferenzen im In- und im Ausland. Im Anschluß an die Mitarbeitervollversammlung mit den Kolleginnen und Kollegen der Partnerarbeitsstellen vom November 2009 (s. den Bericht zu 2009) arbeitete Ch. Schlaps die dort gefaßten Beschlüsse in eine Neufassung des sog. Regelwerks, d. h. der verbindlichen Darstellung der lexikographischen Arbeitsprinzipien und -praktiken des GWb, ein und führte umfangreiche weitere Vorschläge in einer endgültigen Version zusammen, die anschließend in den Arbeitsstellen diskutiert und entschieden wurden. Diese Fassung des 
Regelwerks trat am 31.3.2010 in allen drei Forschungsstellen des Projekts in Kraft. Mit dem Erscheinen des nächsten Bandes der historisch-kritischen Ausgabe der Briefe Goethes wurden unter der Leitung von B. Hamacher mit Unterstützung durch die studentischen Hilfskräfte die Vergleichsarbeiten mit dem bisherigen Textbestand der Weimarer Ausgabe und anderer Editionen fortgeführt und dabei Korrekturen und Neulesungen aufgenommen. Nachexzerptionen aus diversen amtlichen Schriften wurden im Berichtsjahr von E. Dreisbach vorgenommen.

Ch. Schlaps

Veröffentlichungen:

Goethe-Wörterbuch. Hrsg. von der Berlin-Brandenburgischen Akademie der Wissenschaften, der Akademie der Wissenschaften in Göttingen und der Heidelberger Akademie der Wissenschaften. Kohlhammer-Verlag, Stuttgart, Bd. 5, Lfg. 10 (LibanonLokalbildung), 2010.

Goethe-Wörterbuch. Hrsg. von der Berlin-Brandenburgischen Akademie der Wissenschaften, der Akademie der Wissenschaften in Göttingen und der Heidelberger Akademie der Wissenschaften. Kohlhammer-Verlag, Stuttgart, Bd. 5, Lfg. 11 (Lokale manchmal), 2010.

Elke Dreisbach: [Rez.] Johann Wolfgang von Goethe. „Die Actenstücke jener Tage sind in der größten Ordnung verwahrt..." Goethe und die Gründung der Jenaischen Allgemeinen Literaturzeitung im Spiegel des Briefwechsels mit Heinrich Carl Abraham Eichstädt. Hrsg. von Ulrike Bayer. Göttingen 2009. In: Zeitschrift für Germanistik NF 3 (2010), S. 682-684.

Elke Dreisbach: [Rez.] Die Entstehung von Goethes Werken in Dokumenten. Begr. von Momme Mommsen, fortgef. und hrsg. von Katharina Mommsen. Bd. I-IV. Berlin u. a. 2006-2008. In: Jahrbuch der Österreichischen Goethe-Gesellschaft, Bd. 111/112/113 (2007/2008/2009), S. 263-266.

Bernd Hamacher: Offenbarung und Gewalt. Literarische Aspekte kultureller Krisen um 1800. München: Fink 2010.

Bernd Hamacher: Johann Wolfgang von Goethe. Entwürfe eines Lebens. Darmstadt: Wissenschaftliche Buchgesellschaft 2010.

Bernd Hamacher: „Hm! Hm!“ Goethes „sehr ernste Scherze“ und die Allegorie. In: „Kann man denn auch nicht lachend sehr ernsthaft sein?“. In: Sprachen und Spiele des Lachens in der Literatur. Hrsg. von Daniel Fulda, Antje Roeben und Norbert Wichard. Berlin/New York: de Gruyter 2010, S. 71-83.

Bernd Hamacher/Myriam Richter: Der Sprachkörper unter dem Seziermesser. Strukturalismus im Goethe-Wörterbuch. In: Strukturalismus in Deutschland. Literaturund Sprachwissenschaft 1910-1975. Hrsg. von Hans-Harald Müller, Marcel Lepper und Andreas Gardt. Göttingen: Wallstein 2010 (marbacher schriften. neue folge 5), S. 320-337.

Rüdiger Nutt-Kofoth: [Rez.] Harald Wentzlaff-Eggebert: Weimars Mann in Leipzig. Johann Georg Keil (1781-1857) und sein Anteil am kulturellen Leben der Epoche. Eine dokumentierte Rekonstruktion. Mit einem Beitrag von Markus Bertsch und 
unter Mitwirkung von Corinne Dölling. Heidelberg 2009 (Ereignis Weimar-Jena. Kultur um 1800, Bd. 26). In: Goethe-Jahrbuch 126 (2009) [2010], S. 316-318.

Christiane Schlaps: Aspekte der Medizin der Goethezeit im Spiegel des Goethe-Wörterbuchs. In: Würzburger medizinhistorische Mitteilungen 29 (2010), S. 256-277.

Hof und Residenz im spätmittelalterlichen Deutschen Reich (1200-1600)

Leitungskommission:

Vorsitzender: Paravicini

Albrecht (Kiel), Bünz (Leipzig), Fouquet (Kiel), Grubmüller, Honemann (Münster), Johanek (Münster), Moraw, Müller (Mainz), Ranft (Halle/ Saale), Spieß, Zotz (Freiburg i. Br.)

Kontaktadresse: Residenzen-Kommission/Arbeitsstelle c/o ChristianAlbrechts-Universität zu Kiel/ Historisches Seminar, Olshausenstraße 40, 24118 Kiel, Tel./Fax: 0431-880-1484 (Dr. Hirschbiegel), -2296 (Dr. Wettlaufer), resikom@email.uni-kiel.de, http://resikom.adw-goettingen.gwdg. de

Arbeitsbericht: Die Residenzen-Kommission als Einrichtung der Akademie der Wissenschaften zu Göttingen arbeitet mit der Aufgabenstellung, Residenz und Hof im spätmittelalterlichen Deutschen Reich (1200-1600) im europäischen Vergleich zu untersuchen. Die föderale Struktur Deutschlands, die Konkurrenz seiner zahlreichen Städte wird an einer ihrer Wurzeln erforscht: der Entstehung der landesherrlichen Residenzen im späteren Mittelalter. Diese ist auf das engste mit dem Wachstum der Höfe verbunden, der wichtigsten Machtzentren Alteuropas. Die Kommission fördert Monographien einzelner Höfe, Residenzen und Residenzengruppen, organisiert internationale Kolloquien: „Alltag bei Hofe“ (Ansbach 1992), „Zeremoniell und Raum“ (Potsdam 1994), „Höfe und Hofordnungen“ (Sigmaringen 1996), „Das Frauenzimmer“ (Dresden 1998), „Erziehung und Bildung bei Hofe“ (Celle 2000), „Der Fall des Günstlings“ (Neuburg an der Donau 2002), „Der Hof und die Stadt“ (Halle an der Saale 2004), „Hofwirtschaft“ (Gottorf/Schleswig 2006), „Vorbild, Austausch, Konkurrenz. Höfe und Residenzen in der gegenseitigen Wahrnehmung" (Wien 2008), „Städtisches Bürgertum und Hofgesellschaft. Kulturen integrativer und konkurrierender Beziehungen in Residenz- und Hauptstädten vom 14. bis ins 19. Jahrhundert" (Coburg 2010), und veröffentlicht sie in der Reihe „Residenzenforschung“ (23 Einzelbände sind bislang erschienen, dazu die Bände 15-I und 15-II in jeweils zwei Teilbänden sowie 15-III; 
15-IV in wiederum zwei Teilbänden wird 2011 erscheinen). Außerdem sammelt sie aus ihrem Zeitraum die deutschen Hofordnungen und als weitere Quelle die europäischen Reiseberichte (die Bibliographie der deutschen Reiseberichte ist 1994 erschienen [2. Aufl. 2001], der französischen 1999, der niederländischen 2000). Derzeit wird am Abschluß eines Handbuchs spätmittelalterlicher Höfe und Residenzen gearbeitet. Der erste, dynastischtopographische Teil in zwei Bänden zu den Dynastien, Höfen und Residenzen ist 2003 erschienen, der zweite, „Bilder und Begriffe“ betitelte Teil, liegt seit 2005 in ebenfalls zwei Bänden vor, der dritte, einbändige Teil „Hof und Schrift" seit 2007; ein vierter Teil zu den "Grafen und Herren" befindet sich in der redaktionellen Bearbeitung. Als Forum dienen halbjährlich versandte „Mitteilungen“.

Mit anhaltender Unterstützung der Fritz Thyssen Stiftung konnte das Projekt „Höfe und Residenzen im spätmittelalterlichen Reich“ nach Erscheinen des ersten, des zweiten und des dritten Teiles des Handbuches weiter voranschreiten. Die redaktionelle Arbeit am vierten Teil zu den „Grafen und Herren“ steht vor dem Abschluß, Erscheinungstermin ist nunmehr Herbst 2011.

Vom 25. bis zum 28. September 2010 fand in Coburg in Zusammenarbeit mit der Historischen Gesellschaft Coburg e. V. unter ihremVorsitzenden Prof. Dr. Gert Melville (Dresden/Coburg) das 12. Symposium der Kommission zu dem Thema „Städtisches Bürgertum und Hofgesellschaft. Kulturen integrativer und konkurrierender Beziehungen in Residenz- und Hauptstädten vom 14. bis ins 19. Jahrhundert" statt, siehe den beiliegenden Bericht von Sven Rabeler (Kiel), unter „Sonstige Veranstaltungen“, Seite 456.

Erschienen sind mit den Heften 20,1 und 20,2 zwei weitere Ausgaben der Mitteilungen der Residenzen-Kommission, dazu, anläßlich ihres 25jährigen Jubiläums, ein bibliographisches Sonderheft, das sämtliche Publikationen der Residenzen-Kommission seit deren Bestehen erfaßt.

In der Reihe „Residenzenforschung“ sind erschienen als Band 23 die Publikation der Beiträge des 11. Symposiums der Residenzen-Kommission unter dem Titel „Vorbild, Austausch, Konkurrenz. Höfe und Residenzen in der gegenseitigen Wahrnehmung", hg. von Werner Paravicini und Jörg Wettlaufer, Ostfildern: Thorbecke 2010, sowie als Band 24 die Publikation der Akten einer Tagung, die sich vom 19. bis zum 22. Februar 2009 in Salzburg den geistlichen Fürsten widmete: „Höfe und Residenzen geistlicher Fürsten. Strukturen, Regionen und Salzburgs Beispiel in Mittelalter und Neuzeit", hg. von Gerhard Ammerer, Ingonda Hannesschläger, Jan Paul Niederkorn und Wolfgang Wüst, Ostfildern: Thorbecke 2010. Band 25 
wird die Beiträge des 12. Symposiums der Kommission publizieren, befindet sich in Vorbereitung und wird 2011 erscheinen.

Weiterhin in Vorbereitung befindet sich die Edition der Hof-, Regimentsund Ämterordnungen von Jülich-Kleve-Berg durch Brigitte Kasten und Margarete Bruckhaus, Saarbrücken, die als Band 26 der Reihe im Jahr 2011 erscheinen werden.

Die Förderung der Kommission durch das Akademienprogramm endet mit dem Jahre 2010. Ein Neuantrag mit veränderter Fragestellung (siehe den Bericht über das Coburger Symposium) ist gestellt. Trifft er aufZustimmung, wird ab dem Jahresbeginn 2012 eine neue „Residenzen-Kommission“ ihre Arbeit aufnehmen. Für das Jahr 2011 ist eine verringerte Abschlußfinanzierung genehmigt. Sie wird sich hoffentlich als Brücke zu neuen Wegen herausstellen.

W. Paravicini

Veröffentlichungen:

Mitteilungen der Residenzen-Kommission der Akademie der Wissenschaften zu Göttingen [Universitätsdruckerei der Christian-Albrechts-Universität zu Kiel, Aufl. 850, ISSN 0941-0937]:

20,1 (2010) [89 S.]

20,2 (2010) [148 S.]

Mitteilungen der Residenzen-Kommission der Akademie der Wissenschaften zu Göttingen. Sonderheft [Universitätsdruckerei der Christian-Albrechts-Universität zu Kiel, Aufl. 850, ISSN 1617-7312]:

Sonderheft 13: 25 Jahre Residenzen-Kommission 1995-2010. Eine Bibliographie, zusammengestellt von Jan Hirschbiegel, Kiel 2010 [Universitätsdruckerei der ChristianAlbrechts-Universität zu Kiel, Aufl. 850, 83 S., ISSN 1617-7312]

Reihe „Residenzenforschung“:

Vorbild, Austausch, Konkurrenz. Höfe und Residenzen in der gegenseitigen Wahrnehmung, hg. von Werner Paravicini und Jörg Wettlaufer, Ostfildern 2010 (Residenzenforschung, 23) [Jan Thorbecke Verlag, Aufl. 300, 464 S. mit 48 farb. Bildtafeln, Ln., ISBN 978-3-7995-4526-6].

Höfe und Residenzen geistlicher Fürsten. Strukturen, Regionen und Salzburgs Beispiel in Mittelalter und Neuzeit, hg. von Gerhard Ammerer, Ingonda Hannesschläger, Jan Paul Niederkorn und Wolfgang Wüst, Ostfildern (Residenzenforschung, 24) [Jan Thorbecke Verlag, Aufl. 300, 552 S. mit 44 farb. Bildtafeln, Ln., ISBN 978-3-79954527-3]. 


\section{Johann Friedrich Blumenbach-Online}

Leitungskommission:

Vorsitzender: Rupke

Stellv. Vors.: Lossau (Göttingen)

Elsner, Joost, Lauer, Mazzolini, Reitner, Schmutz (Zürich), Schorn-Schütte (Frankfurt)

Kontaktadresse: Papendiek 16, 37073 Göttingen, Tel. 0551-39-9468, Fax: 0551-39-9748, (Dr. Weber), hweber@gwdg.de, www.blumenbachonline.de

Arbeitsbericht: Der Aufbau einer Arbeitsstelle für das zum Jahresbeginn 2010 bewilligte Projekt begann im Januar mit der Besetzung der Mitarbeiterstellen und war im Oktober mit der Ernennung von Dr. Heiko Weber zum Projektkoordinator abgeschlossen (die Projektkoordination war bis dahin kommissarisch von Herrn Reimer Eck wahrgenommen worden). Die konstituierende Sitzung der Leitungskommission fand am 8. Mai 2010 statt. Seit Ende Mai wird das Projekt durch eine eigene Website im Internet repräsentiert.

In organisatorischer Hinsicht wurden für die gegenwärtigen Arbeitsschwerpunkte des Vorhabens drei Projektgruppen gebildet: Textedition, Softwareprogrammierung und Erfassung der Sammlungsobjekte. Angesiedelt sind die Arbeitsgruppen bei der Niedersachsenprofessur für Wissenschaftsgeschichte im Heyne-Haus, bei der Abteilung „Forschung und Entwicklung" der Staats- und Universitätsbibliothek in deren Historischem Gebäude und im Geologischen Zentrum der Universität Göttingen. Die Zusammenarbeit der Arbeitsgruppen erfolgt durch regelmäßig stattfindende Sitzungen und durch eine zu diesem Zweck eingerichtete, kooperative elektronische Projektdokumentation.

Die Grundlage für die online-Edition der Texte Johann Friedrich Blumenbachs wurde im ersten Halbjahr 2010 mit der Erstellung einer Gesamtbibliographie der von dem Gelehrten publizierten Werke geschaffen. Die Bibliographie liegt inzwischen gedruckt vor und wurde auf der Frankfurter Buchmesse präsentiert.

Die aus Sicht des Blumenbach-Projekts besonders relevanten Möglichkeiten einer online-Edition sind Hyperlinking, Multimedialität und Kooperativität. Die Erprobung und Demonstration dieses Potenzials in Form einer Modelledition, die Texte und Sammlungsobjekte abbildet, ist das Hauptziel der ersten Projektphase. Entscheidende Schritte hierfür sind die Material- 
auswahl; die Erarbeitung von Metadatenschemata und die Schaffung der technischen Voraussetzungen:

- Als Materialgrundlage wurde ein Korpus inhaltlich verwandter und in ihrer Genese zusammenhängender Texte Blumenbachs ausgewählt. Im Zentrum stehen dabei Blumenbachs Dissertation „De generis humani varietate nativa" und Blumenbachs Überlegungen zu einer Typologisierung der Menschheit. Die Digitalisierung der entsprechenden Texte und deren Umwandlung in Volltexte nach TEI-Standard wurde vorbereitet und begonnen; hierzu gehören die Ermittlung geeigneter Verfahren, die Festlegung von Qualitätsstandards und die Bereitstellung von Hilfsmitteln für die beauftragten externen Dienstleister (Codierungstabellen für die Wiedergabe von Schriftzeichen in historischen Drucktypen; Pflichtenhefte). Die multimedialen Möglichkeiten einer online-Edition werden durch die Einbindung von Abbildungen nichttextueller Zeugnisse von Blumenbachs Arbeit genutzt. Hierbei handelt es sich vor allem um die in seinen Texten beschriebenen oder abgebildeten Objekte aus seiner umfangreichen naturhistorischen Sammlung. Die Identifizierung und Lokalisierung der ca. 4000 noch erhaltenen, auf Blumenbach zurückgehenden Objekte in heutigen Sammlungen in Göttingen und andernorts war und ist daher ebenfalls Teil der Vorbereitung der Materialgrundlage für die Modelledition.

- Die Nutzung der Texte, vor allem aber der Sammlungsobjekte für elektronische Such- und Auswertungsvorgänge erfordert die Erhebung umfangreicher Metadaten zu diesen und erzwingt zugleich deren planvolle Standardisierung. Die Planung und Entwicklung solcher Schemata und die Programmierung einer Software zur Unterstützung der Erhebung dieser Daten ist darum ein wesentlicher Teil der Vorbereitung für die Modelledition.

- Mit Hilfe der Hyperlinktechnologie werden die einzelne Texte annotiert und einerseits mit Parallelabschnitten in anderen Texten, andererseits mit visuellen Medien (Bilder; animierte 3D-Sequenzen) verknüpft. In einer sogenannten „virtuellen Forschungsumgebung" (VRE) soll diese Bearbeitung für mehrere Forscher kooperativ möglich sein. Hierfür wird die gegenwärtig in einem vom BMBF geförderten Projektkonsortium (Koordinator ist die Staats- und Universitätsbibliothek Göttingen) entstehende elektronische Arbeitsumgebung "TextGrid“ zur Bearbeitung von Textund Bildmaterial eingesetzt. In intensivem Austausch mit deren Entwicklerteam wurden in den vergangenen 12 Monaten Erfordernisse des 
Blumenbach-Projekts an TextGrid spezifiziert und in den Prozess der Programmentwicklung eingebracht.

N. Rupke

Veröffentlichung:

Kroke, Claudia. Johann Friedrich Blumenbach. Bibliographie seiner Schriften. Unter Mitarbeit von Wolfgang Böker und Reimer Eck. (Schriften zur Göttinger Universitätsgeschichte - Band 2) Göttingen 2010, 235 S.

Katalogisierung der orientalischen Handschriften in Deutschland

Leitungskommission:

Vorsitzender: Feistel (Berlin)

Stellv. Vors.: Röhrborn

Bausi (Hamburg), Franke (Marburg), Götz (Köln), Lienhard, Nagel, Niklas (Köln), Schwieger (Bonn), Seidensticker (Jena), Uhlig (Hamburg), Wagner (Gießen), Zauzich (Würzburg)

Kontaktadresse: KOHD c/o Orientabteilung der Staatsbibliothek zu Berlin/Preussischer Kulturbesitz, Potsdamer Straße 33, 10785 Berlin, Tel.: 030-261-6334, Fax: 030-264-6955, h-o.feistel@sbb.spk-berlin.de(Dr. Feistel), http://kohd.staatsbibliothek-berlin.de

Arbeitsbericht: Seit dem letzten Jahresbericht sind im Verzeichnis der Orientalischen Handschriften in Deutschland (im Auftrag der Akademie der Wissenschaften zu Göttingen herausgegeben von Hartmut-Ortwin Feistel; Franz Steiner Verlag Stuttgart) folgende Bände erschienen:

II,17 Indische Handschriften. Teil 17: Die Śāradā-Handschriften der Sammlung anert der Staatsbibliothek zu Berlin - Preussischer Kulturbesitz. [Teil 2.] Beschrieben von Gerhard Ehlers. 2010. [214 Seiten]

XIII,18 Alttürkische Handschriften. Teil 10: Buddhistische Erzähltexte. Beschrieben von Jens Wilkens. 2010. [389 Seiten]

XVII,B,9 Arabische Handschriften. Teil 9: Arabische Handschriften der Bayerischen Staatsbibliothek zu München unter Einschluss einiger türkischer und persischer Handschriften: Band 2. Beschrieben von Florian Sobieroj. [xxiv, 563 Seiten, 13 Tafeln]

XVII,B,10 Arabische Handschriften. Reihe B: Teil 10: Arabische Handschriften der Bayerischen Staatsbibliothek zu München. Band 3: Cod Arab 2300-2552f. Beschrieben von Kathrin Müller. 2010. [xxv, 644 Seiten]

XXIII,7 Birmanische Handschriften. Teil 7: Die Katalognummern 1201-1375. Beschrieben von Anne Peters. 2010. [xxiii, 384 Seiten] 
Damit liegen jetzt 138 Katalog- und 52 Supplementbände vor.

Im Berichtsjahr sind folgende Rezensionen und Artikel, das „Verzeichnis der Orientalischen Handschriften in Deutschland“ betreffend, eingegangen bzw erschienen:

II,16 Ludo Rocher (JAOS. 128,1.2008. 202-203.)

XI,13 Helmut Eimer (ZDMG. 160,2.2010. 526-528.)

XI,14 Helmut Eimer (ZDMG. 160,2.2010. 526-528.)

XIII,22 Wolfgang Scharlipp (Asiatische Studien = Études Asiatiques. 64,3.2010. 737740.)

XVIII,1 Daniel Jensen Sheffield (JAOS. 129,1.2009. 166-167.)

XXIII,6 Tilman Frasch (Southeast Asian Studies. 40,2.2009. 433.)

XLIV,1 Lucia Obi (Bibliotheks Magazin. Mitteilungen aus den Staatsbibliotheken in Berlin und München. 3,2010. 28-31.)

Andere relevante Literatur:

„Katalogisierung der Orientalischen Handschriften in Deutschland“ in: Kulturelles Erbe mit Zukunft : Forschungsvorhaben im Akademienprogramm. Redaktion Adrienne Lochte. - Göttingen: Akademie der Wissenschaften zu Göttingen, 2009. 28-29.

\section{Arbeitsstelle Berlin I}

Leitung und Koordinierung des Gesamtprojekts, „Indische Handschriften“, „Syrische Handschriften “, „Hebräische Handschriften“, „Naxi-Handschriften“, „Chinesische und manjurische Handschriften und seltene Drucke“, „Afrikanische Handschriften“, „Japanische Handschriften und traditionelle Drucke aus der Zeit vor 1868“, „Laotische Handschriften“, „Nepalese Manuscripts“, „Illuminierte hebräische Handschriften“, „Malaiische Handschriften“, „Shan Manuscripts“, „Tocharische Handschriften“, „Yao Handschriften“ (Leitung Dr. Hartmut-Ortwin Feistel) „Ägyptische Handschriften“ (Leitung Professor Dr. Karl-Theodor Zauzich, Würzburg) - „Tamil-Handschriften“, „Khmer- und Thai-KhmerHandschriften“ (Leitung Professor Dr. Ulrike Niklas, Köln)

Gesamtprojekt

Auf Vorschlag des Projektleiters wurde im vergangenen Jahr Professor Dr. Alessandro Bausi, Hamburg, in die Leitungskommission zugewählt. Professor DDr. Siegfried Uhlig hat inzwischen auf eigenen Wunsch die Leitung der Arbeitsstelle Hamburg Herrn Bausi übergeben.

Es ist darauf hinzuweisen, dass im folgenden Jahresbericht nur diejenigen Teilprojekte vorgestellt werden, für die zur Zeit haupt- oder ehrenamtliche Bearbeiter vorhanden sind. Die Besetzung der vom Projekt finanzierten Stellen zum Zeitpunkt des Berichts ist jeweils vermerkt. Darüber hinaus gibt 
es Sprachgruppen, für die im Augenblick keine Bearbeiter zur Verfügung stehen und die deshalb im Bericht nicht erwähnt werden.

„Indische Handschriften “ $<$ II>

[Sanskrit-Handschriften: PD Dr. Gerhard Ehlers, Berlin; Tamil-Handschriften: Thomas Anzenhofer MA, 3/3-Stelle, Bonn; Herr Mathusamy Saravan, Werkvertrag, Bonn]

Der Katalogband VOHD II,17, der die Śāradā-Handschriften der Sammlung Janert mit den Katalognummern 5887-6408 und den Bibliothekssignaturen $\mathrm{Hs}$ or 11501-12000 beschreibt, liegt nunmehr gedruckt vor.

Herr PD Dr. Gerhard Ehlers hat die Arbeiten an Teilband 18 begonnen. Dieser soll die Katalognummern 6409-6907 mit den Bibliothekssignaturen Hs or 12001-12500 umfassen. Die ersten 100 Katalogeinträge sind so gut wie fertig. Layout-Probleme wie beim vorausgehenden Band VOHD II, 17 dürfte es nicht geben, so dass mit einer Fertigstellung im Rahmen des vorgegebenen Zeitplans zu rechnen ist.

Herr Ehlers nahm an der internationalen Tagung „Lecteurs et copistes dans les traditions manuscrits iraniennes, indiennes et centrasiatiques", 15. bis 17. Juni 2010 in Paris, Université Sorbonne nouvelle, mit einem Vortrag teil.

Herr Thomas Anzenhofer MA setzte die Arbeiten an Teilband 14 fort, der die Tamil-Handschriften aus Berlin und München beschreibt. Es wurden 45 Handschriften katalogisiert, wobei es sich - wie bei den im Vorjahr bearbeiteten Materialien - um Rechnungsbücher handelte. Herr Mathusamy Saravan bearbeitete 26 Handschriften, die besonders schwer lesbar und identifizierbar sind. Als Muttersprachler mit Erfahrung im Umgang mit Palmblattmanuskripten konnte er dabei schnellere und bessere Ergebnisse erzielen als ein nichtmuttersprachlicher Wissenschaftler. Die Manuskripte werden dabei, soweit ihr physischer Zustand dies erlaubt, vollständig eingescannt, damit Problemstellen in Indien nochmals mit einheimischen Wissenschaftlern durchgegangen werden können. Gemäss ausdrücklichem Wunsch der Akademie zu Göttingen fertigt Herr Saravanan nicht nur Katalogeinträge an, sondern unternimmt auch Gesamtabschriften (im Hinblick auf eine baldige Edition und eventuelle Übersetzung) von Manuskripten, die besonders interessant erscheinen. So hat er die Edition einer Kupferplatte erstellt, an deren Übersetzung Professor Dr. Ulrike Niklas gemeinsam mit ihm arbeitet. Edition und Übersetzung eines weiteren Manuskripts einer Art Handbuch eines Dorfarztes, in dem etwa 175 Krankheiten und ihre Behandlung beschrieben sind - befindet sich ebenfalls in Arbeit. 
„Syrische Handschriften“ $<\mathrm{V}>$

Die Bearbeitung der syrischen Handschriften der Berliner Turfansammlung (VOHD V,2) wurde von einer Arbeitsgruppe unter der Leitung von Frau Dr. Erica Hunter, London, im vergangenen Jahr fortgesetzt. Mitarbeiter sind Dr. Mark Dickens, Professor Dr. Nicholas Sims-Williams und Professor Dr. Peter Zieme. Das Projekt „The Christian Library of Turfan“ wird vom Arts and Humanities Research Board, London, unterstützt.

Eine erste Durchsicht aller syrischen Fragmente ist inzwischen abgeschlossen; ihre Beschreibung ist in einer Datenbank erfasst. Die nochmalige Überprüfung an Hand der Originale wird im Laufe dieses Jahres beendet werden, so dass die Fertigstellung eines Druckmanuskripts für Oktober 2011 vorgesehen ist.

Das Projekt wird zentrales Thema des achten Seminartages zu „Christianity in Iraq“ im Mai 2011 in London sein, ebenso während der „International Conference of Patristic Studies" im August 2011 in Oxford.

„Chinesische Handschriften“ $<$ XII>

Professor Dr. Martin Gimm und Frau Renate Stephan haben die Arbeiten an Teilband 2 (Münchener Handschriften und frühe Drucke) fortgesetzt.

Die durch den Tod von Professor Kogi Kudara verzögerten Redaktionsarbeiten an Teilband 5 wurden durch die Arbeitsgruppe der „Research Society for Central Asian Culture" unter Professor Matsumi Mitani fortgesetzt. Herr Mitani plant, im kommenden Jahr bei einem Arbeitsaufenthalt in Berlin die notwendigen Überprüfungen an den Originalen der Handschriften abzuschliessen.

Professor Tsuneki Nishiwaki hat die Arbeiten an einem Katalog der chinesischen Blockdrucke in der Berliner Turfansammlung fortgeführt (Teilband 7). Im laufenden Jahr hat ihm ein Arbeitsaufenthalt in Sankt Petersburg die Durchsicht von dort erhaltenen Textfragmenten ermöglicht. Die Endfassung soll, wie bei dem schon früher von ihm bearbeiteten Teilband, unter Mitarbeit von Herrn Dr. Christian Wittern und Frau Dr. SimoneChristiane Raschmann entstehen.

„Ägyptische Handschriften“ <XIX>

Das von Professor Dr. Karl-Theodor Zauzich geleitete DFG-Projekt „Soknopaiu Nesos nach den demotischen Quellen römischer Zeit" wurde mit dem Jahresende 2009 offiziell abgeschlossen. Der Band III der Reihe „Demotische Urkunden aus Dime“ ist im Druck und wird in Kürze erscheinen. Wegen seiner Tätigkeit als Mitherausgeber der Zeitschrift „Enchoria“ war es Herrn Zauzich im Berichtszeitraum nicht möglich, an dem geplanten 
Teilband 5 des Katalogs der „Ägyptischen Handschriften“ kontinuierlich weiterzuarbeiten.

„Khmer Handschriften“ <XXXVI>

Im laufenden Jahr konnte in Köln unter Beteiligung einer Gastdozentin die Bearbeitung der Khmer-Handschriften der Staatsbibliothek zu Berlin aufgenommen werden. 16 Manuskripte wurden abschliessend katalogisiert, weitere 14 sind in Arbeit. In allen Fällen handelte es sich um Teile des PaliKanons in Khmer-Schrift; eine Handschrift enthielt eine gekürzte Fassung des ganzen Kanons für Novizen in einem Kloster.

„Tocharische Handschriften“ $<$ XLI $>$ :

Frau Dr. Christiane Schaefer, Uppsala, führte die Arbeiten an einem ersten Teilband des Katalogs der tocharischen Fragmente aus den Turfanfunden fort.

\section{Arbeitsstelle Berlin II}

„Mitteliranische Handschriften“ (Leitung Dr. Hartmut-Ortwin Feistel, Berlin)

„Mitteliranische Handschriften“ $<$ XVIII>

[Soghdische Handschriften: Dr. Christiane Reck, Berlin]

Frau Dr. Christiane Reck hat im Berichtszeitraum die Bearbeitung der buddhistischen Texte für Teilband 2 fortgesetzt. Es wurden 93 Fragmente beschrieben. Darunter waren weitere 38 Fragmente einer Handschrift des „Vimalakīrtinirdeśasūtra", deren Beschreibung bereits im vorangegangenen Berichtszeitraum begonnen wurde. Damit sind die 61 Fragmente erfasst, die dieser Handschrift zugeordnet werden können. Nur in Einzelfällen konnte eine konkrete bzw eine vermutete Identifizierung vorgenommen werden. Meistens sind die Fragmente dazu aber zu klein und die erhaltenen Textstücke zu unspezifisch. Die anderen beschriebenen Fragmente sind zum Teil von Yutaka Yoshida publiziert bzw als Teile verschiedener Sūtras identifiziert worden; die meisten Fragmente konnten aber nicht näher bestimmt werden. Darüber hinaus wurden die 12 Fragmente einer Handschrift eines bisher unidentifizierten Kommentars zum „Vajracchedikasūtra“, eines in der Überschrift als „Vajraśāstra“ bezeichneten Textes, beschrieben.

Frau Reck setzte, unterstützt durch Frau Susann Rabuske (BBAW), die Registrierung der Benutzung und Publikationen der iranischen Teile der Sammlung in der Datenbank fort. Auch die Eingabe der Transliterationen der Texte in die von Desmond Durkin-Meisterernst entwickelte Datenbank mitteliranischer Texte wurde fortgesetzt. Für die Handbibliothek des Aka- 
demienvorhabens „Turfanforschung“ wurden 99 (darunter 17 für KOHD) Bände inventarisiert.

Es erschien ausserdem der Aufsatz „Some Remarks on the Manichaean Fragments in Sogdian Script in the Berlin Turfan Collection“, in: The Way of Buddha 2003: The 100th Anniversary of the Otani Mission and the 50th of the Research Society for Central Asian Cultures. (Cultures of the Silk Road and Modern Science.1.) Kyoto 2010. 69-74.

Frau Reck nahm im vergangenen Jahr an folgenden Kongressen teil:

- Seventh International Conference of Manichaean Studies, Chester Beatty Library, Dublin, 8.-12. September 2009, mit einem Vortrag zum Thema „Sogdian Manichaean Confessional Fragments in Sogdian Script in the Berlin Turfan collection“. Bei dieser Konferenz wurde sie auch als Mitglied des Board der International Association of Manichaean Studies und als Schatzmeisterin bestätigt.

- Gattungsgeschichte des manichäischen Schrifttums: Arbeitstagung der Kommission für manichäische Studien an der Akademie der Wissenschaften zu Göttingen, 4. bis 5. März 2010 in Göttingen, mit dem Vortrag „Fragmente von Büchern: Zwei Sammelhandschriften im Vergleich".

- Lecteurs et copistes dans les traditions manuscrites iraniennes, indiennes et centrasiatiques, 15. bis 17. Juni 2010 in Paris, Université Sorbonne nouvelle, mit einem Vortrag „The Middle Iranian manuscripts of the Berlin Turfan collection: variety and diversity, original and re-use". Außerdem hielt sie an der Universität Potsdam, Institut für Religionswissenschaft, im Rahmen der Ringvorlesung „Zarathustras Erben. Religionen im Iran" eine Vorlesung zum Thema "Gnosis II: Manichäismus eine untergegangene Weltreligion iranischer Herkunft".

Im Rahmen des Projekts „The Christian Library of Turfan“ (siehe oben, „Syrische Handschriften") hat Professor Dr. Nicholas Sims-Williams, London, die Katalogisierung der nestorianischen Fragmente der Turfan-Sammlung fortgesetzt, wobei er von Herrn Dr. Desmond Durkin-Meisterernst und Frau Reck unterstützt und betreut wurde. Mit dem Abschluss des Teilbandes „Iranian Fragments in Syriac Script“ kann in der nahen Zukunft gerechnet werden.

\section{Arbeitsstelle Berlin II / Kassel (ehemals Marburg)}

„Alttürkische Handschriften“ (Leitung Professor Dr. Klaus Röhrborn, Göttingen) - „Türkische Handschriften“, „Persische Handschriften“, „Islami- 
sche Handschriften-Sammlungen“ (Leitung Professor Dr. Manfred Götz, Köln)

„Alttürkische Handschriften“ <XIII, 9 ff>

[Alttürkische Handschriften: Dr. Simone-Christiane Raschmann, Berlin; Dr. Zekine Özertural, 1/2 Stelle, Kassel; Dr. Michael Knüppel, 1/2 Stelle, Kassel]

Frau Dr. Simone-Christiane Raschmann setzte die im letzten Berichtszeitraum begonnenen Arbeiten für den Katalogband „Buddhica aus der BerlinerTurfansammlung. Teil 1: Das apokryphe Sutra Säkiz Yükmäk und Varia“ (Alttürkische Handschriften: Teil 18 = VOHD XIII, 26) fort; es wurden 135 Beschreibungen sowie die zugehörigen Konkordanzeinträge angefertigt. Die Fragmente haben noch keine Katalognummern. Sie sollen so aufgenommen werden, dass die Reihenfolge dem Text des Sūtras entspricht. Eine Zuordnung zu verschiedenen Abschriften wird nicht vorgenommen, wohl aber eine Zuordnung zu verschiedenen Textrezeptionen nach den Angaben von Juten Oda (siehe unten). Die Konkordanzen umfassen auch die Teile des Sütras, die in den nach der Schriftart konzipierten Bänden (VOHD XIII,9; XIII,20 und XIII,23) bereits beschrieben worden sind. Im Juli 2010 wurde die Arbeit an den Berliner Fragmenten unterbrochen, um neue Erkenntnisse einzuarbeiten, die aus der jüngst erschienenen Gesamtedition des Sūtras von Juten Oda zu gewinnen sind. Im Übrigen richtete Frau Raschmann bei der Beschreibung ihr Augenmerk besonders auf die bisher nahezu unbearbeiteten, meist in Kursivschrift verfassten Aufschriften auf den Rückseiten bzw auf den auf der Rückseite zur Reparatur aufgeklebten Fragmenten, die in der Mehrzahl inhaltlich vom Haupttext auf der Vorderseite der Fragmente unabhängig sind. Derartige Texte sind in den bisher erschienenen Katalogbänden nicht beschrieben worden.

Frau Raschmann hat weiterhin die Datenbank der Berliner TurfanSammlung mit den für die Katalogisierung essentiellen Einträgen aktualisiert.

Vom 3. bis zum 5. September 2009 nahm Frau Raschmann, wie schon im letzten Jahresbericht erwähnt, in Sankt Petersburg an einer Tagung teil („Dunhuang studies: prospects and problems for the coming second century of research") und referierte über das alttürkische „Zehn-Könige-Sūtra“, das den wesentlichen Teil des Katalogbandes „Buddhica aus der Berliner Turfansammlung: Teil 2" (Alttürkische Handschriften: Teil 20 = VOHD XIII,28) bilden soll. Auf einer weiteren Tagung - „Lecteurs et copistes dans les traditions manuscrites iraniennes, indiennes et centrasiatiques", 15. bis 17. Juni 2010 in Paris, Université Sorbonne nouvelle - referierte sie 
über neue Erkenntnisse aus ihrer Arbeit im KOHD-Projekt, und auf der PIAC-Tagung (Sankt Petersburg, 25. bis 30. Juli 2010) hielt sie einen Vortrag über die Fragmente des alttürkischen Goldglanz-Sūtras in der Berliner Turfan-Sammlung und in anderen Handschriftensammlungen. Anlässlich der Teilnahme an der PIAC-Tagung hielt sich Frau Raschmann ab dem 20. Juli 2010 zu einem Arbeitsaufenthalt am Institut für orientalische Handschriften der Russländischen Akademie der Wissenschaften auf.

Ausserhalb ihrer Dienstzeit erledigte Frau Dr. Raschmann Restaurierungs- und Fotoaufträge in der Turfan-Sammlung und beteiligte sich an der Koordination des von der DFG bewilligten Teilprojekts „Digitalisierung der syrischen und Sanskrit-Fragmente der Berliner Turfansammlung.

Folgende Publikationen von Frau Raschmann sind im letzten Jahr erschienen

- „Traces of Christian communities in the Old Turkish documents“, in: Studies in Turkic philology. Festschrift in honour of the $80^{\text {th }}$ birthday of Professor Geng Shimin. Edited by Zhang Dingjing and Abdurishid Yakup. Beijing 2009. 408-425.

- „Altun Yaruk Sudur. The prophecy concerning the ten thousand divine sons (book IX, chapter 23)" in: The Way of Buddha 2003: The 100th Anniversary of the Otani Mission and the 50th of the Research Society for Central Asian Cultures. (Cultures of the Silk Road and Modern Science.1.) Kyoto 2010. 25-33.

- „Herbst-Baumwolle (küzki käpäz)“, in: Trans-Turkic-Studies. Festschrift in honour of Marcel Erdal. Edited by M Kappler, M Kirchner, P Zieme. Istanbul 2010. (Türk

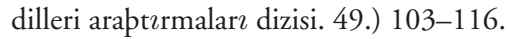

- „Fragmenta Buddhica Uigurica“. Ausgewählte Schriften von Peter Zieme. Herausgegeben von Simone-Christiane Raschmann und Jens Wilkens. Berlin 2009. (Studien zur Sprache, Geschichte und Kultur der Türkvölker. 7.)

Herr Dr. Michael Knüppel und Frau Dr. Zekine Özertural überarbeiteten im Berichtszeitraum den Katalogband „Mahāyāna-Sūtras und Kommentartexte" (Alttürkische Handschriften: Teil 16 = VOHD XIII, 24). Anfang des Jahres 2010 hielt der japanische Wissenschaftler Kitsudō Kōichi in der Berlin-Brandenburgischen Akademie der Wissenschaften einen Vortrag. Nach den dort präsentierten Erkenntnissen gehören verschiedene Texte von teilweise disparatem Inhalt, die in den oben genannten Katalogband aufgenommen worden waren, zu einer umfangreichen Sammelhandschrift, die in der uigurischen Literatur in dieser Form kein Gegenstück hat. Etwa ein Drittel der Einträge des oben erwähnten Katalogbandes musste neu konzipiert und angeordnet werden. Alle Konkordanzen waren neu zu erstellen. Der Band umfasst jetzt 368 Katalognummern mit etwa 420 Beschreibungen.

Es hat sich gezeigt, dass es zweckdienlich ist, dass ein Katalogband jeweils nur von einem Mitarbeiter bearbeitet wird, wenn einmal der Abschluss des 
Bandes in greifbare Nähe rückt. Auf dem Titelblatt dieses Bandes sollte dann allein der Name dieses Mitarbeiters stehen. Der Band „Mahāyāna-Sūtras und Kommentartexte" wird deshalb unter dem Namen von Zekine Özertural erscheinen, der folgende Band (Alttürkische Handschriften: Teil 17 = VOHD XIII, 25) unter demjenigen von Michael Knüppel.

Im Berichtszeitraum konnten ferner die Arbeiten an dem Band „Heilkundliche, astrologische, kalendarische und magische Texte, Wahrsagebücher, Dhāraòi-Texte und Verwandtes" weitgehend zum Abschluss gebracht werden, der jetzt etwa 320 Katalog-Nummern umfasst. Viele Texte dieses Bandes, vor allem solche zur Heilkunde und zur Mantik, stellten die Bearbeiter vor besondere Anforderungen. Rahmeti Arat hat in seiner Edition Textstücke aus verschiedenen Fragmenten zusammengestellt, ohne dies in der Edition detailliert zu vermerken. Die Katalogisierung musste die Fragmente hingegen nach deren tatsächlichem Zustand beschreiben. Bei insgesamt vier Besuchen in Berlin wurden deshalb problematische Textstellen an Hand der Originale geprüft, gleichzeitig wurden die in diesem Band beschriebenen Fragmente vermessen.

Weiterhin konnten im Berichtszeitraum erste Vorarbeiten für den folgenden Katalogband „Alttürkische Stabreimtexte und Varia Buddhica“ (Alttürkische Handschriften: Teil 21 = VOHD XIII, 29) geleistet werden.

Frau Özertural und Herr Knüppel nahmen auch an der Arbeitstagung „Gattungsgeschichte des manichäischen Schrifttums“, 4. bis 5. März 2010, teil, die von der Kommission für manichäische Studien der Akademie der Wissenschaften zu Göttingen veranstaltet wurde (Vortrag von Herrn Knüppel: „Zur späten manichäisch-uigurischen Dichtung“, Vortrag von Frau Özertural: „Über die innere Gliederung des alttürkischen Beichttextes Chuastuanift"). Frau Özertural ist auch (zusammen mit Dr. Jens Wilkens) mit der Herausgabe der Tagungsakten betraut.

Im April 2010 hat Professor Dr. Klaus Röhrborn in der Universitätsbibliothek Kassel einen öffentlichen Vortrag über das Katalogisierungsprojekt gehalten.

Der ehrenamtliche Mitarbeiter Professor Dr. Jens Peter Laut, Göttingen, hat den Abschluss der von im bearbeiteten Teilbände VOHD XIII, 11-12 für die nahe Zukunft zugesagt.

Der ehrenamtliche Mitarbeiter Dr. Dieter Maue hat die Arbeiten an einem zweiten Teilband "Dokumente in Brahmi und tibetischer Schrift“ aufgenommen (Alttürkische Handschriften. Teil 19 = VOHD XIII, 27). 
"Islamische Handschriftensammlungen“" <XXXVII> Professor Dr. Manfred Götz hat im vergangenen Jahr seine Arbeiten an islamischen Handschriften der Bayerischen Staatsbibliothek München fortgesetzt.

\section{Arbeitsstelle Bonn}

„Tibetische Handschriften“ (Leitung Professor Dr. Peter Schwieger, Bonn) „Tibetische Handschriften“ $<$ XI> [Saadat Arslan MA, 1/2 Stelle, Bonn; PD Dr. Karl-Heinz Everding, Bonn] Frau Saadat Arslan war mit der Erstellung des Indexbandes der Sammlung „Rin-chen gter-mdzod“ beschäftigt. Einträge aus fünf Bänden (XI, 10-14) mussten gesichtet und geordnet werden. Es handelte sich dabei um insgesamt 2048 Seiten mit 2566 beschriebenen Texten. Grundlage waren Unterlagen in Form von mehreren Dateien, die im Laufe der Jahre mit verschiedenen Versionen desselben Textverarbeitungsprogramms erstellt worden waren und zusammengefasst werden mussten. Umformatierung und Vereinheitlichung der diakritischen Zeichen nahmen erhebliche Zeit in Anspruch. Diese Arbeiten erwiesen sich als umfangreicher und komplexer als anfangs angenommen. Insgesamt liegen nunmehr etwa 12700 Einträge vor, geordnet nach Personen, Gottheiten, Werktiteln und Orten. Die Einträge mussten noch in Tibetisch und Sanskrit unterteilt werden. Beim Ordnen der Einträge nach dem tibetischen Alphabet musste neben der einfachen Anordnung der Grundbuchstaben auch die Anordnung der Ligaturen mit ihren verschiedenen Kombinationsmöglichkeiten berücksichtigt werden. Auf diese Weise enthält das zugrundeliegende Ordnungs- und Sortierschema eine Reihenfolge von insgesamt 345 Elementen.

Innerhalb des letzten Jahres hat Herr PD Dr. Karl-Heinz Everding die Arbeiten an Teilband 18 weitgehend abgeschlossen. Der Katalog umfasst die Beschreibungen von tibetischen Prachthandschriften, die mit Gold, Silber oder Edelsteinfarben geschrieben worden sind, von bis zu 600 Jahre alten tibetischen Blockdrucken, die aus dem westlichen Zentraltibet (gTsang) besonders aus dem Großraum sKyid-grong - stammen, von wertvollen alten Handschriften, die unbekannte religiöse Überlieferungstraditionen enthalten, und nicht zuletzt Beschreibungen des ersten Teils einer umfangreichen Sammlung von Beijinger Blockdrucken und Handschriften des 17. bis frühen 20. Jahrhunderts, die die Staatsbibliothek zu Berlin - Preußischer Kulturbesitz bereits vor längerer Zeit von Professor Dr. Walter Heissig zu erwerben vermocht hat. 
Die Beschreibung und Indexierung der Werke der ersten drei Kategorien ist abgeschlossen. Abgesehen vom literarischen und historischen Wert der einzelnen Quellen, ermöglichen diese Werke aufgrund ihrer sehr ausführlichen, bislang zum Großteil unbearbeiteten Text- und Druckerkolophone interessante neue Einblicke in den Herstellungsprozess und das sozio-historische Umfeld der Entstehung des tibetischen Blockdruckwesens.

Auch die Bearbeitung des ersten Teils der Beijinger Blockdrucke ist von tibetologischer Seite so gut wie fertiggestellt. Bearbeitet wurden 202 Texte dieser Textsammlung, die vor allem aus rituellen Verrichtungen besteht und einen Gesamtumfang von etwa 334 Texten besitzt. Dabei konnte eine Publikation von RO Meisezahl („Tibetische Handschriften und Drucke, vornehmlich chinesischer Herkunft, in der Staatsbibliothek (Preussischer Kulturbesitz), zu Berlin“, in: Studies of Mysticism in Honour of the 1150th Anniversary of Kobo-Daishi’s Nirvānsam, Acta Indologica VI [1984]. 145346.), als Grundlage benutzt werden. Ebenda hat Meisezahl eine äußere Beschreibung der von ihm ausgewählten Texte nebst Transliteration des Titels und des Kolophons sowie Beschreibungen der Texte vorgelegt, die unter spezieller Fokussierung auf die ikonographische Beschreibung der Gottheiten in den einzelnen Werken verfasst worden sind.

Entsprechend dem Standard, wie er in KOHD-Band XI, 5 entwickelt worden ist, wird eine umfassende Neubearbeitung der gesamten Sammlung vorgelegt, deren erster Teil in Band XI, 18 veröffentlicht wird. Dabei werden die äußere Beschreibung der Werke präzisiert, die Texttitel und Kolophone werden transliteriert und übersetzt, eine Kategorisierung der Werke vorgenommen, der aktuelle Stand der literarischen Bearbeitung der Werke aufgearbeitet, und Inhaltsverzeichnisse und Beschreibungen werden für diejenigen Werke verfasst, die noch nicht hinreichend beschrieben worden sind.

Wenn die Bearbeitung des ersten Teils der Beijinger Blockdrucke von tibetologischer Seite auch weitgehend fertiggestellt ist, so gilt es noch, die chinesischen Paginierungen sowie die chinesischen Text- und Titelzusätze in das Manuskript einzuarbeiten, die in tibetischer oder in mongolischer Sprache gegebenen Namen der Sponsoren und der Kaiser zu identifizieren und dadurch die Datierungen vereinzelter Werke zu verbessern. Damit die Beschreibungen dieser Werke die gleiche umfassende Beschreibung erfahren, wie sie Manfred Taube der Beschreibung der Beijinger Blockdrucke in den Bänden XI, 1-4 hat zuteilwerden lassen, sind deshalb ergänzende Arbeiten von sinologischer Seite erforderlich. Nach der Einarbeitung der chinesischen Randsignaturen usw stehen noch letzte Arbeiten am Index, an der Einleitung und die Gestaltung des Lay-outs aus. 
Der Band XI, 18 enthält damit Beschreibungen sehr unterschiedlicher Werke, die den verschiedensten Literaturgattungen zuzuordnen sind. Neben historiographischen Werken stehen Werke zur Astronomie, zur Divination und zur Medizin. Weitere Schwerpunkte des Katalogs bilden religiöse Belehrungen und rituelle Verrichtungen, alle Arten von Gebeten, Evokationsritualen, Weihe- und Opferritualen sowie kanonische Texte.

Zum Jahreswechsel wurden die Arbeiten an Band XI, 19 mit der Beschreibung des zweiten Teils der Sammlung Beijinger Blockdrucke in Angriff genommen. Davon sind mittlerweile 118 Werke beschrieben.

Frau Hanna Schneider MA hat im Sommer 2010 die Manuskripte des Katalogs der tibetischen Urkunden aus Südwest-Tibet abgeschlossen. Bevor die beiden Bände in Druck gehen können, ist allerdings noch eine formale Überarbeitung notwendig.

\section{Arbeitsstelle Göttingen}

„Sanskrithandschriften aus den Turfanfunden“, „Birmanische Handschriften“, „Singhalesische Handschriften“ (Leitung Dr. Hartmut-Ortwin Feistel)

„Sanskrithandschriften aus den Turfanfunden“ $<\mathrm{X}>$

[Dr. Klaus Wille-Peters, $1 / 2$ Stelle, Göttingen]

Für den Teilband 11 hat Dr. Klaus Wille-Peters im Berichtszeitraum 442 Katalognummern (SHT 4607-5048) bearbeitet. Die Katalognummern SHT 4607-4777 enthalten die restlichen Fragmente des im letztjährigen Bericht erwähnten restaurierten Expeditionsklumpens. Bei den folgenden Katalognummern handelt es sich ausschliesslich um sehr kleine Fragmente, von denen einige als aus dem „Vinaya“, dem „Dīrghāgama“ und dem „Samyuktāgama“ stammend identifiziert werden konnten.

Bei zwei Dienstreisen nach Berlin vom 30.11. bis zum 4.12.2009 und vom 17. bis zum 21.5.2010 hat Herr Wille-Peters die Abschriften der Katalognummern 4441-4950 für Teilband 11 anhand der Originale überprüft sowie verschiedene Einzelfragen zu vorhergehenden Katalognummern geklärt. Frau Anne Peters hat während dieser Zeit die Fragmente der Katalognummern SHT 4756-4777 und 5781-6662 vermessen.

Neben der Arbeit an Teilband 11 der Sanskrithandschriften aus den Turfanfunden hat Herr Wille-Peters die Mitarbeiterinnen der Berlin-Brandenburgischen Akademie der Wissenschaften bei dem DFG-Projekt zur Digitalisierung, Archivierung und Internetrepräsentation der Sanskrit-Fragmente in der Berliner Turfan-Sammlung kontinuierlich beraten. 
Zusammen mit Jens-Uwe Hartmann hat Herr Wille-Peters folgenden Aufsatz veröffentlicht: „Apotropäisches von der Seidenstrasse: eine zweite Löwenhandschrift", in: From Turfan to Ajanta: Festschrift for Dieter Schlingloff on the Occasion of his Eightieth Birthday. Editors E Franco und M Zin. Lumbini International Research Institute, 2010. 371-394.

„Birmanische Handschriften“ $<$ XXIII $>$

[Diplom-Soziologin Anne Peters, 1/2 Stelle, Göttingen]

Für Teilband 7 sind im Berichtszeitraum von Frau Anne Peters die restlichen Katalognummern 1368-1375 bearbeitet worden. Nach Abschluss der redaktionellen Arbeiten konnte der Band Ende 2009 zur Kalkulation eingereicht werden und ist im Jahr 2010 erschienen.

Für Teilband 8 konnte Frau Peters die Katalognummern 1376-1443 (68 Handschriften mit insgesamt 89 Texten) fertigstellen.

\section{Arbeitsstelle Hamburg}

„Äthiopische Handschriften“, „Koptische Handschriften“ und „Arabische Handschriften der Kopten“ (Leitung Professor Dr. Alessandro Bausi)

„Äthiopische Handschriften“ <XX>

[Dr. Veronika Six, Hamburg]

Frau Dr. Veronika Six erarbeitet für die Zeitschrift „Aethiopica. International Journal of Ethiopian and Eritrean Studies" (Hamburg) Beschreibungen äthiopischer Handschriften, in Fortsetzung ihrer im VOHD publizierten Bände. In diesem Jahr sind jedoch keine Neuerwerbungen deutscher Bibliotheken bekannt geworden. Allerdings beantwortete Frau Six verschiedentlich Anfragen von Institutionen - (darunter der SUB Hamburg) - zur Identifizierung sowie zur Begutachtung äthiopischer sowie arabisch-koptischer Handschriften.

„Koptische Handschriften“ <XXI>

[Dr. Ina Hegenbarth-Reichardt, Hamburg; Dr. Paola Buzi, 1² Stelle, Hamburg]

Die Katalogisierung der koptischen Handschriften der Staatsbibliothek zu Berlin - Preußischer Kulturbesitz wurde durch den ehrenamtlichen Mitarbeiter Professor (em.) Dr. Lothar Störk und durch Frau Dr. Ina Hegenbarth-Reichardt fortgesetzt. Seit dem 1.Januar 2010 widmet sich zusätzlich Frau Dr. Paola Buzi auf einer neu geschaffenen halben Stelle der Katalogisierung der Handschriften der SBB. Es wurde entschieden, das Corpus zu teilen und zwei Teilbände mit bohairischen bzw. mit sahidischen Manuskripten anzufertigen. Der erste Teilband (VOHD XXI, 6) wird von 
Frau Hegenbarth-Reichardt fertiggestellt, der zweite (VOHD XXI, 7) von Frau Buzi. Ein dritter Teilband (VOHD XXI, 5) soll die Katalogisierungsarbeiten von Herrn Störk enthalten und ist noch in Vorbereitung.

Es wurde auch beschlossen, die Arbeiten unter Verwendung des international anerkannten koptischen Unicode-basierten Schriftzeichens „IFAO N Copte“ fortzusetzen. Word-Makros werden eine einfache Umsetzung der aktuellen ASCII-Dateien in UNICODE-Dateien erlauben. Verwendet wird auch ein neuentwickeltes Erfassungsschema, das den Standards der modernen Koptologie entspricht.

Herr Störk konnte im Berichtszeitraum die Drucklegung von Teilband VOHD XXI, 5 noch nicht abschliessen. Nach dem neu aufgestellten Plan soll Herr Störk Handschriften berücksichtigen, an deren Erwerb er selbst beteiltigt war und die er inzwischen geordnet hat. Allerdings musste er die Arbeit aufgrund eines Unfalls unterbrechen und konnte sie bisher noch nicht wieder aufnehmen. Unter Umständen muss die Fertigstellung dieses Bandes einer anderen Mitarbeiterin übertragen werden.

Frau Hegenbarth-Reichardt hat schon 2008 die Arbeit für Teilband VOHD XXI, 6 mit Beschreibungen von etwa 40 koptischen Manuskripten abgeschlossen. Der Teilband umfasste den Grossteil des Nachlasses des Gelehrten Theodor Petraeus, einige biblische Bücher, eine Reihe von sahidischen Fragmenten sowie einige arabische Handschriften. Bei der Bearbeitung des Layouts und dem gleichzeitigen Arbeiten an einem Band mit Addenda et Corrigenda stellte Frau Hegenbarth-Reichardt jedoch fest, dass noch weitere 40 koptische Manuskripte des Berliner Bestandes unbearbeitet geblieben waren. Es handelte sich dabei um liturgische, biblische, literarische und grammatische Texte aus allen Epochen vom 5./6. bis zum 19. Jahrhundert, die neben dem Arabischen sowohl in bohairischer als auch in sahidischer Sprache verfasst worden sind. Nach Ablauf des Mutterschaftsurlaubs nahm sie im August 2009 ihre Tätigkeit wieder auf und bemühte sich, den fertiggestellten Teilband XXI, 6 um die hinzugekommenen Handschriften zu erweitern. Nach eingehenden Überlegungen wurde dann beschlossen, das Corpus zu teilen und zwei Teilbände mit bohairischen (VOHD XXI, 6) bzw. mit sahidischen (VOHD XXI, 7) Manuskripten anzufertigen. Im Augenblick ist der Teilband VOHD XXI, 6 (bohairische Manuskripte) von Frau Hegenbarth-Reichardt so gut wie abgeschlossen. Frau Buzi und Frau Hegenbarth-Reichardt haben gemeinsam Teilband VOHD XXI, 7 (sahidische Manuskripte) bearbeitet, wobei einige fragmentarische Handschriften noch zu katalogisieren sind.

Frau Hegenbarth-Reichardt nahm vom 1. bis zum 3. Dezember 2009 in Hamburg an „The Launching Conference of the European Science Foun- 
dation, Research Networking Project Comparative Oriental Manuscript Studies (COMST)“ mit einem Vortrag über das KOHD-Projekt teil.

Frau Buzi beschäftigte sich im Berichtszeitraum ebenfalls mit der Katalogisierung der Handschriften der SBB. In Zusammenarbeit mit Frau Hegenbarth-Reichardt bereitet sie derzeit den Teilband VOHD XXI, 7 vor. Sie bearbeitete Handschriften, deren komplette Beschreibung zum Juni 2011 zu erwarten ist. Dazu gehören sahidische Blätter, die aus verschiedenen Manuskripten des Weißen Klosters stammen und zum Grossteil auf das 9./10. Jh. zu datieren sind, sowie zwei urkundliche Papyrusrollen, die aus West-Theben stammen. Außerdem befasste sie sich mit zwei wegen ihrer Seltenheit besonders wichtigen Handschriften, die in nubischer Sprache verfasst worden sind, sowie mit zwei ausserordentlich alten (möglicherweise auf das 4. Jahrhundert zu datierenden) und fast vollständigen Papyrushandschriften, die zwar in der Wissenschaft bekannt, aber ebenfalls bisher nicht in einem Katalog erfasst sind (Proverbia Salomonis und Epistula Clementis). Frau Buzi hat die Texte identifiziert und überprüfte regelmässig, ob aus derselben Handschrift stammende und somit ergänzende Blätter in den Katalogen oder Veröffentlichungen zu finden sind. Sie hat darüber hinaus Kontakte mit der Berliner Papyrussammlung wegen der Katalogisierung der dortigen koptischen Handschriften aufgenommen.

Frau Buzi hat vom 5. bis zum 6. Juli 2010 in Bologna am „V. Colloquio di Egittologia e Antichità Copte: Lo scriba e il suo re: dal documento al Monumento“ mit dem Vortrag „Cataloguing the Coptic Manuscripts of the Staatsbibliothek zu Berlin" und vom 22. bis zum 23. Juli 2010 in Hamburg am „Comparative Oriental Manuscript Studies (COMSt). Workshop Digital support for manuscripts analysis" teilgenommen.

Frau Buzi hat im vergangenen Jahr folgende Beiträge veröffentlicht:

„Catalogo dei manoscritti copti Borgiani conservati presso la Biblioteca „Vittorio Emanuele III" di Napoli, con un profilo scientifico del cardinale Stefano Borgia e Georg Zoega" (Accademia dei Lincei - Memorie, Serie IX, Volume XXV, Fascicolo 1, Roma: Accademia Nazionale dei Lincei, 2009 [2010])

„Una seconda chiesa a Bakchias. Nuove proposte interpretative sulla fase tardo-antica e cristiana della kome alla luce dei risultati della Campagna di scavo 2008“ in: Rapporto preliminare della XVII. Campagna di Scavo a Bakchias. A cura di Sergio Pernigotti Enrico Giorgi - Paola Buzi. Imola: La Mandragora, 2009 [2010]. S. 75-89;

„Arabische Handschriften der Kopten“ <XLIII>

[Dr. Vernonika Six, Hamburg]

Frau Six setzte die Beschreibung der Fragmente der christlich-arabischen Handschriften der Kopten aus dem Besitz der Staats- und Universitätsbibliothek Hamburg (SUBH) fort. Mittlerweile ist die Identifizierung der 
Fragmente so weit gediehen, dass kaum mehr Inhalte von bisher unbestimmten Fragmenten geklärt werden können. Eine Zusammengehörigkeit etlicher Blätter wird allerdings abschliessend noch herausgearbeitet werden können.

Zur Zeit arbeitet Frau Six an der Abfassung des einleitenden Teils zu den Bänden, mit Literaturliste, Beschreibung der Arbeitsweise und Erklärungen zu etlichen vagen Angaben, die aus dem schwierigen Material resultieren, sowie an einer Einschätzung des Werts der Sammlung. Eine der Hauptaufgaben ist dabei die Erstellung des Registers, angelegt als Generalregister, um einen Überblick über die Inhalte der Fragmente zu erhalten, die über 5000 Blätter verteilt sind. Nach langwierigen Überlegungen hat Frau Six beschlossen, die Auflistung im Registerteil in diesem Fall auf die Signaturen zu beschränken und nicht, wie allgemein üblich, zusätzliche Verweisungen auf Seitenzahlen zu geben. Da einige Stichworte über einen Großteil der vergebenen Signaturen verteilt sind, wurde so die Reihenfolge der Signaturen beibehalten, eben auch im Erstellen des Registers (also A-Z, AA-ZZ, AAA). Diese Vorgehensweise soll zukünftigen Benutzern die Suche erleichtern, da die Information, in welchem Teil der Bände die gesuchte Signatur abgelegt ist, sofort ersichtlich wird. Wie allerdings die voraussichtliche Dreiteilung der Teilbände aussehen wird, steht zum gegenwärtigen Zeitpunkt noch nicht fest.

Wie bereits im letzten Bericht dargelegt, ist inzwischen eindeutig zu belegen, dass die vorgefundene Zweiteilung der Sammlung der christlicharabischen Blätter nach Provenienzangabe: Makarioskloster und Pšoikloster, keine Gültigkeit hat, da sich die Provenienzen innerhalb einer Signaturengruppe in einigen Fällen vermischt haben.

Mit Unterstützung von Professor Dr. Alessandro Bausi konnten Probleme mit der Software für arabische Schrift gelöst werden. Ebenso konnte geklärt werden, dass auch hier (wie im Fall der koptischen Fragmente siehe unten) eine Umstellung von ASCII auf UNICODE mit Hilfe von Macros einfach durchzuführen ist.

Frau Six hat an folgenden Kongressen teilgenommen:

- „17th International Conference of Ethiopian Studies (ICES)“vom 1. bis zum 6. November 2009 an der Addis Ababa University, mit dem Vortrag „A Psalter From Tübingen, Although Inconspicuous the Content, Nevertheless a Treasure for Manuscriptology";

- „8th International Conference on the History of Ethiopian Art and Architecture (ICHEAA)"vom 6. bis zum 8. November 2009 am GoetheInstitut in Addis Ababa, mit dem Vortrag „Four Directions of the Winds: 
the Many Ways of Their Pictorial Presentation on Ethiopian Parchment Scrolls";

- „Symposium über die Fragestellung der Sehnsucht nach der Hölle: Höllen- und Unterweltsvorstellungen in Orient und Okzident"vom 12. bis zum 14. Mai 2010 in der Leucorea, Wittenberg, mit dem Vortrag „Teufel - Diabolos - Satan — In der Vorstellung des christlich-orthodoxen Gläubigen Vertreter der Hölle oder ,nur` Symbol des Bösen?“

Der Vortrag von Frau Six auf dem 30. Deutschen Orientalistentag ist online veröffentlicht: „Der Katalog über die arabischen Handschriftenfragmente der Kopten aus dem Bestand der Staats- und Universitätsbibliothek Hamburg" [http://orient.ruf.uni-freiburg.de/dotpub/six.pdf].

\section{Arbeitsstelle Jena}

„Arabische Handschriften“ (Leitung Professor Dr. Tilman Seidensticker, Jena)

„Arabische Handschriften" $<$ XVII>

[Dr. Rosemarie Quiring-Zoche, 1/2 Stelle, Jena; PD Dr. Florian Sobieroj, $1 / 2$ Stelle, Jena]

Der Schwerpunkt der Arbeit von Frau Dr. Rosemarie Quiring-Zoche lag im Berichtszeitraum 2010 auf der Handlist, für die sie 243 Werke in 73 Kodizes neu katalogisiert hat. Außerdem hat sie die Aufnahmen von Frau Beate Wiesmüller (siehe dazu den Jahresbericht für 2008) in die Handlist eingegliedert. Es stellte sich heraus, dass die Wiesmüllerschen Beschreibungen sämtlich überarbeitet werden mussten, da hier - im Gegensatz zu den Quiring-Zocheschen Aufnahmen - die ältere Ausgabe von Brockelmanns "Geschichte der arabischen Litteratur" zitiert wird und auch anderes vereinheitlicht werden musste. Einige unidentifizierte Werke liessen sich noch nachträglich bestimmen. Zusammen mit den Wiesmüllerschen Aufnahmen umfasst die Handlist jetzt Beschreibungen von 416 Kodizes mit 598 Titeln, letztere oft in mehreren Exemplaren.

Für den Katalogband VOHD XVII, B, 7 hat Frau Quiring-Zoche 11 Kodizes mit 30 herausragenden Werken ausführlich beschrieben. Dieser Band enthält jetzt die Beschreibungen von 333 Werken in 145 Kodizes. Für beide Bände wurden die Indizes „Signaturen“, „Personen“, „Titel in Lateinschrift“, „Orte“, „Sachen“ und „Datierungen“ fortgeführt.

Vom 3. bis zum 5. Dezember 2009 nahm Frau Quiring-Zoche mit einem Vortrag über Kolophone in arabischen Hss. an der internationalen Konferenz „On Colophons“ der Forschergruppe „Manuscript Cultures in Asia and Africa" an der Universität Hamburg teil. In der Folgezeit überarbeitete 
sie ihren Beitrag, so dass er jetzt unter dem Titel "Colophons in Arabic Manuscripts. A Phenomenon without a Name“ in druckfertiger Form vorliegt.

Herr PD Dr. Florian Sobieroj hat im Berichtszeitraum den Katalogband VOHD XVII, B.9, seinen zweiten Katalog der arabischen Handschriften der Bayerischen Staatsbibliothek München, fertiggestellt; der Band ist inzwischen erschienen. Die Beschreibungen der arabischen Handschriften der BSB werden von Cod arab 1665 (die letzte Signatur von XVII, B, 9 ist 1664) an im Handlistformat fortgesetzt. Die Handlistbeschreibungen sind kürzer als die des bisher gewählten Formats und unterscheiden sich auch dadurch, dass das Explicit nicht mehr aufgenommen ist, außer in den Fällen, wo der Textanfang fehlt, jedoch das Textende enthalten ist. Bei den sufischen Handschriften wurde zumeist auch das Explicit aufgenommen, da Herr Sobieroj erwogen hatte, einen Katalog sufischer Handschriften abzufassen, der ausführliche Beschreibungen enthalten sollte (diese Idee ist wegen Unvereinbarkeit mit den Zeitplänen wieder verworfen worden). Zeitgleich mit den Beschreibungen wurden auch die Indizes mitabgefasst. Zahlreiche in schwer lesbarem maghribinischen Duktus geschriebene Handschriften, die als anonyme und titellose Fragmente vorliegen, haben eine zeitaufwendige Bearbeitung erfordert. Die Konvolute aus oft nicht zusammengehörenden Fragmenten konnten im Rahmen einer Handlist jedoch nur in Auswahl bearbeitet werden. Abgesehen von zahlreichen Handschriften maghribinischer Herkunft, ist hinsichtlich der Provenienz eine Sammelhandschrift erwähnenswert, die bei Kazan in Südrussland entstanden ist. Im Berichtszeitraum wurden 100 Kodizes mit rund 150 Werken katalogisiert. Zusammengerechnet mit den in den Vorjahren für diesen Katalog bearbeiteten Handschriften, ergibt dies eine Gesamtziffer von etwa 225 Kodizes mit etwa 365 Werken.

Frau Dr. Kathrin Müller (Bayerische Akademie der Wissenschaften/ München) hat im Berichtsjahr zunächst die Druckvorlage für den Band VOHD XVII, B, 10 fertiggestellt; der Band ist inzwischen erschienen

Die für die zukünftige Bearbeitung arabischer Handschriften zu verwendenden Schriftarten wurden auf UNICODE-System („Gentium“ für Lateinschrift, „Scheherazade“ für arabische Schrift) umgestellt. Nach Absprache mit Herrn Sobieroj wurden von Frau Müller für den nächsten Band diejenigen Handschriften bearbeitet, die den in Band VOHD XVII,B, 10 beschriebenen Handschriften vorausgehen, also rückwärts ab Cod arab 2299 in Richtung auf Cod arab 2000 hin. Seit November 2009 wurden 44 Handschriften mit 113 enthaltenen Werken bearbeitet. 
Am 5. November 2009 wurde das Projekt KOHD von der Kommission für Semitische Philologie auf dem Tag der Offenen Tür der Bayerischen Akademie der Wissenschaften mit einem Poster und mit einer Auslage der bisher erschienenen Bände der Serie VOHD XVII,B,1 bis B, 8 vorgestellt.

Professor Dr. Tilman Seidensticker hat sich weiterhin an den Aktivitäten der Hamburger DFG-Forschergruppe „Manuskriptkulturen in Asien und Afrika“ beteiligt. Er hat für deren „Newsletter Manuscript Cultures“ 2 (2009, Seiten 1-4) einen Aufsatz mit dem Titel „Ordered Disorder: Vestiges of Mixed Written and Oral Transmission of Arabic Didactic Poems“ verfasst. Gegenwärtig arbeitet er an einem Teilprojektantrag zum Layout in arabischen Handschriften für den geplanten Sonderforschungsbereich, der aus dieser Forschergruppe hervorgehen soll.

Herr Seidensticker hielt folgende Vorträge mit Bezug zu arabischen Handschriften:

- „Die „Katalogisierung der Orientalischen Handschriften in Deutschland“ zwischen Minimal- und Maximalprogramm“, Vortrag im „Workshop Islamische Handschriften in Deutschland“, Orientalisches Institut/ Universitätsbibliothek Leipzig, 28. bis 29. Januar 2009;

- „Islamische Kleinhandschriften“, Vortrag im Bayerischen Orient-Kolloquium Bamberg, 20. Mai 2010;

- „Der Tübinger Umar aus kodikologischer Sicht“, Vortrag im „Arabian Nights Workshop“, 26. bis 29. Mai 2010, Universität Erlangen;

- „Eine kleine Einführung in die klassische arabische Literatur“, Vortrag anlässlich der Eröffnung der Ausstellung „Die Wunder der Schöpfung“ in der Bayerischen Staatsbibliothek München, 15. September 2010.

H.-O. Feistel

\section{Leibniz-Edition (Leibniz-Archiv Hannover und Leibniz-Forschungsstelle Münster) \\ Interakademische Leitungskommission: \\ Vorsitzender: Künne \\ Dingel (Mainz), Knobloch (Berlin), Leinkauf(Münster), Mittelstraß (Kon- stanz), Patterson, Peckhaus (Paderborn), Poser (Berlin), Siep (Münster)}

Kontaktadresse: Niedersächsische Landesbibliothek, Leibniz-Archiv, Waterloostraße 8, 30169 Hannover, Tel.: 0511-1267-327, Fax 05111267-202, Herbert.Breger@gwlb.de (Prof. Dr. Breger), http://www.nlbhannover.de/Leibniz/ (Arbeitsstelle Hannover); 
Leibniz-Forschungsstelle-Münster, Robert-Koch-Straße 40, 48149 Münster, Tel.: 0251-83329-25, Fax 0251-83329-31 stemeo@uni-muenster.de (PD Dr. Meier-Oeser), http://www.uni-muenster.de/Leibniz/ (Arbeitsstelle Münster)

Gemeinsame Homepage: http://www.leibniz-edition.de

Arbeitsbericht: (Bericht der Leibniz-Editionsstelle Hannover (LeibnizArchiv)):

Die Leibniz-Gesamtausgabe wird von der Göttinger Akademie und der Berlin-Brandenburgischen Akademie gemeinsam herausgegeben. Während die Berliner Akademie seit 1901 an der vollständigen Ausgabe der Schriften und der Briefe arbeitet, ist die Göttinger Akademie erst seit 1985 an dieser Ausgabe beteiligt. Von den 30 seit 1985 erschienenen Bänden sind 25 von den beiden Arbeitsstellen (Hannover und Münster) der Göttinger Akademie erarbeitet worden.

Leibniz' Briefwechsel ist in vieler Hinsicht eine wichtige Quelle für das Werk des Gelehrten. Leibniz korrespondierte mit ungefähr 1100 Korrespondenten aus nahezu allen sozialen Schichten und vielen europäischen Ländern bis nach China. Die Fülle der im Briefwechsel erörterten Themen erstreckt sich über alle Bereiche des Wissens. In den mathematischen Schriften gewinnt der Leser einen Einblick in Leibniz' Schaffensprozess. Leibniz hat oft auch auf die Veröffentlichung relativ reifer Überlegungen verzichtet, so dass die Veröffentlichung des Nachlasses wichtige Gesichtspunkte zur Beurteilung seines Werkes liefert.

Die Leibniz-Ausgabe ist in acht Reihen gegliedert; die hannoversche Editionsstelle arbeitet an den Reihen I (Allgemeiner, politischer und historischer Briefwechsel), III (Mathematischer, naturwissenschaftlicher und technischer Briefwechsel) und VII (Mathematische Schriften). Jeder Band umfaßt 800 bis 1000 Seiten.

Im Berichtszeitraum wurde die Bearbeitung der Bände I, 23 (Januar bis September 1704), I, 24 (Oktober 1704 bis Juli 1705), III, 8 (Januar 1699 bis Dezember 1701) und VII, 6 (Arithmetische Kreisquadratur 1673 1676) fortgesetzt. Die Schlussredaktion des Textteiles des Bandes I, 22 (Januar - Dezember 1703) wurde abgeschlossen; Register und Einleitung liegen teilweise vor. Die Bände I, 21 (April bis Dezember 1702) und III, 7 (Juli 1696 - Dezember 1698) werden voraussichtlich 2011 an den Verlag gegeben.

Die Arbeitsstelle hat bisher neun abgeschlossene Bände sowie vorläufige Fassungen von fünf in Bearbeitung befindlichen Bänden ins Internet gestellt. Insgesamt handelt es sich dabei um mehr als 11.000 Seiten. Außer- 
dem hat die Arbeitsstelle ein kumuliertes Korrespondenzverzeichnis mit mehr als 12.000 Briefen von und an Leibniz sowie ein kumuliertes Personenverzeichnis mit mehr als 30.000 Datensätzen sowie sechs laufend erweiterte Konkordanzen zwischen der Akademieausgabe und früheren LeibnizAusgaben der Forschung im Internet zugänglich gemacht.

Ferner werden Transkriptionen von bisher unveröffentlichten Briefen von und an Leibniz ins Netz gestellt. Dabei wurde bewusst mit Briefen aus Leibniz' letzten Lebensjahren (also nicht aus dem Zeitraum, in dem Bände in Vorbereitung sind) begonnen. Bisher konnten 3000 Seiten ins Netz gestellt werden; die Resonanz der Forschung darauf ist sehr positiv.

H. Breger

Arbeitsbericht: (Bericht der Leibniz-Forschungsstelle Münster):

Die Leibniz-Forschungsstelle ist eine der vier in Münster, Hannover, Potsdam und Berlin angesiedelten Arbeitsstellen, die das Gesamtwerk von Leibniz erschließen und in der Leibniz-Akademieausgabe historisch-kritisch edieren. Wie das Leibniz-Archiv Hannover wird sie im Rahmen des Akademienprogramms von der Akademie der Wissenschaften zu Göttingen betreut. Ihre Aufgabe besteht in der Erforschung und Edition der philosophischen Schriften (Reihe VI) und des philosophischen Teils des 2007 von der UNESCO zum Weltkulturerbe erklärten Briefwechsels von Leibniz (Reihe II).

Die Edition der Texte erfolgt grundsätzlich in chronologischer Reihenfolge. In den Bänden VI, 1-VI, 4 sind bislang die philosophischen Schriften bis 1690 herausgegeben worden. Abweichend von der chronologischen Ordnung, ist jedoch bereits 1962 Band VI, 6, erschienen, welcher Leibniz' Auseinandersetzung mit Locke aus den Jahren 1703-1705 enthält. Für die nun noch zu überbrückende Zeit zwischen 1690 bis 1705 sind vermutlich zwei weitere Bände der philosophischen Schriften zu erwarten. Die konzeptionelle Vorbereitung für deren Herausgabe wurde im Jahr 2010 aufgenommen, da in der internationalen Forschung zur Philosophie der frühen Neuzeit ein großes Interesse an den Werken dieser Phase der Ausgestaltung des metaphysischen Systems von Leibniz besteht.

Nach dem Erscheinen von Band II, 2 (Philosophischer Briefwechsel 1686-1694) im Jahr 2009 ist die editorische Arbeit jedoch zunächst auf den philosophischen Briefwechsel konzentriert, der mit den Bänden II, 3 und II, 4 bis zum Jahr 1705 aufschließen soll.

Die Bearbeitung des Bandes II, 3, der insgesamt 261 Briefe aus der Zeit von 1695 bis 1700 umfasst, wurde fortgesetzt. 270 Seiten, d. h. 36\% 
des Gesamttextbestandes, wurden bislang ins Netz gestellt. Diese Form der online-Präsentation wird sukzessive fortgeführt, so dass im Frühjahr 2011 über 75\% des Bandes im Internet verfügbar sein werden. Mit einem Abschluss der Bearbeitung des Bandes ist bis Ende 2011 zu rechnen.

Der Inhalt des Bandes II, 4 (1701-1705) ist in Abstimmung mit den anderen Reihen festgelegt worden. Fehlende Briefe wurden erfasst, so dass unmittelbar nach Beendigung von Band II, 3 mit der editorischen Bearbeitung begonnen werden kann. Im Zuge dieser Arbeiten wurden die Grunddatei des Briefcorpus durch die Abschrift noch fehlender Transkriptionen für die Bände II, 4 und II, 5 vervollständigt sowie der Druckortekata$\log$ aktualisiert. Damit sind alle neueren Drucke und Übersetzungen von Leibniz-Texten der Jahrgänge 1991 bis 2008 auf der Grundlage der OnlineLeibniz-Bibliographie erfasst und in die beiden Kataloge, den Druckortekatalog und den Ritterkatalog, eingepflegt worden.

Die Leibniz-Forschungsstelle Münster unterstützt auswärtige Wissenschaftler und Wissenschaftlerinnen, die an Ort und Stelle die Bibliothek und das Archiv als Arbeitsinstrumente nutzen. Im Jahr 2010 hat sie Prof. Dr. Juan Nicolás (Granada) und Dr. Jeffrey MacDonough (Harvard) technisch betreut.

St. Meier-Oeser

\section{Lexikon des frühgriechischen Epos (Thesaurus Linguae Graecae) \\ Leitungskommission: \\ Vorsitzender: Schmitt \\ Harlfinger (Hamburg), Heitsch, Hettrich (Würzburg), Nickau (Göttin- gen), Schindel}

Kontaktadresse: Indogermanistik/FU, Fabeckstraße 7, 14195 Berlin, Tel.: 030-838-55028, drmeier@zedat.fu-berlin.de (Prof. Dr. Meier-Brügger); Thesaurus-Linguae-Graecae, Von-Melle-Park 6 VIII, 20146 Hamburg, Tel.: 040-42838-4768, william.beck@uni-hamburg.de (Dr. Beck), http://www.rrz.uni-hamburg.de/Thesaurus/

Arbeitsbericht: Im Jahr 2010 wurde das Lexikon des Frühgriechischen Epos abgeschlossen. Die in diesem Jahr noch zu erledigenden Aufgaben waren:

1) Die Fertigstellung der letzten beiden Lieferungen: $24 \varphi \eta^{\prime}-\chi \alpha \lambda x o ́ \varsigma$ und $25 \chi \alpha \lambda$ xótu 
Zusammen mit dem Vorwort, den Corrigenda et Addenda und einer vollständigen Abkürzungsliste und nach einem letzten Korrekturdurchgang war der vollständige Band IV Ende Juli im Druck.

2) Vorbereitung, Durchführung und Nachbereitung eines Abschlusskolloquiums mit dem Thema: „Homer - gedeutet durch ein großes Lexikon“, das vom 6. bis 8. Oktober 2010 im Erwin-Panofsky-Saal des Hauptgebäudes der Universität Hamburg stattfand.

Durch die großzügige Unterstützung der Göttinger Akademie, der Hamburger Stiftung zur Förderung von Wissenschaft und Kultur sowie des Senats der Freien und Hansestadt Hamburg konnten herausragende Homerkenner aus vielen Ländern als Referenten gewonnen und die Tagung in einem angemessenen Rahmen durchgeführt werden. Die Tagung wurde durch den Präsidenten der Göttinger Akademie, Christian Starck, eröffnet; auch Vertreter des Präsidiums der Universität Hamburg und des Hamburger Senats sprachen Grußworte. Zum Eröffnungsabend waren auch der Vorsitzende der Kommission der Union der Akademien, Volker Gerhard, und die Generalsekretärin der Göttinger Akademie, Frau Angelika Schade, gekommen. Im öffentlichen Abendvortrag gab der Doyen der deutschen Homerforschung, Joachim Latacz, vor einem zahlreichen Publikum einen Überblick und eine Analyse der Höhepunkte des Homerischen Einflusses auf die Europäische Kulturentwicklung. Den zweiten öffentlichen Abendvortrag hielt am Donnerstag, dem 7. Oktober, der Direktor des Deutschen Archäologischen Instituts Athen, Wolf- Dietrich Niemeier, in dem er die Forschungssituation zum historischen Hintergrund der homerischen Epen darstellte.

Auf der durchwegs sehr gut besuchten Tagung zeigten Referentinnen und Referenten aus den USA, den Niederlanden, Frankreich, der Schweiz, Österreich, Italien, Griechenland und Deutschland sowie Mitarbeiter der Hamburger Arbeitsstelle unter verschiedenen Apekten die vielfältigen Impulse auf, die vom Lexikon des Frühgriechischen Epos für die Homerdeutung ausgegangen sind. Das beeindruckende Niveau und die reichen Ergebnisse waren Anlass, eine Publikation der Tagungsvorträge im Rahmen der Abhandlungen der Göttinger Akademie der Wissenschaften vorzusehen. Der Band soll im Sommer 2011 zum Druck fertiggestellt sein. Die Redaktion übernimmt Michael Meier-Brügger.

Der Abschluss des Lexikons des Frühgriechischen Epos konnte auch die Aufmerksamkeit der überregionalen Presse gewinnen. In ausführlichen Beiträgen würdigten insbesondere die "Frankfurter Allgemeine Zeitung", die „Neue Zürcher Zeitung" und die "Süddeutsche Zeitung“ die Bedeu- 
tung des von dem großen Klassischen Philologen Bruno Snell gleich nach dem Ende des Zweiten Weltkriegs gegründeten Unternehmens. Auch wenn Snells Anliegen, der Barbarei des Kriegs die Erinnerung an die kulturellen Grundlagen Europas entgegenzustellen, heute andere Bezugspunkte hat, das Anliegen, die Begriffe und Inhalte, die Europa geprägt haben und die die Besonderheit seiner Kultur ausmachen, durch die wissenschaftliche Analyse ihrer Bedeutung präsent zu halten, wurde in seiner aktuellen Relevanz anerkannt, der nicht unerhebliche Beitrag hervorgehoben, den das Lexikon leistet.

3) Die Retrodigitialisierung des Lexikons des Frühgriechischen Epos

Die Vorbereitungen der Retrodigitalisierung des Lexikons wurden im Jahr 2010 weiter vorangetrieben. Der Teil eines Antrags an die DFG, der die Begründung für den wissenschaftlichen Gewinn einer Retrodigitalisierung liefert, wurde in Zusammenarbeit zwischen dem Redaktor der Arbeitsstellte, William Beck, und dem Vorsitzenden der Leitungskommission der Akademie fertiggestellt. Für die Bewältigung der technischen Probleme der Retrodigitalisierung leistete das Trierer Kompetenzzentrum für elektronische Erschließungs- und Publikationsverfahren in den Geisteswissenschaften wichtige Hilfe. Besonders günstig ist, dass auch das Interesse des Editor in Chief, Gregory Crane, der Perseus Digital Library an einer Zusammenarbeit mit dem LfgrE gewonnen werden konnte. Auf einem Arbeitstreffen am 15. Dezember in Hamburg wurden konkrete Verfahren der Zusammenarbeit besprochen und eingeleitet.

4) Abwicklung der Arbeitsstelle, Übergabe an die Hamburger Universität Die letzten Aufgaben, die im Jahr 2010 erledigt werden mussten, waren die Abwicklung der Arbeitsstelle in Hamburg und die Übergabe an die Universität Hamburg. Durch eine Übereinkunft der Göttinger Akademie mit der Universität Hamburg konnte erreicht werden, dass die über viele Jahre gepflegte Spezialbibliothek mitsamt den sie erschließenden Katalogen in den bisherigen Räumen bleiben kann. Die Bibliothek wird von der Göttinger Akademie dem Seminar für Klassische Philologie der Universität Hamburg als Dauerleihgabe zur Verfügung gestellt. Die Räume werden renoviert und können dann für wissenschaftliche Projektarbeiten genutzt werden.

Besonders wichtig für den pünktlichen und erfolgreichen Abschluss der Arbeiten am Lexikon des Frühgriechischen Epos war die Tatsache, dass die Mitarbeiter der Hamburger Arbeitsstelle, die bereits pensioniert waren, sich unentgeltlich und ununterbrochen an der Abfassung und Korrektur von Artikeln beteiligt hatten. Auch der Redaktor, Michael Meier-Brügger, stand 
dem Lexikon mit Rat und Tat zur Verfügung, ohne dafür einen finanziellen Ausgleich zu fordern und trotz der Verpflichtungen an seinem Lehrstuhl in Berlin.

William Beck, der Ende 2009 in den Ruhestand gegangen ist, war durch einen Werkvertrag weiter beschäftigt, damit er die Arbeiten an Ort und Stelle koordinieren konnte. Frau Barbara Schönefeld ist im September 2010 aus dem regulären Dienst ausgeschieden, war aber bis Dezember 2010 mit einem Werkvertrag weiter beschäftigt. Ohne ihre effektive Mithilfe hätte die Abschlusstagung nicht organisiert, die Abwicklung nicht erfolgreich bewältigt werden können.

A. Schmitt

Mittelhochdeutsches Wörterbuch (Arbeitsstelle Göttingen)

Leitungskommission:

Vorsitzender: Grubmüller

Gärtner (Trier), Henkel, Klein (Bonn), Schumann, Stackmann

Kontaktadresse: Papendiek 14, 37073 Göttingen, Tel.: 0551-39-6412, uhdpmhdw@gwdg.de (Dr. Diehl), http://www.uni-goettingen.de/de/92908.html

Arbeitsbericht: Das Vorhaben „Mittelhochdeutsches Wörterbuch“ bietet eine umfassende lexikographische Bearbeitung des mittelhochdeutschen Wortbestandes in den zeitlichen Grenzen von 1050 bis 1350. Seine Quellenbasis bildet ein Corpus von philologisch gesicherten Texten aller Textsorten der Periode. Auf der Grundlage des Quellencorpus wurde ein maschinenlesbares Textarchiv angelegt und aus diesem durch computergestützte Exzerpierung ein Belegarchiv erstellt, welches das Material für die Ausarbeitung des Wörterbuches bietet. Aufgrund seiner Quellenbasis gewährt das Wörterbuch erstmals einen die ganze Periode zeitlich und räumlich gleichmäßig berücksichtigenden Überblick über die Verwendungsbedingungen und die Bedeutungsentwicklung des mittelhochdeutschen Wortbestandes und kann daher als zuverlässiges Hilfsmittel für die Erforschung der deutschen Sprache des Mittelalters sowie für das Verstehen und die philologische Erschließung mittelhochdeutscher Texte dienen. Das Vorhaben wird von der Göttinger und der Mainzer Akademie gemeinsam getragen und von zwei Arbeitsstellen in Göttingen und Trier durchgeführt. 
Die zur Stärkung des Gesamtprojekts im Rahmen der langfristigen Planungen zum Sommer 2009 zusätzlich eingerichtete halbe Mitarbeiterstelle (J. Richter M.A.) wurde ebenso verlängert wie die von beiden Akademien gemeinsam getragene Aufstockung der für EDV-Arbeiten zuständigen Stelle in Trier (U. Recker-Hamm M.A.). Damit konnte der im Vorjahr begonnene Ausbau des projekteigenen Artikelredaktionsprogramms TAReS fortgesetzt werden. Im Herbst hat der Wechsel von Dr. Runow auf eine Ratsstelle an der LMU für eine kurze Stellenvakanz gesorgt. Seit Mitte November hat sich unser Team jedoch mit Frau Luise Czajkowski M. A. wieder vervollständigt.

In Göttingen ist die Bearbeitung der 7. Lieferung (ëbentiure - erbieten) abgeschlossen, sie geht zu Beginn des kommenden Jahres zusammen mit der Trierer Lieferung 8 (erbietunge - gar) in Druck. Die Artikelarbeiten an der zehnten, den ersten Band abschließenden Lieferung (gemeine geveigen) sind bis zur Hälfte fortgeschritten. Durch die Korrektur und die Integration zusätzlicher maschinenlesbarer Texte ins Redaktionssystem konnte das Belegarchiv erweitert und damit auch die Artikelbearbeitung erleichtert werden.

Wie bereits in den letzten Jahren haben die Mitarbeiter der Arbeitsstelle auch im Jahr 2010 an verschiedenen externen wissenschaftlichen Veranstaltungen und Kongressen teilgenommen. Neben universitären Lehrveranstaltungen wurden für Seminare und auswärtige Besucher Führungen durch die Arbeitsstelle angeboten bzw. Materialien zur Verfügung gestellt. Der 2009 eingerichtete Praktikumsplatz konnte im laufenden Jahr mehrfach besetzt werden. Die Übernahme einer qualifizierten Praktikantin auf eine Hilfskraftstelle belegt den Nutzen dieser Dienstleistung auch für die Arbeitsstelle selbst.

Das Evaluationsverfahren (Begehung am 18.9.2009 in Trier) wurde im Berichtsjahr erfolgreich abgeschlossen. Die notwendige Ergänzung der Kommission ist in die Wege geleitet.

K. Grubmüller

Veröffentlichungen:

Susanne Baumgarte/Gerhard Diehl/Holger Runow: Wörterbuchmacher als Wörterbuchnutzer. Das neue Mittelhochdeutsche Wörterbuch und das Deutsche Rechtswörterbuch, in: Das Deutsche Rechtswörterbuch - Perspektiven, hrsg. von Andreas Deutsch, Heidelberg 2010, S. 159-175. 
Ortsnamen zwischen Rhein und Elbe - Onomastik im europäischen Raum Leitungskommission:

Vorsitzender: Henne

Aufgebauer (Göttingen), Debus (Kiel), Lehfeldt, Oexle, Reitemeier (Göttingen), Udolph

Kontaktadresse: Robert-Koch-Straße 40, 48149 Münster, Tel.: 02518331464, Fax: 0251-8331466, kirstin.casemir@ortsnamen.net (Dr. Casemir), http://www.ortsnamen.net

Arbeitsbericht: Das Vorhaben soll kreisweise sämtliche bis 1600 in schriftlichen Quellen erwähnte Ortsnamen Niedersachsens, Bremens und Westfalens unter Einschluß der Wüstungen onomastisch aufbereiten. Dies umfaßt eine Belegsammlung, die die Überlieferung des einzelnen Ortsnamens über die Jahrhunderte spiegelt, eine Zusammenfassung der bisher erschienenen Literatur zur Deutung des Namens sowie als Schwerpunkt eine systematisch gegliederte Deutung des Namens.

Im Mai 2010 erschien der zweite Band des Westfälischen Ortsnamenbuches, die Untersuchung der Ortsnamen des Kreises Lippe, der in einer Veranstaltung im Lippischen Landesmuseum in Detmold der Öffentlichkeit vorgestellt wurde. Druckfertig liegt das Manuskript des 7. Bandes des Niedersächsischen Ortsnamenbuches (Kreis Helmstedt/Stadt Wolfsburg) vor, so daß der Band um das Jahresende veröffentlicht werden wird. Die Arbeiten an den Folgebänden des Westfälischen Ortsnamenbuches gehen planmäßig voran und befinden sich in der Redaktion bzw. stehen unmittelbar vor der Redaktion, so daß im Jahr 2011 die Bände 3 und 4 gedruckt werden können.

Wie in den vergangenen Jahren steht die Arbeitsstelle durch Vorträge der Mitarbeiter, Tagungsteilnahmen und Beantwortung zahlreicher Anfragen in einem regen Austausch mit der wissenschaftlichen wie der breiteren Öffentlichkeit. Das examensbedingte Ausscheiden mehrerer Hilfskräfte konnte durch die Gewinnung qualifizierter Studenten einer Lehrveranstaltung an der Westfälischen Wilhelms-Universität Münster kompensiert werden.

Der im Vorjahr begonnene Aufbau einer Datenbank der Belegkonkordanzen durch studentische Hilfskräfte des Projektes wurde fortgesetzt und umfaßt derzeit 14.000 Datensätze. Durch diese Datenbank werden Paralleldrucke bzw. Regesten einer und derselben Urkunde in unterschiedlichen Editionen erfaßt, so daß die Bearbeiter rasch die maßgebliche Edition ermitteln sowie Doppelexzerptionen vermeiden können. 
Die wissenschaftliche Leitungskommission sprach sich auf ihrer jährlichen Sitzung am 4.6.2010 dafür aus, die Kommission durch Herrn Prof. Dr. Arnd Reitemeiter, Direktor des Instituts für Historische Landesforschung an der Georg-August-Universität Göttingen, zu erweitern.

H. Henne

Veröffentlichungen:

Birgit Meineke: Die Ortsnamen des Kreises Lippe. Westfälisches Ortsnamenbuch (WOB). Im Auftrag der Akademie der Wissenschaften zu Göttingen herausgegeben von Kirstin Casemir und Jürgen Udolph. Band 2. Verlag für Regionalgeschichte, Bielefeld 2010

\section{Papsturkunden des frühen und hohen Mittelalters}

Leitungskommission:

Vorsitzender: Herbers (Erlangen)

Görz (Erlangen), Kölzer (Bonn), López Alsina (Santiago de Compostela), Maleczek (Wien), Schieffer

Kontaktadresse: Friedländer Weg 11, 37085 Göttingen, Tel.: 05515316499, Fax: 0551-5316512, wkoenig@gwdg.de (Dr. Könighaus), http:// www.papsturkunden.gwdg.de

Arbeitsbericht: Im Berichtszeitraum waren innerhalb des von der Union der Akademien finanzierten und seit Februar 2007 laufenden Projektes „Papsturkunden des frühen und hohen Mittelalters" folgende Mitarbeiterinnen und Mitarbeiter angestellt: in der Arbeitsstelle Göttingen für die Iberia Pontificia die Herren Daniel Berger (bis August 2010), Thomas Czerner, M.A. (seit Oktober 2010), Frank Engel, M.A. und Dr. Waldemar Könighaus (Bohemia-Moravia Pontificia und Polonia Pontificia); in der Arbeitsstelle Erlangen: Frau Judith Werner und Herr Dipl.-Hist. Markus Schütz (Neubearbeitung des Jaffé) sowie Herr Thorsten Schlauwitz, M. A. (Iberia Pontificia; Neubearbeitung des Jaffé; Digitalisierung). Darüber hinaus waren in beiden Arbeitsstellen mehrere Hilfskräfte beschäftigt.

Unter dem Titel „Das begrenzte Papsttum. Spielräume päpstlichen Handelns. Legaten - delegierte Richter - Grenzen" veranstaltete das Akademienprojekt in Zusammenarbeit mit dem spanischen Schwesterprojekt „El Pontificado Romano: relaciones con el Noroeste Peninsular y bases docu-

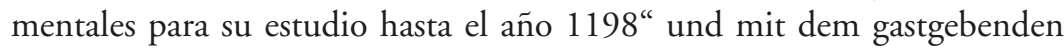
Centro de Estudos de História Religiosa der Universidade Católica Portuguesa in Lissabon am 9. und am 10. Juli 2010 eine internationale Tagung 
(s. dazu unter „Sonstige Veranstaltungen“, Seite 447). Die Beiträge sollen in den Abhandlungen der Göttinger Akademie publiziert werden. Ein Arbeitstreffen in Porto vom 3. bis zum 5. Dezember 2009 hatte sich mit der Vorbereitung dieser Konferenz sowie mit den Modalitäten der weiteren deutsch-iberischen Kooperation befaßt.

\section{Iberia Pontificia}

Die Kooperation des Projektes mit spanischen und mit portugiesischen Wissenschaftlern und Wissenschaftlerinnen wurde fortgesetzt (zu den regelmäßig stattfindenden Arbeitstreffen der Iberia-Mitarbeiter und der diesjährigen Konferenz vgl. auch oben unter 1. Arbeitsstelle Göttingen).

Diözese Burgos: Dank der Unterstützung durch das spanische Partnerprojekt „El Pontificado Romano: relaciones con el Noroeste Peninsular y bases documentales para su estudio hasta el año 1198“ konnte Herr Daniel Berger im Dezember 2009 eine dreiwöchige Archivreise nach Burgos und Madrid unternehmen, auf der die notwendigen Archiv- und Bibliotheksrecherchen (insbesondere in der Biblioteca Nacional in Madrid) zum Abschluß gebracht werden konnten. Das Regestencorpus hat sich durch diese Reise noch einmal auf nun insgesamt 219 Nummern erweitert; noch ausstehende Überlieferungsfragen konnten weitestgehend geklärt werden. Der Schwerpunkt der Bearbeitung lag im Berichtszeitraum auf der Abfassung der historischen Einleitungen zu den insgesamt 17 Lemmata des Bandes. Von diesen hat Herr Berger bis zum Ausscheiden aus dem Projekt im August 2010 die entsprechenden Texte für 15 Institutionen fertiggestellt. Ein Gesamtmanuskript des Bandes, das dank der kollegialen Unterstützung von Herrn Frank Engel bereits einmal Korrektur gelesen worden ist, wurde dem Sekretär übergeben. Eine Begutachtung nimmt seit September Herr Prof. Dr. Fernando López Alsina (Santiago de Compostela) vor; um eine weitere Durchsicht wurde parallel der Altsekretär gebeten. Die Abfassung der noch fehlenden Narrationes möchte Herr Berger als freier Mitarbeiter so bald wie möglich zu Ende führen, so daß der Band in absehbarer Zeit erscheinen kann. - Diözese Ávila: Herr Frank Engel hat im Berichtszeitraum die Auswertung von gedruckten Quellenwerken und Literatur mit Blick auf Papstkontakte in der Diözese Ávila fortgesetzt. Die Zahl der Regestenentwürfe zu diesem Bistum beläuft sich auf mittlerweile knapp 140. In vielen Fällen hat die Durchsicht von Publikationen Fehlanzeigen oder nur weitere Editionen und Regesten zu bekannten Urkunden erbracht, daneben jedoch zahlreiche „Extravaganten“ für andere iberische Bistümer und die geistlichen Ritterorden; ihre Zahl beträgt mittlerweile über 220 . Die Ausarbeitung und Kommentierung der zu Ávila gehörigen Regesten ist 
weit fortgeschritten. Von den historischen Einleitungen ist im wesentlichen noch die zum Lemma „Episcopatus“ zu erarbeiten, zu der jedoch ebenfalls bereits Konzepte vorliegen. Allerlei „Baustellen“ innerhalb des Manuskripts zum Regestenband resultieren aus den Schwierigkeiten bei der Literaturbeschaffung. Eine erste Interpretation der erarbeiteten Befunde, näherhin zur delegierten Gerichtsbarkeit in der Diözese Ávila, konnte Herr Engel im Rahmen der von den Mitarbeitern des Akademienprojekts mitorganisierten Tagung „Das begrenzte Papsttum“ vortragen (Lissabon, 09./10.07.2010). Im Rahmen des 6. Workshops „Historische Spanienforschung“ (Kochel am See) referierte er am 18. September 2010 über Stand und Perspektiven der Iberia Pontificia.

Auch in diesem Jahr standen die Transkriptionen der Aufzeichnungen aus den spanischen Archiven und Bibliotheken im Mittelpunkt der Tätigkeit von Herrn Thorsten Schlauwitz. Alle Faszikel sind nun transkribiert und von Hilfskräften korrigiert worden. Derzeit steht noch ein weiterer Korrekturgang durch Herrn Schlauwitz aus. Die Informationen aus den transkribierten Faszikeln sind in eine Datenbank eingegeben worden, einschließlich der Verweise auf die Signaturen in den jeweiligen Aufzeichnungen und auch - sofern vorhanden - auf die Archivsignaturen. Zudem wurde die Datenbank um die Funktion ergänzt, selbst erstellte Digitalisate von Editionen und Faksimiles aus spanischen Publikationen an die jeweiligen Datensätze anzuhängen. Dies soll einerseits als effizientes Hilfsmittel für die Mitarbeiter der Iberia Pontificia dienen, andererseits einen Überblick über die Qualität der bisher erschienenen Editionen verschaffen, um über eine Publikation der in den Aufzeichnungen vorhandenen Urkundentranskriptionen besser entscheiden zu können. Bisher wurden 565 Digitalisate zu 406 Papsturkunden aus Spanien erstellt und verlinkt. Zusätzlich ist eine Literaturdatenbank (Citavi) mit derzeit 786 Titeln angelegt worden, die ebenfalls den Mitarbeitern zur Verfügung steht.

\section{Polonia Pontificia}

Herr Waldemar Könighaus hat mit der Bearbeitung des Bandes „Polonia Pontificia" begonnen und sich dabei zunächst dem Bistum Breslau gewidmet. Es konnten bereits einige Vorarbeiten zum Bistum und zu den Stadtstiften St. Maria auf dem Sande der Augustiner-Chorherren und St. Vinzenz der Prämonstratenser geleistet werden. Während einer Archivund Bibliotheksreise nach Warschau im September 2010 sichtete Herr Könighaus die Papstprivilegien für das Bistum Leslau (Włocławek) und das Augustiner-Chorherrenstift Czerwińsk, u. a. wurden mehrere mittelalterliche und neuzeitliche Abschriften der päpstlichen Privilegien ermittelt. In 
der nächsten Zukunft sollen die Forschungen auf die Bistümer Krakau und Płock mit den innerhalb dieser Diözesen liegenden Klöstern ausgedehnt werden.

Bohemia-Moravia Pontificia

Im Berichtsjahr arbeitete Herr Könighaus die Ergänzungen und Korrekturen der Gutachter (Prof. Dr. Hiestand und Prof. Dr. Werner Maleczek, Wien) in das Manuskript der „Bohemia-Moravia“ ein und schloß den Band ab. Alle drucktechnischen Details wurden im Laufe des Sommers in mehreren Gesprächen mit dem Verlag Vandenhoeck \& Ruprecht geklärt, so daß Herr Könighaus im Sommer mit Hilfe des Programms „InDesign“ ein publizierbares Manuskript erstellen konnte. Inzwischen ist dieses Werk im Januar 2011 erschienen. Im Mai 2011 hat auch eine Buchpräsentation in Prag stattgefunden, in deren Rahmen der Band vorgestellt wurde. Des weiteren hielt Herr Könighaus im Juni 2010 in der Villa Vigoni bei der Konferenz „Die Ordnung der Kommunikation und die Kommunikation der Ordnungen im mittelalterlichen Europa. Zentralität: Papsttum und Orden im Europa des 12. und 13. Jahrhunderts“ zum Thema „Die Päpste und die Klöster Ostmitteleuropas“ einen Vortrag. Anfang September 2010 stellte Herr Könighaus das Projekt Bohemia-Moravia Pontificia im Rahmen der Konferenz „Pontes ad fontes“ in Brünn vor.

Neubearbeitung des Jaffé

Für die Erlanger Arbeitsstelle des Akademienprojektes haben Frau Judith Werner sowie die Herren Markus Schütz und (bis Ende Dezember 2009) Thorsten Schlauwitz die Arbeit an der 3. Auflage der „Regesta Pontificum Romanorum" fortgesetzt.

\section{Teilband 1: 33-844}

Für den ersten, bis zum Jahr 844 reichenden Band liegen die Regesten bis zum Jahr 604 manuskriptfertig vor. Die Regesten bis zum Jahr 844 befinden sich in der internen Korrektur. Bei der bibliographischen Überarbeitung der Regesten wurden fehlerhafte Verweise aus der zweiten Auflage des Jaffé und widersprüchliche Datierungen aus unterschiedlichen Regestenbänden korrigiert sowie neuere Editionen der an den Papst gerichteten Schreiben aufgenommen. Die Begutachtung des ersten Bandes ist für Ende 2010 vorgesehen.

Die bis jetzt fertiggestellten Regesten (gut 3.100 Stück) hat Herr Könighaus Korrektur gelesen. Weitere 190 Seiten bzw. ca. 1.250 Regesten liegen 
ihm zur Zeit zur Durchsicht vor; bis jetzt konnten davon alle Regesten bis zum Pontifikat Vigilius' (gut 900 Nummern) korrigiert werden.

II. Teilband 2: 844-1073

Im August 2009 begann Frau Werner die Arbeit am zweiten Teilband der Neubearbeitung des Jaffé, der die Jahre 844 bis 1073 umfaßt. Für die Zeiträume von 844 bis 858 (Sergius II. bis Benedikt III.), 911 bis 1024 (Anastasius III. bis Benedikt VIII.) und 1024 bis 1046 (Johannes XIX. bis Gregor VI.) liegen mit den „Regesta Imperii““-Teilbänden I 4,2 von Klaus Herbers (1999), II 5 von Harald Zimmermann (1998) und III 5 von Karl Augustin Frech (2006) bereits drei relativ aktuelle Regestenwerke vor, aus denen insgesamt ca. 2.050 Regesten in die Datenbank eingearbeitet werden konnten. Diese müssen teilweise noch um die lateinische Version des Kurzregests und des Sachkommentars ergänzt werden. Die umfassenden Literaturangaben der „Regesta Imperii“"-Bände wurden bereits auf die jeweils aktuellste kritische Edition und eventuelle Editionen bei Mansi, Migne oder in den Reihen der MGH reduziert. Auch für die Zeit von 858 bis 867 (Nikolaus I.) wird demnächst ein Teilband der „Regesta Imperii“ vorliegen, aus dem dann ca. 440 weitere Regesten in die Datenbank übernommen werden können.

Für die Jahre 867 bis 911 (Hadrian II. bis Sergius III.) wurden ca. 800 Regesten aus Jaffé/Ewald bzw. Jaffé/Löwenfeld sowie aus den beiden Editionsbänden der Papsturkunden von Harald Zimmermann (1984/85), die die Zeit von 896 bis 1046 abdecken, in die Datenbank eingearbeitet. Bei diesen, besonders für den Zeitraum von 867 bis 896, muß vor allem noch die aktuelle Literatur nachgetragen werden. Außerdem werden sich für diese Periode wohl noch weitere Regesten, vor allem Erwähnungen, ergeben. Ähnliches gilt für die Jahre 1046-1073 (Clemens II. bis Alexander II.), für die bereits ca. 220 Regesten in Rohfassung durch eine Hilfskraft in die Datenbank eingegeben wurden.

K. Herbers

\author{
Patristische Kommission (Arbeitsstelle Göttingen) \\ Leitungskommission: \\ Vorsitzender: Mühlenberg \\ Gemeinhardt (Göttingen), Nesselrath
}

Kontaktadresse: Friedländer Weg 11, 37085 Göttingen, Tel.: 05513894330, emuehle@gwdg.de (Prof. Dr. Mühlenberg) 
Arbeitsbericht: Unter dem Namen Dionysius Areopagita wurden Anfang des 6. Jahrhunderts griechische Schriften eines Christen verbreitet. Darin war souverän der Athener Neuplatonismus in christliches Denken integriert; jahrhundertelang diente dieses als Modell für Theologen und christliche Philosophen. Die Werke des „Dionysius“ werden auf der Basis der Überlieferung in mittelalterlichen Handschriften kritisch ediert.

Der erste Teilbereich des Vorhabens „Dionysius Areopagita“ ist die kritische Edition des „akkumulierten Dionysius Areopagita“ (Editorin: Prof. Dr. Beate R. Suchla). Für den Band der Begleitkommentare (Scholien) zu „De divinis nominibus“ wurde der griechische Text einschließlich der Apparate konstituiert. Die Praefatio ist erweitert worden, der Entwurf ist abgeschlossen. Die Korrekturdurchgänge werden fristgemäß bis Jahresende ausgeführt. Die technische Umsetzung zu einer digitalen Druckvorlage ist eine Mischung aus Glück, Konzentration und Geduld.

Der zweite Teilbereich betrifft im jetzigen Arbeitsschritt die kritische Edition der „Epistula ad Timotheum de morte apostolorum Petri et Pauli“ (Editoren: Prof. Dr. Beate R. Suchla/Dr. M. Muthreich). Die Arbeit konzentrierte sich auf die äthiopische Fassung. Deren Überlieferungsbestand in Handschriften ist festgehalten und durchgesehen worden. Es gibt mehrere Rezensionen, und bisher deutet alles darauf hin, daß die äthiopischen Texte direkt aus dem Griechischen (ohne koptische Vermittlung) übersetzt wurden. Es hat sich inzwischen ergeben, daß verschiedenartige Überlieferungsträger (Überlieferungsorte) unterschieden werden können: Das Schriftstück wird tradiert als Anhang zum Neuen Testament, im Kontext von Apostellegenden und in dogmatischen Florilegien.

Im dritten Teilbereich („Liber de haeresibus/Anakephalaiosis“. Editoren: Prof. Dr. Beate R. Suchla/Chr. Birkner) ist die Bestandsaufnahme der handschriftlichen Überlieferung vorerst abgeschlossen (ca. 1000 Handschriften). Nach ihrer Katalogisierung wurden die Handschriften geordnet; es sind mehrere Rezensionen festgestellt. Der Arbeitsschritt, Testimonien zu identifizieren, wurde begonnen.

Über die Forschungen, die sich an die Arbeiststelle „Patristik: Dionysius Areopagtita" angegliedert haben, kann wie folgt berichtet werden: Im Zusammenhang mit Forschungen zu den „Apophthegmata Patrum“ hat Frau Professor C. Faraggiana (Bologna/Ravenna) ein Dossier zu Makarios erarbeitet. Das Druckmanuskript ist revidiert worden; es erwiesen sich mehrere Streufunde den verschiedenen Überlieferungen unter dem Namen des Jesajas Monachos als so eng verwandt, daß Nachträge und Vergleiche nicht ausgeschlossen werden durften. 
Gregor von Nyssa, „De anima et resurrectione“: Unabgeschlossene Edition (Prof. Andreas Spira ${ }^{\dagger}$ 2004). Herr Dr. W. Brinker (Mainz) hat seinen Beitrag abgeschlossen. Alle diese die Edition betreffenden Materialien lagern jetzt in der hiesigen Arbeitsstelle.

E. Mühlenberg

Qumran-Wörterbuch

Leitungskommission:

Vorsitzender: Kratz

Lohse, Perlitt, Smend, Spieckermann

Kontaktadresse: Vereinigte Theologische Seminare, Platz der Göttinger Sieben 2, 37073 Göttingen, Tel.: 0551-39-7130, Fax 0551-39-2228, rkratz@gwdg.de (Prof. Dr. Kratz)

Arbeitsbericht: Das Unternehmen gilt den antiken Handschriften vom Toten Meer. Diese im vergangenen Jahrhundert in der Nähe der Ruinensiedlung Khirbeth Qumran entdeckten Überreste von rund 1000 meist hebräischen und aramäischen Manuskripten stammen aus der Zeit vom 3. Jh. v. Chr. bis zum 2. Jh. n. Chr. Bei den Texten handelt es sich um eine einzigartige Quelle für die Erforschung der Geschichte des antiken Judentums sowie des Alten Testaments und für den Entstehungshintergrund des Neuen Testaments. Die Aufgabe des Unternehmens besteht in der Erarbeitung eines philologischen Wörterbuchs, das den gesamten Wortschatz der nichtbiblischen Texte vom Toten Meer erfasst und das Material etymologisch, morphologisch sowie semantisch aufbereitet. Das Wörterbuch schließt damit die bisher kaum erforschte Lücke zwischen dem älteren biblischen und dem jüngeren rabbinischen Hebräisch und Aramäisch. Das wichtigste Arbeitsinstrument ist eine im Rahmen des Projekts speziell für die Bedürfnisse des Unternehmens entwickelte Datenbank. In ihr sind sämtliche Quellentexte, alle wichtigen in der Forschungsliteratur vorgeschlagenen, oft umstrittenen Lesungen der einzelnen Wörter sowie alle weiteren für das Wörterbuch relevanten Informationen (Editionen, Literatur, Zählungsabweichungen etc.) erfasst. Sämtliche Editionen der Texte werden gesichtet, abweichende Lesungen elektronisch registriert und die Eingabe dieser "Varianten " in einem separaten Arbeitsgang kontrolliert und gegebenenfalls korrigiert. Die Datenbank ist komplett aufgebaut und wird laufend aktualisiert. Eine Spezialbibliothek umfasst eine große Photosamm- 
lung der Handschriften und sämtliche Editionen der Texte vom Toten Meer und wird kontinuierlich um einschlägige Neuerscheinungen erweitert.

Von Mai 2002 bis Dezember 2005 wurde das Qumran-Wörterbuch als Langzeitprojekt von der DFG gefördert. Mit Beginn 2006 ist das Unternehmen in das Programm der Akademie der Wissenschaften zu Göttingen übergegangen und ist hier zusammen mit dem Septuaginta-Unternehmen und dem Editionsvorhaben SAPERE im Centrum Orbis Orientalis (CORO) angesiedelt.

Im Berichtsjahr 2010 wurde an der Abfassung von Wörterbuchartikeln im Bereich der Buchstaben aleph-zajin gearbeitet. Die philologische Voranalyse der aramäischen Belege ebenso wie die der Sirachbelege wurde begonnen bzw. weitergeführt und ist in beiden Fällen erfreulich fortgeschritten. Abgeschlossen werden konnte die Varianteneingabe/-korrektur zur umfangreichen Edition von Wacholder/Abegg. Die Aufnahme wertvoller Varianten aus der sogenannten "Zettelkonkordanz" ist inzwischen beim Buchstaben he angelangt. Varianten aktueller Neueditionen und Dissertationen, besonders auch aus Israel, wurden ebenso berücksichtigt. Die Zahl relevanter Qumran-Veröffentlichungen ist in den vergangenen Jahren stark angestiegen, und so nimmt die Bibliotheksarbeit einen zunehmend größeren Raum in der Projektarbeit ein. Die Qumran-Bücher aus der Bibliothek Stegemann (Schenkung durch Frau Prof. Dr. Ursula SpulerStegemann 2009) wurden integriert. Auf unterschiedlichen Ebenen wurde die Datenbank des Projekts ausgebaut. Sie verfügt nunmehr auch über ein erneuertes Indexsystem. Erweitert wurde die Datenbank auch im Blick auf ein von Dr. Noam Mizrahi an der Theologischen Fakultät in Göttingen durchgeführtes Projekt zu den biblischen Handschriften von Qumran (Beginn August 2010). Die sprachlichen Analysen von Dr. Mizrahi werden ebenfalls dem Wörterbuchprojekt zugute kommen, welches neben dem nichtbiblischen Bestand auch philologische Spezifika der biblischen Handschriften von Qumran berücksichtigt. Gemeinsam mit Dr. Noam Mizrahi und Dr. Philippe Hugo (Septuaginta-Unternehmen Göttingen/Fribourg) wurde für März 2011 im Rahmen des Graduierten-Kollegs „Gottesbilder Götterbilder - Weltbilder“ ein internationaler Workshop zum Thema „Bits and Bible - New Digital Approaches to Edit Biblical Texts" konzipiert und vorbereitet. Ziel des Workshops ist es, Grundlagenforschung am biblischen Text zukünftig international zu vernetzen. Die Datenbank des Lexikonprojekts besitzt dafür modellhaften Charakter. Aus Sondermitteln der Akademie konnte für den projektinternen Gebrauch mit dem Scannen der Microficheedition der Qumran-Handschriften begonnen werden, die - gerade in elektronischer Form - ein hervorragendes Arbeitsinstrument darstellt. Vor- 
bereitungen zu einer Neuedition der Damaskusschrift auf der Basis einer materiellen Rekonstruktion (H. Stegemann u.a.) als zukünftig maßgeblicher Edition für das Wörterbuch wurden vorangetrieben. Das Karl-Georg Kuhn-Archiv wurde fortgeführt. Untersuchungen an den Handschriftenoriginalen in Jerusalem trugen auch im Jahr 2010 zu einer Sicherung der Textgrundlage des Wörterbuchs und einem Ausbau der Arbeitskontakte an Ort und Stelle bei (École Biblique/Israel Museum/Hebrew University). Bestehende Verbindungen zu verschiedenen internationalen Forschungseinrichtungen wurden vertieft und neue angebahnt, z. B. zu den Universitäten Madrid (Prof. Dr. Pablo Torijano) sowie Toronto und Yale (Prof. Dr. Hindy Najman). Besuch erhielt das Projekt z.B. von Prof. Dr. Adrian Schenker (Fribourg) und Dr. Jonathan Norton (London). Die Datenbank des Projekts wurde auf dem Gesenius-Kongress in Halle (März 2010) und dem IOQS in Helsinki (August 2010) öffentlich vorgestellt. Das Projekt führte auch im Jahr 2010 regelmäßig Lehrveranstaltungen zu den Texten vom Toten Meer an der Theologischen Fakultät durch, darunter erstmals auch wieder eine Einführung in Qumran.

R.G. Kratz

\author{
Runische Schriftlichkeit in den germanischen Sprachen \\ Leitungskommission: \\ Vorsitzende: Marold (Kiel) \\ Bammesberger (Eichstätt), Heizmann, Henkel, Lenker (Eichstätt), Ronne- \\ berger-Sibold (Eichstätt)
}

Kontaktad resse: Akademieprojekt "RuneS", c/o Nordisches Institut der Cristian-Albrechts-Universität Kiel, Leibnizstraße 8, 24118 Kiel, Tel.:04318802563, Fax: 0431-880-3252, emarold@t-online.de (Prof. Dr. Marold), runenprojekt@nord-inst.uni-kiel.de

Arbeitsbericht: Ziel des Projekts ist eine umfassende Untersuchung und Darstellung runischer Schriftlichkeit, die bewusst die bisher eingehaltenen Grenzen der großen Gruppen der Schriftsysteme (älteres fupark, jüngeres fupark und anglo-friesisches fuporc) überschreitet und alle drei Systeme mit einheitlichen Methoden untersucht. Zwei Aspekte bilden die zentralen Fragestellungen, die jeweils einem Modul zugrundeliegen: 1. der mediale Aspekt mit seinem Fokus auf dem Verhältnis von Phonie und Graphie („Verschriftung" in Modul II) und 2. der konzeptionelle und funktionale Aspekt 
der Schriftlichkeit („Verschriftlichung“ in Modul III). In beiden Modulen wird neben der systematischen Untersuchung auch die Frage nach einem möglichen Einfluss der lateinischen Schriftlichkeit auf die Entstehung und Weiterentwicklung der runischen Schriftlichkeit gestellt werden. Eine weitere Frage wird sein, wie sich die doch lange andauernde Koexistenz beider Schriftsysteme gestaltet hat. Den beiden Forschungsschwerpunkten geht ein Modul voraus (Modul I), das die Basis der Untersuchungen bildet.

Ziel der Arbeiten in Modul I ist es, eine fundierte, einheitlich strukturierte Corpusgrundlage für die wissenschaftlichen Untersuchungen zur runischen Schriftlichkeit in den Modulen II und III zu schaffen. Ebenfalls in diesem Modul werden die Methoden der Untersuchung in den folgenden beiden Modulen (Graphematik und Pragmatik) präzisiert und erprobt. Als Ergebnis soll eine Datenbank vorliegen, die die Basisdaten der für die Untersuchungen in Modul II und III ausgewählten Inschriften enthält.

Auf der Basis der im Antrag formulierten Modulziele lässt sich das Arbeitsprogramm für Modul I nach folgenden Punkten gliedern:

- theoretisch-methodische Vorarbeiten in den Bereichen Graphematik und Pragmatik

- Entwicklung einer Datenbankstruktur und Aufbau der Datenbank

- Erstellung der Corpusgrundlage

Allgemeine Vorbemerkungen zu den einzelnen Punkten des Arbeitsprogramms:

Da die geplanten theoretisch-methodischen Vorarbeiten einen möglichst umfassenden, gleichzeitig aber auch detailgenauen Überblick über das zu untersuchende Material verlangen, lag der Schwerpunkt der Arbeiten in den Arbeitsstellen Eichstätt-München, Göttingen und Kiel im Jahr 2010 auf der Erstellung der Corpusgrundlage und damit 1. auf der Fortführung der in Arbeit befindlichen Editionen und 2. der Auswahl der Inschriften aus dem jüngeren fupark. Auch die beiden Projekttreffen im April/Mai und Oktober in Göttingen waren daher vornehmlich diesem Projektbereich gewidmet.

\section{Theoretisch-methodische Vorarbeiten in den Bereichen Graphematik und Prag- matik}

Die theoretisch-methodischen Vorarbeiten standen im Jahr 2010 vor allem im Zeichen der Graphematik. Neben einer ersten Sichtung der allgemeinen Forschungsliteratur im Bereich historische Graphematik brachte besonders die Tagung „LautSchriftSprache - ScriptandSound: The (Dis)ambiguity of the Grapheme“ wichtige Impulse für die geplanten Arbeiten. Durch 
die internationale und interdisziplinäre Ausrichtung der Tagung eröffnete sich die Möglichkeit, die geplante methodische Vorgehensweise im Untersuchungsmodul Graphematik mit Schrifthistorikern unterschiedlicher philologischer Fachdisziplinen zu diskutieren und so deren Erfahrungen aus ähnlichen, noch unpublizierten Forschungsvorhaben kennenzulernen. Außerdem zeigte sich in den Gesprächen, dass die Ergebnisse des Projekts „RuneS“ auch für die allgemeine Schriftforschung von Bedeutung sein werden. So dürfte etwa die Entwicklung einer stringenteren terminologischen Definition z. B. von Graph, Graphtyp, Allograph anhand der Runeninschriften auch für andere Projekte im Bereich der Schriftforschung von Interesse sein.

Weitere Vorarbeiten konzentrierten sich auf die Nutzung neuester technischer Methoden zur präziseren zeitlichen und räumlichen Erfassung des runischen Untersuchungsmaterials. Diese Arbeiten wurden von der Arbeitsstelle Eichstätt-München angeregt und begonnen und werden in Kooperation mit dem Lehrstuhl für Physische Geographie an der KU EichstättIngolstadt vorbereitet.

Es ist geplant, die im Rahmen der physischen Geographie entwickelten neuesten technischen Möglichkeiten zu erproben, um die Runeninschriften genauer als bisher zeitlich einordnen und damit auch graphematische Entwicklungen besser nachvollziehen zu können. Als erstes Versuchsobjekt für den Einsatz eines solchen Gerätes diente die von der Datierung her höchst umstrittene Runeninschrift im Kleinen Schulerloch nahe Eichstätt (Essing, bei Kelheim). Dabei wurde ein am Lehrstuhl für Physische Geographie (Prof. Dr. Michael Becht, Dipl.-Geogr. Christian Breitung) an der KU Eichstätt-Ingolstadt vorhandenes spezielles Messgerät (terrestrischer 3D Laserscanner) eingesetzt, um möglicherweise Aufschluss über das Alter dieser Inschrift zu erhalten. Nachdem sich bei einer Versuchsmessung im Juli 2010 herausgestellt hat, dass dieses Gerät für solch feine Ritzungen aufgrund der Breite des Laserstrahls nicht geeignet ist, ist geplant, bei einer weiteren Exkursion nächstes Frühjahr Aufnahmen mit einer speziellen Digitalkamera zu machen und diese mit der photogrammetrischen Software LEICA PHOTOGRAMMETRY SUITE auszuwerten. Beides ist am Lehrstuhl für Physische Geographie vorhanden und kann vom Projekt „RuneS“ genutzt werden.

Ebenfalls mit Unterstützung des Lehrstuhls für Physische Geographie ist mit den Vorbereitungen für die Erstellung von digitalen georeferenzierten Karten (d. h. Karten mit Längen- und mit Breitengraden), in die Daten eingetragen werden können, begonnen worden. Auf diesen können die Objekte nach verschiedenen Parametern getrennt oder in Kom- 
bination (auch mit Animationseffekten) verzeichnet werden: Fundorte, Datierung, Dialektgebiete, Grenzen der Verwaltungsgebiete im Mittelalter, Graphtypen etc. Die Karten werden auf bereits vorhandenen Karten von G. Waxenberger basieren; die neuen Karten werden jedoch georeferenziert sein, damit die Fundstellen nach Koordinaten eingetragen werden können. So lässt sich etwa die zeitliche und geographische Staffelung von bestimmten Typen einzelner Runen noch genauer sichtbar machen, was für das zweite Modul „Runische Graphematik“ von großer Bedeutung sein wird. Die Konzeption der gewünschten Karten wurde in Kooperation mit dem Lehrstuhl für physische Geographie erarbeitet. Anfragen bei verschiedenen britischen Organisationen ergaben, dass auf der Website der Ordnance Survey //www.ordnancesurvey.co.uk/ entsprechende Karten zur Verfügung stehen, auf denen verschiedene Parameter nach Bedarf sichtbar gemacht bzw. ausgeschaltet werden können. Nun müssen zunächst die technischen Voraussetzungen für die Bearbeitung dieser Karten geschaffen werden (GIS Software), um dann mit der Einfügung unserer Daten beginnen zu können.

\section{Entwicklung einer Datenbankstruktur und Aufbau der Datenbank}

Bei der Entwicklung der Datenbankstruktur wird auf die Erfahrungen des von der DFG geförderten Kieler Runenprojekts zurückgegriffen. Dort wurde eine relationale Datenbank konzipiert, die Informationen zu unterschiedlichen Aspekten des runischen Objekts in verschiedenen Einzeldateien bündelt (zu Inschriftobjekt, Lesung und Deutung, sprachlichen Charakteristika und zur Sekundärliteratur) und über ein relationales Verknüpfungssystem vielfältig aufeinander beziehbar macht. So können z. B. Wortformen, die in mehreren runischen Texten belegt sind, nur einmal erfasst und linguistisch beschrieben, dieser Datensatz jedoch zu mehreren Objekten/Inschriften in Bezug gesetzt werden. Auf diese Weise bleiben die Einzeldateien überschaubar, und Doppeleingaben werden vermieden. Die Anlage einer relationalen Datenbank ermöglicht somit ein grundsätzlich effizienteres Arbeiten, was vor dem Hintergrund der Bearbeitung großer Datenmengen besonders plausibel erscheint. Im Rahmen der Projektarbeiten wird zur Zeit erprobt, in welchem Umfang die Kieler Struktur auf die vorliegenden Belange und Fragestellungen übertragen werden kann. Analog zu obigem Beispiel aus der Kieler Datenbank scheint das Konzept im Hinblick auf formelhafte Textelemente direkt übertragbar. Auch identische Graphtypen aus einer Vielzahl unterschiedlicher Inschriften ließen sich durch eine relational strukturierte Erfassung effizienter abbilden, da nicht bei jeder Inschrift die Informationen neu eingegeben, sondern 
lediglich eine neue Verknüpfung zu einer potentiellen Datei „Graphtypen“ erstellt werden müsste. Ob dagegen die Fortführung einer Dateidifferenzierung zwischen Inschriftobjekt und Lesung/Deutung für den vorliegenden Rahmen übernommen wird, werden erst kommende Erprobungen zeigen müssen.

Einen weiteren Aspekt der Datenbankkonzeption stellt die praktische Umsetzung in Form eines vernetzten, Web-basierten Arbeitens dar. Hier sind verschiedene Modelle vorstellbar, deren möglicher Umsetzung jedoch erst im kommenden Jahr eingehender nachgegangen werden kann. Vor allem wird dabei dazu zu klären sein, wo diese Datenbank basiert sein und von wem sie betreut werden soll. Dies hängt nicht zuletzt vom Ausbau der Möglichkeiten in der Akademie Göttingen ab. Mit dem Aufbau der Datenbank wird nach der Klärung dieser grundsätzlichen Fragen 2011 begonnen werden.

\section{Erstellung der Corpusgrundlage}

Grundsätzliches zur gemeinsamen Vorgehensweise: Bei den beiden Arbeitstreffen in Göttingen wurde ein gemeinsamer editorischer Leitfaden erarbeitet, der den noch im Entstehen begriffenen Editionen eine vergleichbare Grundstruktur geben soll. Die dabei vereinbarten Editionsprinzipien umfassen folgende Punkte:

- Die Editionen präsentieren ihr Material in Form von einzelnen Editionsartikeln.

- Die Editionsartikel fußen auf dem von K. Düwel und H. Roth in einem Beitrag in „Nytt om runer“ (1986, 18ff.) entworfenen Aufbauschema. Den ersten Teil der Editionstexte bilden grundsätzlich die Informationen und Daten zum Inschriftenträger selbst: Hierunter fallen die Objektbeschreibung, die Fundkategorie und der archäologische Fundzusammenhang bzw. die Fundgeschichte des Objekts. Ergänzt werden diese Daten um Aussagen zu Verbreitung, Funktion und Zeitstellung des Inschriftenträgers. Der folgende runologische Teil umfasst die Beschreibung der Inschrift nach Autopsie (wenn möglich) sowie deren Lesung und Deutung, einen sprachwissenschaftlichen Kommentar sowie eine typologische Einordnung und Funktionszuordnung der Inschrift. Beide Editionsteile münden idealerweise in eine Gesamtinterpretation des runischen Objekts. In zahlreichen Fällen wird es allerdings nicht möglich sein, rivalisierende Lesungen und die darauf aufbauenden Deutungen zu einer abschließenden Gesamtinterpretation zusammenzuführen, hier müssen die Lese- und die Deutungsvarianten bestehen bleiben. 
- Zur Verbesserung der Benutzerfreundlichkeit der Editionen werden alle Editionsartikel einleitende Kurzskizzen („Steckbriefe“) enthalten. Diese werden - wenn möglich - auch bereits eine Abbildung des Objekts/der Inschrift bieten.

- Ein noch in Teilen neu zu entwerfendes Siglensystem wird die Verweise innerhalb und unter den einzelnen Editionen erleichtern.

- Auch terminologisch wird auf möglichst große Vergleichbarkeit geachtet werden.

\section{Gemeinsame Arbeitsprozesse im Berichtsjahr 2010}

Die editorische Arbeit umfasste im Jahr 2010 an allen Arbeitsstellen folgende Punkte:

- inhaltliche, formale und sprachliche Überarbeitung bestehender Editionstexte,

- Einarbeitung der auf den Projekttreffen in Göttingen gemeinsam erarbeiteten Vorgaben struktureller Art (Reihenfolge der Datenpräsentation, Nummerierung, einleitender Objektsteckbrief s.o.),

- Autopsie und Dokumentation von Neufunden bzw. Sichtung von neuem Material zu Altfunden, die in die Editionen eingehen.

\section{Arbeitsschritte und Stand der Arbeiten im Einzelnen}

Die Arbeit an den einzelnen Arbeitsstellen stellte sich im Einzelnen wie folgt dar:

Arbeitsstelle Eichstätt-München

Die Corpusgrundlage wurde aktualisiert durch:

- die Aufteilung des Corpus in zwei Subkorpora (Pre-Old English, Old English). Im Berichtsjahr 2010 wurden vor allem die Editionstexte für das Subkorpus der frühen Inschriften im Hinblick auf eine gesonderte Editionseinheit bearbeitet.

- die Einarbeitung u.a. der Ergebnisse zweier Autopsiereisen, die z.T. zu neuen oder zu revidierten Lesungen geführt haben: 1) Autopsiereise im September 2010: Objekte im British Museum (London), Ruthwell Cross, Bewcastle Cross, Lindisfarne Stones, Whitby Comb; 2) Autopsiereise im November 2010 (Norwich Castle Museum): Caistorby-Norwich/Harford Farm Brooch, Caistor-by-Norwich Astragalus, Heacham Tweezers. Bei den Autopsiereisen wurden alle Objekte sowohl neu fotografiert als auch erstmals per Videokamera dokumentiert; das Ruthwell Cross, die umfangreichste Inschrift, wurde auf diese Weise 
fortlaufend kommentiert, so dass der derzeitige Zustand jeder einzelnen Rune nicht nur visuell, sondern ergänzend auch sprachlich festgehalten ist. Die Objekte in Norwich wurden darüber hinaus gezeichnet und vermessen. Zusätzlich wurden einige Abbildungen vom Norwich Castle Museum zur Verfügung gestellt. Das gesamte Dokumentationsmaterial wurde in ein neu erstelltes digitales Archiv aufgenommen; mit der Auswertung ist begonnen worden.

- die Aufnahme von Neufunden der letzten Jahre ins Corpus: Die zunehmende Suche mit Metalldetektoren hat auch einige Funde mit runischen Texten zutage gefördert. Diese Funde sind exzeptionell im Hinblick auf Material (Bleiplättchen), Runen (altenglische und skandinavische Runen) und Sprache (u. a. Latein). Auf der Autopsiereise im November 2010 (Norwich Castle Museum) wurden verschiedene Bleiplättchen untersucht und die relevanten Daten erfasst: Shropham, St. Benet, March-Gegend, Baconsthorpe Bookmark/Tweezers. Diese Neufunde dürften die altenglische Runenreihe in ihren dialektalen Ausprägungen sowie das Subcorpus der merzischen Texte in neuem Licht erscheinen lassen. Die Autopsiedaten werden derzeit im Hinblick auf Graphem und Phonem ausgewertet. In Verbindung mit den zu erwartenden neuen Erkenntnissen durch die Neufunde von Norfolk wurde ein entsprechendes Dissertationsthema vergeben: „Das merzische Subkorpus im Lichte der Neufunde von Norfolk" (Betreuung durch G. Waxenberger).

- Arbeiten an der Gesamtbibliographie (student. Hilfskraft).

Bei den Autopsiereisen konnten bestehende Kooperationen ausgebaut und neue aufgebaut werden: 1) Die bestehende Kooperation mit der Kunsthistorikerin Leslie Webster, früher tätig als Keeper, Department of Prehistory and Europe am British Museum (London), wurde über deren Pensionierung hinaus verlängert. 2) Die Kooperation mit dem Department for Prehistory and Europe im British Museum, jetzt unter Leitung von Dr. Sonja Marzinzik, wurde wiederaufgenommen. 3) Mit dem Curator of Archaeology, Norwich Castle Museum and Art Gallery, Dr. Tim Pestell, wurde eine längerfristige Kooperation vereinbart; eine weitere Reise nach Norwich ist für Sommer 2011 bereits geplant. 4) Eine Kooperation mit Susan Harrison, Curator (Collections), North Territory, English Heritage in Bezug auf die Lindisfarne-Steine ist vereinbart worden. 5) Im Zusammenhang mit den Lindisfarne-Steinen steht auch Christine Maddern, die ihre Doktorarbeit über die Grabsteine in Northumbria geschrieben hat: Christine Maddern [forthcoming], „Raising the Dead: Early Medieval Name Stones in Northumbria“. Auch mit ihr ist eine Kooperation geplant. 
Der Stand der Arbeiten präsentiert sich nach dem Berichtsjahr 2010 wie folgt:

1) Altenglisches Corpus

- ca. $20 \%$ fertige Editionstexte

- ca. 60\% Editionstexte vorhanden, in verschiedenen Stadien der Aktualisierung

- ca. 20\% noch zu schreibende Editionstexte (Neufunde)

2) Friesisches und skandinavisches Corpus, Manuskriptrunen

- Das friesische Corpus ist durch die Dissertation von Concetta Giliberto (1997), „Le iscrizioni runiche sullo sfondo della cultura frisone altomedievale“, Diss. Palermo, ediert und wird daher nicht erneut in Buchform ediert, sondern für die Projektarbeit in den folgenden Modulen II und III in die Datenbank aufgenommen.

- Dies gilt auch für die skandinavischen Runen in Großbritannien, für die ebenfalls bereits Editionen vorliegen (vgl. Antragstext: Stand der Forschung).

- Die englischen Manuskriptrunen werden in die Datenbank aufgenommen. Da Derolez (1954) veraltet ist, wurde mit der Sammlung der Daten beim „Linguarum Vett. Septentrionalium Thesaurus Grammatico-Criticus et Archaeologicus“ von George Hickes (Oxford 1703-5) begonnen.

Arbeitsstelle Göttingen

1. Neuedition der südgermanischen Inschriften

Die Corpusgrundlage wurde aktualisiert und erweitert durch:

- Einarbeitung u. a. der Ergebnisse einer Autopsiereise nach Köln und Bad Honnef: K. Düwel hat in Köln die Inschrift von Bad Ems autopsiert anlässlich eines Treffens mit P. Pieper, zu dem auch D. Steinmetz mit der Beuchter Fibel aus Wolfenbüttel stieß. Im Anschluss daran nimmt K. Düwel den Nachlass von H. Arntz in Bad Honnef in Augenschein, vor allem um Photos und Diapositive zu erhalten, die, da sie bedeutenden Aufschluss über den ältesten Zustand der Runen geben können, hier digitalisiert werden sollen.

- Erstellung einer Materialsammlung zum Phänomen der paraschriftlichen (runenähnlichen und/oder runenbegleitenden) Zeichen. Diese umfasst momentan etwa 50 Objekte. Diese Objekte stammen vorwiegend aus dem Zeithorizont der südgermanischen Runeninschriften. Auch jüngere und ältere Stücke wurden berücksichtigt. In diesem Zusammenhang fanden Arbeitstreffen mit den Kollegen F. Stein (Saarbrücken) und J. Precht 
(Verden) statt, bei denen neues Material autopsiert werden konnte. Ferner war die Auswertung des Nachlasses von Wolfgang Krause aufschlussreich.

- Digitalisierung von Bildmaterial für die Edition (student. Hilfskraft).

Der Stand der Arbeiten präsentiert sich nach dem Berichtsjahr 2010 wie folgt: Grundsätzlich soll die Edition unter Mitarbeit von F. Siegmund (Basel, Archäologie), R. Nedoma (Wien, Namenkunde), P. Pieper (Düsseldorf, Autopsien) entstehen. Bei Arbeitstreffen wurden die nähere Zusammenarbeit und die dabei geltenden Editionsprinzipien (s.o.) besprochen. Vom runologischen Standpunkt aus wurde die Edition folgender Funde abgeschlossen: Aalen, Aquincum, Aschheim I-III, Bad Ems, Bad Krozingen, Beuchte, Bezenye und Herbrechtingen. Für Aalen, Bad Krozingen und Beuchte liegen auch die archäologischen Partien von F. Siegmund vor, desgleichen Herbrechtingen von S. Oehrl. Von R. Nedoma konnte vorerst nur Aalen fertiggestellt werden; die übrigen namenkundlichen Beiträge zu den oben genannten Inschriften werden zum Ende des Jahres vorliegen. Epigraphische und pragmatische Aspekte wurden durch detaillierte Beschreibungen der Runenzeichen und durch die Erörterung der Funktion der Inschriften berücksichtigt.

\section{Edition der Runica Manuscripta}

Im Zentrum der Arbeiten standen die Erstellung und Aktualisierung der Corpusgrundlage:

In einem ersten Arbeitsschritt wurden die Vorarbeiten von Heizmann und Bauer (vgl. Antragstext: Stand der Forschung) zusammengeführt. Dabei wurden insgesamt 115 Handschriften berücksichtigt. Aufgrund der Verschiedenheit des Handschriftenmaterials - bei Bauer überwiegend nachmittelalterliche Handschriften - erwies sich eine Neustrukturierung des Materials als zwingend notwendig. Da graphematische Gesichtspunkte bei den Vorarbeiten kaum Berücksichtigung fanden, wird es in einem nächsten Schritt vonnöten sein, das bisher berücksichtigte Material neu zu sichten und um das Thema Graphematik zu ergänzen. Für einzelne Handschriften wurde diese Arbeit begonnen. Ebenfalls begonnen wurde die Recherche zu dem runologischen Material in dänischen und in schwedischen Handschriften. Zu diesem Bereich gibt es bislang kaum Forschungen, und es zeigt sich weiter, dass die Hilfsmittel vielfach ungenügend sind. Es wird daher in mehreren Fällen unumgänglich sein, Bibliotheksrecherchen an Ort und Stelle durchzuführen. Diese Arbeiten sollen im Rahmen der Doktorandenstelle erfolgen, die ab dem Frühjahr 2011 für Göttingen vorgesehen ist. Über den Umfang dieses Materials besteht derzeit noch keine fundierte 
Vorstellung. Die bisherigen Recherchen lassen aber vermuten, dass dieses Material nicht wirklich ergiebig ist.

Nicht in dieses Editionsprojekt einbezogen sind die Zeugnisse einer ersten „wissenschaftlichen“ Beschäftigung mit Runen, die von verschiedenen Isländern seit dem 17. Jahrhundert stammen und nur in handschriftlicher Überlieferung erhalten sind. Der in vielerlei Hinsicht wichtigste dieser Texte - weil sonst verlorenes mittelalterliches Handschriftenmaterial berücksichtigend - von Jón Ólafsson, die berühmte „Runologia“, wird jedoch als eigenes Projekt von Bauer und Heizmann ediert. Die Abschrift des Autographen wird noch vor Jahresende abgeschlossen sein.

\section{Arbeitsstelle Kiel}

Die Corpusgrundlage für die Inschriften im älteren und im jüngeren fupark wurde aktualisiert und erweitert durch:

- die Aufnahme und Auswertung von Lesungen und Deutungen zu den Inschriften im älteren fupark aus Forschungspublikationen des Zeitraums 1900-1950. Die Daten wurden direkt in die im Rahmen des DFG-Projekts angelegte Access-Datenbank eingegeben und sind so für den Aufbau der neuen Datenbank bereits digital verfügbar.

- die Aufnahme und Auswertung von Neufunden der letzten beiden Jahre: Hier ist allen voran der Stein von Hogganvik zu nennen, der im Herbst 2009 in Vest-Adger, Süd-West-Norwegen, entdeckt wurde und mit seiner Inschrift zu den längsten bislang vorliegenden Inschriften des älteren fupark zählt. Neben typischen graphemischen, textuellen und lexikalischen Merkmalen zeigt die Inschrift auch interessante Besonderheiten (Doppelschreibung identischer Schriftzeichen), die neben den Runenformen selbst eine interessante Grundlage für die Untersuchungen des zweiten und des dritten Forschungsmoduls darstellen werden. Auf Grund der graphemischen und der sprachlichen Merkmale wird die Inschrift zurzeit in den Zeitraum 350-500 n. Chr. datiert. Ebenfalls mit Schriftzeichen des älteren fupark versehen sind zwei neue Fibeln aus Lauchheim (Baden-Württemberg), deren Beschriftung im Rahmen der jüngsten Auswertungen des Fundmaterials aus den Grabungen der Jahre 1986-2005 zutage trat. Beide Objekte wurden im Rahmen des Treffens der Feldrunologen im April 2010 in Schloss Gottorf, Schleswig autopsiert und die Ergebnisse aufgenommen.

- die Autopsie eines Großteils der Objekte aus Haithabu und Schleswig (jüngeres fupark), die im Rahmen des Treffens der Feldrunologen in Schleswig durchgeführt wurde. 
- Die systematische Recherche und das Einsammeln von Bildmaterial zu einem Teil der im Corpus enthaltenen Objekte.

Auswahl aus den Inschriften im jüngeren fupark

- Hinsichtlich des Corpus der zu bearbeitenden Inschriften wurde im Antrag bereits darauf hinweisen, dass hier eine Auswahl getroffen werden muss. Im Berichtszeitraum 2010 wurde ein Kriterienkatalog erarbeitet, der als Grundlage dieser Auswahl dienen könnte. Folgende Kriterien wurden dabei in Betracht gezogen: 1) die zur Verfügung stehenden Editionen und ihre wissenschaftliche Brauchbarkeit, 2) bereits vorliegende Forschungsergebnisse zu Teilaspekten und 3) die zu bearbeitenden Fragestellungen.

- Angestrebt wird eine grundsätzlich repräsentative Auswahl, die zeitliche, räumliche, funktionale und traditionsgeschichtliche Kriterien berücksichtigt: 1) zeitliche Dimension: Da in der Länge des Zeitraums, in dem Inschriften im jüngeren fupark überliefert sind, nicht von einer homogenen Kommunikationskultur ausgegangen werden kann, muss die Auswahl exemplarisch ältere und jüngere Zeitabschnitte berücksichtigen. 2) räumliche Dimension: Das jüngere fupark wird in einem sehr weiten geographischen Raum verwendet, der in etwa dem der wikingischen Ausdehnung entspricht. Es ist zu erwarten, dass auch hier keine Homogenität der Schriftkultur vorausgesetzt werden kann. Der nordatlantische Raum (wikingerzeitliche Kolonien) bietet sich für Untersuchungen im Bereich von kulturellen Entwicklungen an, in denen isolierte Tradition und durch Kulturkontakte entstandene Variation gegeneinander stehen. In den skandinavischen Kernländern, in denen sich in diesem Zeitraum die Ländergrenzen und die Einzelsprachen etablierten, wäre zu untersuchen, ob auch die Schriftlichkeit diesen Entwicklungen folgt oder regional bestimmt bleibt. 3) funktionale Kriterien: Die Funktion der Runenschrift ändert sich im Bereich des jüngeren fupark erheblich. Bestehende Schrifttraditionen ändern sich (z. B. die Memorialinschriften), neue Räume der Schriftlichkeit treten in Erscheinung (z. B. in den Alltagsinschriften der Stadtkultur). 4) Ein weiteres Kriterium für die Auswahl wird der Blick auf die Nachbartraditionen (älteres fupark, anglo-friesische Inschriften) ergeben, so dass der gewünschte Vergleich erfolgen und mögliche Bezüge aufgezeigt werden können.

E. Marold 
Sanskrit-Wörterbuch der buddhistischen Texte aus den Turfan-Funden und der kanonischen Literatur der Sarvāstivāda-Schule

Leitungskommission:

Vorsitzender: Hartmann (München)

Job (Göttingen), Laut, Oberlies, Röhrborn, Schmithausen (Hamburg), von Simson

Kontaktadresse: Am Reinsgraben 4, 37085 Göttingen, Tel.: 055158125, Fax 0551-43173, swtf@gwdg.de (Dr. Chung), http://swtf.adwgoettingen.gwdg.de/

Arbeitsbericht: In Ruinenstätten und verlassenen Höhlenklöstern entlang der nördlichen der beiden alten "Seidenstraßen“ in Ostturkistan, der heute zur Volksrepublik China gehörenden Provinz Xinjiang, wurden in den letzten beiden Jahrzehnten des 19. und in den ersten Jahrzehnten des 20. Jahrhunderts von Expeditionen aus verschiedenen Ländern, darunter auch vier deutschen Expeditionen (1902-1914), archäologische Grabungen durchgeführt. Dabei wurde eine große Anzahl von Manuskripten in vielen verschiedenen Sprachen, zu einem erheblichen Teil in Sanskrit, der klassischen Kultursprache Indiens, entdeckt. Ein großer Teil dieser Handschriften gelangte in die nach einem der Hauptfundorte benannte „Turfan“Sammlung in Berlin. Wie sich bei der Bearbeitung der Handschriften herausstellte, gehören die Texte überwiegend zum Kanon der Sarvāstivādin, einer buddhistischen Schule des „Hīnayāna“, die vom Nordwesten Indiens aus entscheidend zur Ausbreitung des Buddhismus in Zentral- und in Ostasien beigetragen hat. Inzwischen wurden viele der Texte editiert und zum Teil auch übersetzt. Die Katalogisierung der Sanskrithandschriften dieser Sammlung ist ein ebenfalls in Göttingen ansässiges Projekt der Akademie der Wissenschaften (Katalogisierung der orientalischen Handschriften in Deutschland: Sanskrithandschriften aus den Turfanfunden).

Das in der Göttinger Arbeitsstelle entstehende „Sanskrit-Wörterbuch der buddhistischen Texte aus den Turfan-Funden" (SWTF) ist ein zweisprachiges (Sanskrit-Deutsch) Wörterbuch, das die lexikographische Erschließung dieser in zentralasiatischen Handschriften überlieferten buddhistischen Sanskrit-Literatur zum Ziel hat. Durch die Ausführlichkeit der Zitate sowie die bis auf wenige, klar definierte Ausnahmen vollständige Aufnahme von Wortschatz und Belegstellen der ausgewerteten Texte erhält das Wörterbuch sowohl den Charakter einer speziellen Konkordanz wie auch den einer allgemeinen Phraseologie des buddhistischen Sanskrits der kanonischen Sarvāstivāda-Texte. Die im Wörterbuch berücksichtig- 
ten Texte dürften einen Großteil der gängigen Phrasen des buddhistischen Sanskrits enthalten. In den maßgeblichen Wörterbüchern des klassischen Sanskrits von O. Böthlingk und R. Roth (erschienen 1855-1875 und 1879-1889) und M. Monier-Williams (erschienen 1899) ist buddhistisches Textmaterial nur sehr spärlich vertreten; dasselbe gilt auch für andere Sanskrit-Wörterbücher. Das Wörterbuch des „Buddhist Hybrid Sanskrit“ von F. Edgerton (erschienen 1953) beschränkt sich auf einen Teil des Wortschatzes der buddhistischen Sanskritliteratur unter dem Gesichtspunkt der Laut- und der Formenlehre und berücksichtigt vornehmlich Abweichungen vom klassischen Sanskrit. Darüber hinaus waren zur Zeit der Veröffentlichung dieser Wörterbücher die im SWTF erfaßten Texte größtenteils noch nicht zugänglich. Daher leistet das SWTF einen bedeutsamen Beitrag zur indischen Lexikographie.

Das Projekt wird als Vorhaben der Akademie der Wissenschaften zu Göttingen im Rahmen des Akademienprogramms von der Bundesrepublik Deutschland und vom Land Niedersachsen gefördert; die Veröffentlichung steht unter dem Patronat der Union Académique Internationale, Brüssel.

Die 22. Lieferung des Wörterbuchs (= Band IV, 2; Wortstrecke: varnavāditā bis veștita) ist im Berichtszeitraum vom Verlag ausgeliefert worden. Die 23. Lieferung (= Band IV, 3; Wortstrecke: vesțita-śiras bis șas) wurde planmäßig in der zweiten Jahreshälfte 2010 zur Kalkulation und zum Druck gegeben und ist Anfang des Jahres 2011 vom Verlag ausgeliefert worden. Die Arbeiten an der 24. Lieferung (sas bis su-hrt) sind so weit gediehen, daß diese Lieferung wie geplant im Jahr 2011 in Druck gehen wird.

Th. Oberlies

\section{Veröffentlichungen:}

Sanskrit-Wörterbuch der buddhistischen Texte aus den Turfan-Funden und der kanonischen Literatur der Sarvāstivāda- Schule. Begonnen von Ernst Waldschmidt. Hrsg. von Jens-Uwe Hartmann. 22. Lieferung: varna-vāditā bis veștita. Vandenhoeck \& Ruprecht, Göttingen 2010. 80 S., ISBN 978-3-525-26170-5. 


\section{SAPERE}

Leitungskommission:

Vorsitzender: Nesselrath

Berner (Bayreuth), Borg (Exeter/UK), Feldmeier, Forschner (Erlangen), Gall (Bonn), Hirsch-Luipold (Göttingen), Kratz, G. A. Lehmann, Opsomer (Bonn)

Kontaktadresse: SAPERE-Arbeitsstelle, Friedländer Weg 11, 37085 Göttingen, Tel.: 0551-3818312, Christian.Zgoll@phil.uni-goettingen.de (Dr. Zgoll)

Arbeitsbericht: Das Forschungsprojekt SAPERE (Scripta Antiquitatis Posterioris ad Ethicam REligionemque pertinentia = Schriften der späteren Antike zu ethischen und religiösen Fragen), das seit Anfang 2009 von der Göttinger Akademie betreut wird, hat es sich zur Aufgabe gemacht, griechische und lateinische Texte der späteren Antike, die eine besondere Bedeutung für die Religions-, Philosophie- und Kulturgeschichte haben, vor dem Vergessen zu bewahren. Insgesamt wurden 24 Werke, die sich mit Fragen von bleibender Aktualität beschäftigen, für das Akademieprojekt ausgewählt. Die Texte sollen dabei so erschlossen werden, dass sie über enge Fachgrenzen hinaus einer interessierten Öffentlichkeit wieder zugänglich gemacht werden: Im Zentrum jedes Bandes steht eine Schrift im griechischen oder lateinischen Original mit einer gut lesbaren und zugleich möglichst genauen deutschen oder englischen Übersetzung. Einleitend werden der Autor und die Schrift selbst vorgestellt; für ein besseres Verständnis des Textes vor dem Hintergrund seiner Zeit sorgen zahlreiche Anmerkungen. Das eigentlich Innovative des Editionsprojektes besteht in der fachübergreifenden Bearbeitung: An jedem Band sind Fachleute aus verschiedenen Disziplinen beteiligt - aus Theologie, Religionswissenschaften, Geschichte, Archäologie, älteren und neueren Philologien -, die wichtige Aspekte des Werkes aus der Perspektive ihres Faches in Essays erläutern. Dabei geht es immer auch um die gegenwärtige Bedeutung des Werkes für Forschung und Gesellschaft.

Im Jahr 2010 hat die SAPERE-Arbeitsstelle ihre kontinuierliche Arbeit an der Betreuung neuer Bandprojekte und an der Drucklegung abgeschlossener Bände tatkräftig fortgesetzt. Drucklegungsarbeiten wurden im ersten Halbjahr $2010 \mathrm{zu}$ dem Band 17 („Polis - Freundschaft - Jenseitsstrafen. Synesios von Kyrene, Briefe an und über Johannes") durchgeführt; der Band ist im September 2010 erschienen. Zu folgenden geplanten Bänden wurden Konzeptionen erarbeitet (oder weiterentwickelt) und Mitarbeiter 
gewonnen: Band 20 („Ps.-Platon, Über den Tod (Axiochos)“), Band 21 („Ps.-Aristoteles, De mundo“), Band 23 („Synesios von Kyrene, Aigyptioi Logoi“), Band 24 („Das Buch der Weisheit/Sapientia Salomonis“), Band 25 („Armut - Arbeit - Menschenwürde: Dion von Prusa, Euböische Rede"), Band 27 („Diog. Laert IX 61-116: Das Leben Pyrrhons“), Band 28 („Alexander von Lykopolis, De placitis Manichaeorum").

Die SAPERE-Arbeitsstelle hat ferner in der zweiten Jahreshälfte 2010 zwei Tagungen organisiert und durchgeführt: die Jahrestagung 2010 zusammen mit dem Wissenschaftlichen Beirat von SAPERE am 20. und am 21. August sowie ein Fachkolloquium zu dem Band „Für Religionsfreiheit, Recht und Toleranz. Libanios' Rede Für den Erhalt der heidnischen Tempel“, dessen Erscheinen für das Jahr 2011 vorgesehen ist, am 15. und am 16. November. Zu beiden Tagungen s. Genaueres unter „Sonstige Veranstaltungen“, Seite 454 und Seite 467.

H.-G. Nesselrath

Veröffentlichungen:

Plutarch, On the daimonion of Socrates: Human liberation, divine guidance and philosophy: Der Philosoph und sein Bild (SAPERE XVI), edited by Heinz-Günther Nesselrath; Introduction, Text, Translation and Interpretative Essays by Donald Russell, George Cawkwell, Werner Deuse, John Dillon, Heinz-Günther Nesselrath, Robert Parker, Christopher Pelling, Stephan Schröder, Tübingen 2010.

Polis - Freundschaft - Jenseitsstrafen. Synesios von Kyrene, Briefe an und über Johannes (SAPERE XVII), eingeleitet, übersetzt und mit interpretierenden Essays versehen von Katharina Luchner, Bruno Bleckmann, Reinhard Feldmeier, Herwig Görgemanns, Adolf Martin Ritter, Ilinca Tanaseanu-Döbler, Tübingen 2010.

Schleiermacher-Edition, Kritische Gesamtausgabe (Arbeitsstelle Kiel)

Leitungskommission:

Vorsitzender: Ringleben

Detering, Kaufmann, Spieckermann

Kontaktadresse: Leibnizstraße 4, 24118 Kiel, Tel.: 0431-880-3484, meckenstock@email.uni-kiel.de (Prof. Dr. Meckenstock)

Arbeitsbericht: Friedrich Daniel Ernst Schleiermacher (1768-1834) entfaltete seit den Preußischen Reformen in seinen drei gleichzeitigen Berliner Amtsstellungen (ab 1809/10) als evangelischer Prediger an der Dreifaltigkeitskirche, Theologieprofessor an der neu gegründeten Universität und 
philosophisch-philologisches Mitglied der Akademie der Wissenschaften eine große Wirksamkeit. Kirche und Wissenschaft, Kanzel und Katheder waren die Pole seiner Tätigkeit, die er auch literarisch und politisch zu gestalten strebte. Seit seiner Studienabschlussprüfung 1790 bis zu seinem Tod predigte Schleiermacher regelmäßig in sonntäglichen Gemeindegottesdiensten, in Vorbereitungsgottesdiensten für Abendmahlsfeiern, in besonderen Kasualgottesdiensten bei Taufen, Trauungen, Begräbnissen und in Sondergottesdiensten aus staatlichen oder kirchlichen Anlässen. Das dokumentieren zahlreiche Predigtdrucke und eigenhändige Predigtentwürfe sowie viele Predigtnachschriften von fremder Hand.

Das im Jahr 2003 an der Kieler Schleiermacher-Forschungsstelle unter der Leitung von Prof. Meckenstock eröffnete Editionsvorhaben „Schleiermacher, Predigten (Kritische Gesamtausgabe, III. Abteilung)" ist auf zwölf Bände angelegt. Bei Beginn des Editionsvorhabens waren 583 publizierte Predigten erfasst. In einer fünfjährigen Sichtung, Transkription und ordnenden Wiederherstellung der überlieferten und häufig verwirrten Predigttexte mussten die umfänglichen Handschriftensammlungen im Schleiermacher-Archiv der Staatsbibliothek zu Berlin Preußischer Kulturbesitz (Depositum 42a, ehemals im Verlagsarchiv Walter de Gruyter) und im Schleiermacher-Nachlass des Archivs der Berlin-Brandenburgischen Akademie der Wissenschaften erfasst und für die Edition vorbereitet werden. Dadurch wurden neu insgesamt 750 bisher unbekannte Predigten ermittelt. Seit 2008 werden in Übereinstimmung mit dem Gesamtzeitplan die KGA-Predigtbände durch Editoren auf wissenschaftlichen Teilzeitstellen erarbeitet. Durch zwei Ankäufe der Berliner Staatsbibliothek im Januar und November 2010 sind weitere Predigten in Gestalt von SchleiermacherAutographen und Nachschriften fremder Hand neu bekannt geworden oder neu belegt.

Im Jahr 2010 wurde die Editionsarbeit planmäßig fortgesetzt. Vier Bände mit jeweils etwa 100 Predigten konnten zu Weihnachten 2010 termingerecht im wesentlichen fertiggestellt werden. Band III, 4 (Predigten 18091815), zunächst bis März 2010 von Simon Paschen betreut, wurde von Patrick Weiland (geb. Wacker) übernommen und erfolgreich abgeschlossen. Ebenso gelang mit großem Einsatz den Editorinnen Katja Kretschmar (geb. Momberg) bei Band III,5 (Predigten 1816-1819), Elisabeth Blumrich bei Band III,6 (Predigten 1820-1821) und Kirsten Kunz bei Band III,7 (Predigten 1822-1823) der erfolgreiche Abschluss ihrer im Herbst 2008 begonnenen Bandeditionen. Diese vier jeweils etwa 900 Seiten starken Bände können, wenn der Verlag De Gruyter (Berlin) alle technischgestalterischen Fragen geklärt haben wird, in die Herstellung gehen. 
In einer neuen Arbeitsphase wird mit Jahresbeginn 2011 die Editionsarbeit an den vier folgenden Predigtbänden (KGA III, 8-11 für die Doppeljahre 1824/25, 1826/27, 1828/29, 1830/31) aufgenommen und die Druckherstellung der abgeschlossenen Bände begleitet.

Günter Meckenstock setzte die editorische Arbeit am Kalendarium von Schleiermachers Predigttätigkeit, an den von Schleiermacher publizierten ersten vier Predigtsammlungen (KGA III,1) und an Schleiermachers handschriftlichen Predigtausarbeitungen der Jahre 1790-1808 (KGA III,3) fort. Beide Bände samt Kalendarium der überlieferten Predigttermine sollen im Jahr 2011 editorisch fertiggestellt werden.

Die jährliche Sitzung der Herausgeber und Leitungskommissionen fand am 4. Juni 2010 in den Räumen der Berlin-Brandenburgischen Akademie der Wissenschaften statt. Von der Leitungskommission der Göttinger Akademie nahm an ihr Professor Ringleben teil.

G. Meckenstock

\section{Septuaginta}

Leitungskommission:

Vorsitzender: Kratz

Feldmeier, Hanhart (Göttingen), Lohse, Mühlenberg, Nesselrath, Perlitt, Smend, Spieckermann

Kontaktadresse: Friedländer Weg 11, 37085 Göttingen, Tel.: 055150429690, Fax: 0551-50429699, bernhard.neuschaefer@theologie.unigoettingen.de (Dr. Neuschäfer), Septuaginta.UXAW@mail.uni-goettingen. de, http://www.septuaginta-unternehmen.gwdg.de

Arbeitsbericht: Das Septuaginta-Unternehmen gilt einem der größten und einflussreichsten Werke der Weltliteratur: der nach der antiken Legende, von der die Septuaginta ihren Namen hat, durch 72 jüdische Gelehrte in 72 Tagen, tatsächlich aber in mehreren Generationen hergestellten griechischen Übersetzung des hebräischen Alten Testaments. Die Aufgabe des 1908 gegründeten Unternehmens besteht in der kritischen Edition der Septuaginta unter Verwertung der gesamten erreichbaren Überlieferung, d.h. der über die ganze Welt verstreuten griechischen Handschriften von den vorchristlichen Fragmenten bis ins 16. Jh. n. Chr., der Tochterübersetzungen (in lateinischer, syrischer, koptischer, äthiopischer und armenischer Sprache) und der Zitate der griechischen und der lateinischen Kirchenväter. 
Die Göttinger Edition, die das Ziel verfolgt, durch kritische Sichtung der Überlieferung den ältesten erreichbaren Text wiederherzustellen, umfasst in bisher 23 erschienenen Bänden zwei Drittel des Gesamtvorhabens.

Die Arbeit wurde nach den von der Septuaginta-Kommission aufgestellten Richtlinien fortgeführt.

Editionen: Die Erarbeitung des Bandes „Die Psalterhandschriften vom IX. Jh. an" (Suppl. vol. 1,3) wurde im Berichtsjahr weitergeführt: zum einen durch die Beschreibung von 20 Ps-Hss, die von den Mitarbeitern Albrecht, Bossina und Neuschäfer während einer Dienstreise nach Thessaloniki (Patriarchal Institute) und in die Mönchsrepublik Athos (Klöster Vatopedi, Philotheou, Dionysiou) eingesehen werden konnten, zum andern durch die Übertragung der bislang vorliegenden Manuskriptfassung des Bandes in die Struktur einer Datenbank. Die darin geplanten Verknüpfungsmöglichkeiten der jeweiligen Hss-Beschreibung mit den Bilddateien der betreffenden Hs sowie mit weiteren relevanten Daten veranschaulichen beispielhaft die Angemessenheit einer elektronischen Version des geplanten Ps-Hss-Verzeichnisses im Rahmen einer im Aufbau befindlichen Datenbank der Septuaginta-Hss (s. dazu unten).

Die Bandherausgeber setzten in ehrenamtlicher Arbeit ihre Editionstätigkeit an den Bänden „Regnorum II“ (Ph. Hugo/T. Law), „Regnorum III“ (P. A. Torjiano), „Canticum“ (E. Schulz-Flügel) und „Paralipomenon I“ (T. Janz) fort. Die Edition von „Paralipomenon II“ (R. Hanhart) ist inzwischen bis Kapitel 29 gediehen. Von dem Band „Ecclesiastes“ (P. Gentry) liegt eine bis auf die Einleitung vollständige Erstfassung mit beiden Apparaten (texkritisch/hexaplarisch) vor. Die Neubearbeitung des Bandes „Duodecim prophetae“ (J. Ziegler) durch F. Albrecht steht vor dem Abschluss.

Plangemäß kollationierten die Mitarbeiter der Arbeitsstelle 35 Hss des Psalters. Wie vorgesehen, wurden zudem 40 Psalter-Hss revidiert. Die Kollation der ältesten Hss des Psalmenkommentars Theodorets sowie begleitende Untersuchungen über den Psaltertext dieses für die Identifizierung der antiochenischen Textüberlieferung so wichtigen Kommentars konnten fortgesetzt werden.

Digitalisierung/Datenbank: Die Digitalisierung des umfangreichen Handschriftenbestandes des Septuaginta-Unternehmens mit detaillierten Beschreibungen der gescannten Handschriften wurde im Berichtsjahr, bezogen auf die Ps-Hss, fortgeführt. Zugleich erreichte die umfassende Strukturierung der Septuaginta-Hss-Datenbank, die in enger Zusammenarbeit mit dem IT-Referenten der AdW, Herrn Dr. Bode, sowie Herrn PD Dr. Kottsieper (Qumran-Wörterbuch) erfolgte, ein so fortgeschrittenes Stadium, dass eine baldige Inangriffnahme der Programmierung möglich wird. 
Kontakte: Folgende Gastforscher weilten während des Berichtsjahrs zur Fortführung ihrer Editionen, Monographien und Einzelstudien in Zusammenarbeit mit den Mitarbeitern des Septuaginta-Unternehmens in der Göttinger Arbeitsstelle: Prof. Dr. Peter J. Gentry (Louisville/USA) im Januar und Juni, Prof. Dr. Olivier Munnich (Paris) im Januar/Februar und August, Prof. Dr. Pablo Torijano (Madrid) von Februar bis Juni, Dr. Timothy Janz (Rom) im Februar, Prof. Dr. Eva Schulz-Flügel (Tübingen) im Juni, September und November, Prof. Dr. Kristin De Troyer (St. Andrews) im Juni/Juli und Prof. Dr. Robert Hiebert mit Nathaniel Dykstra (Langley) im August. Seit 1. November 2008 ist Dr. Ph. Hugo (Fribourg/Schweiz) als Stipendiat des Schweizerischen Nationalfonds mit mehrjährigem Forschungsaufenthalt in der Arbeitsstelle tätig. Im Rahmen einer gemeinsamen Tagung der Septuaginta-Arbeitsstelle und des Forschungsvorhabens „Die Griechischen Christlichen Schriftsteller" der BBAW in Berlin (Arbeitsstellenleiter: Prof. Dr. Dr. h. c. Christoph Markschies) am 4./5. Febr. 2010 wurden Überlieferungs- und Editionsfragen der Octateuch-Katene sowie der Psalmen-Katenen erörtert. Die Mitarbeiter des Septuaginta-Unternehmens nahmen darüber hinaus teil an der Teuchos-Konferenz „Handschriftenund Textforschung heute" (21.-23. April 2010) in Hamburg sowie an dem Internationalen Kongress der IOSCS (28. Juli bis 1. August 2010) in Helsinki.

Lehre: Im Wintersemester 2009/10 und WS 2010/11 fanden an der Theologischen Fakultät die Übungen „Einführung in das griechische Alte Testament" (Chr. Schäfer) sowie im Sommersemester 2010 die Übungen „Septuaginta und Neues Testament“ (F. Albrecht) und „Die rechtliche Stellung der Juden in Alexandria“" (B. Neuschäfer) statt. Vom 7. bis zum 9. Juli 2010 veranstaltete die Arbeitsstelle unter Leitung von Frau Prof. Dr. De Troyer eine summer school zum Thema „Der Text des Alten Testaments Zur Textkritik und Textgeschichte von 2 Sam 24,18-25“.

R. G. Kratz 